FABIO MASSATOSHI MARUYAMA

\title{
ANÁLISE ESTRUTURAL DINÂMICA DE UM VASO DE PRESSÃO (REATOR PWR) UTILIZANDO O MÉTODO DDAM
}

Dissertação apresentada à Escola Politécnica da Universidade de São Paulo para a obtenção do título de Mestre em Ciências

Área de Concentração: Engenharia Naval e Oceânica - Estruturas

Orientador: Prof. Dr. Bernardo Luis Rodrigues de Andrade

São Paulo 
Este exemplar foi revisado e alterado em relação à versão original, sob responsabilidade única do autor e com a anuência de seu orientador.

São Paulo, 15 de janeiro de 2013.

Assinatura do autor

Assinatura do orientador

\section{FICHA CATALOGRÁFICA}

Maruyama, Fabio Massatoshi

Análise estrutural dinâmica de um vaso de pressão (reator PWR) utilizando o método DDAM / F.M. Maruyama. -- ed.rev. -São Paulo, 2013.

$111 \mathrm{p}$.

Dissertação (Mestrado) - Escola Politécnica da Universidade de São Paulo. Departamento de Engenharia Naval e Oceânica.

1. Dinâmica das estruturas I. Universidade de São Paulo. Escola Politécnica. Departamento de Engenharia Naval e Oceânica II. t. 
Aos meus pais,

Edson e Neuza. 


\section{Agradecimentos}

Ao Professor Oscar Brito Augusto por toda ajuda e orientação que contribui de forma imprescindível para a execução deste trabalho.

Ao Professor Bernardo Luis Rodrigues de Andrade pela orientação e pelo apoio durante todo o trabalho.

Ao Centro Tecnológico da Marinha em São Paulo, em particular ao Comandante Antoun e ao Comandante Odilon pelo suporte quanto a informações sobre o tema apresentado.

À Marinha do Brasil, pelo incentivo e apoio à pesquisa através da bolsa de estudos concedida.

A todos os familiares e amigos que incentivaram e colaboraram, mesmo que indiretamente, para que este estudo pudesse ser concretizado. 


\section{Resumo}

O objetivo deste trabalho é verificar a aplicação do Dynamic Design Analysis Method - DDAM na análise de estruturas submetidas a carregamentos de choque. Esse método foi desenvolvido pela Marinha Norte Americana e se propõe a estimar esforços inercias provenientes das respostas de equipamentos de bordo, sejam de navios ou submarinos, a cargas impulsivas, mais precisamente, ondas de choque submarinas. Para a compreensão plena dessa metodologia, foi necessário um estudo sobre vibrações e espectros de resposta, tópicos teóricos que fundamentam esse procedimento. Devido à escassez de informações divulgadas por se tratar de conteúdo militar, foi realizado um estudo de caso para uma estrutura simples, uma viga engastada e seus resultados foram comparados com um prévio trabalho publicado. Com isso, foi possível a aplicação do DDAM em uma estrutura mais complexa como o vaso do reator nuclear do tipo PWR de um submarino, ainda que em um modelo simplificado desse equipamento. No entanto, os resultados mostraram a validade do uso do DDAM na análise estrutural dinâmica de equipamentos de uma maneira qualitativa.

Palavras-chave: Dinâmica das Estruturas. Vibrações. Espectro de Resposta. Espectro de choque. DDAM. Superposição Modal. 


\begin{abstract}
The main purpose of this dissertation is to verify the use of the Dynamic Design Analysis Method - DDAM in the study of structures subjected to shock loadings. This method was developed by the U.S. Navy and is intended to estimate inertial forces resultant from the response of shipboard equipment, from surface ships or submarines, due to impulsive loads or, more precisely, underwater pressure shock waves. To fully comprehend this method, it was necessary to acknowledge fundamentals of dynamics of structures like free vibrations, response spectrum analysis correlated topics. And due to lack of public information since it is a military technology, a case study of a cantilever beam was done with its results compared to a previous published paper. Then, the DDAM was applied to a more complex structure a PWR nuclear reactor vase simplified model, in order to show the effectiveness of the method in dynamic structural analysis.
\end{abstract}

Keywords: Dynamics of Structures. Free Vibrations. Response Spectrum. Shock Spectrum. DDAM. Mode Superposition. 


\section{Sumário}

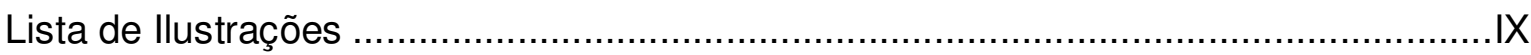

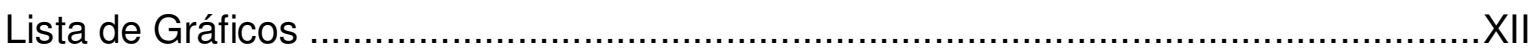

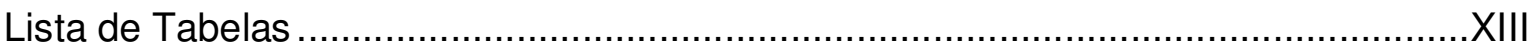

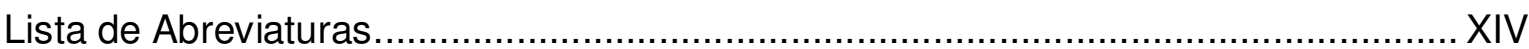

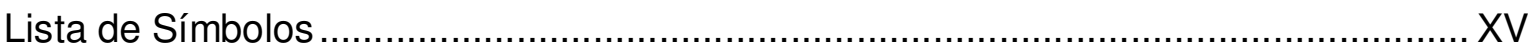

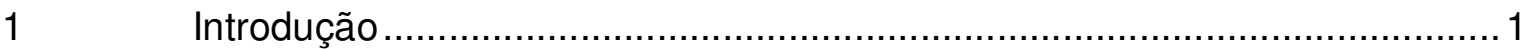

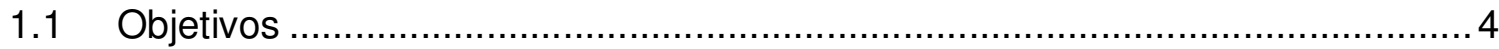

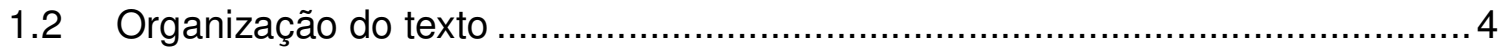

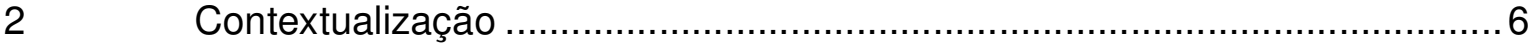

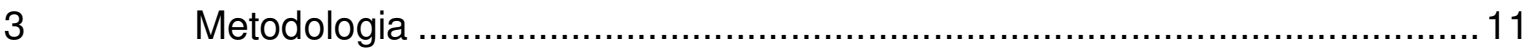

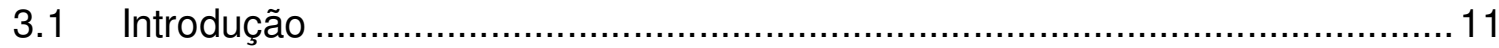

3.2 Dinâmica de Estruturas - Sistema Linear de Massas Concentradas -

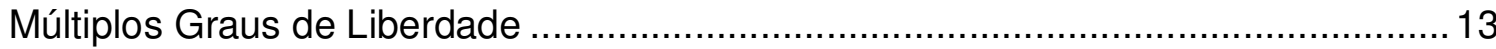

3.3 Dinâmica Linear de Estruturas - Análise Modal.......................................... 15

3.4 Dinâmica Linear de Estruturas - Superposição Modal - Ortogonalidade

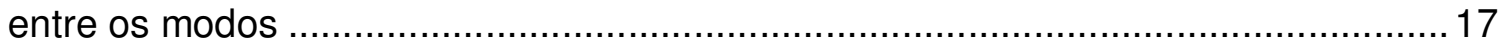

3.5 Dinâmica Linear de Estruturas - Superposição Modal - Autovetores .............. 19

3.6 Dinâmica Linear de Estruturas - Vibrações Forçadas ……….......................20

3.7 Dinâmica Linear de Estruturas - Resposta a uma excitação de base .............21

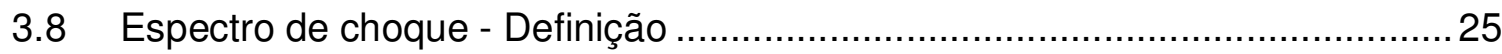

3.9 Espectro de choque - Análise Espectral................................................27 
3.10 Dynamic Design Analysis Method - DDAM...............................................28

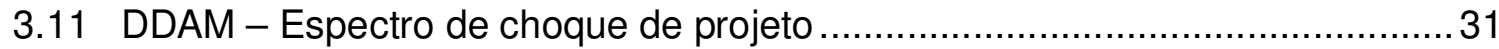

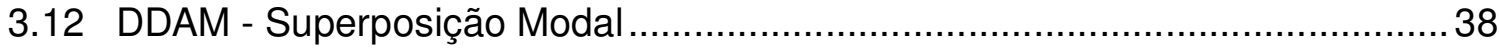

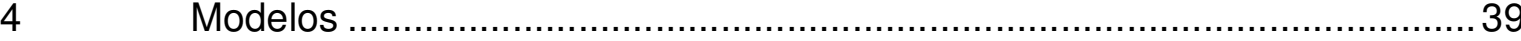

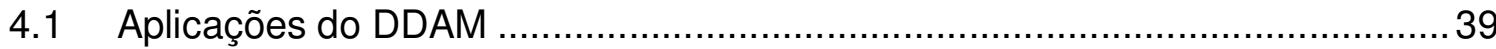

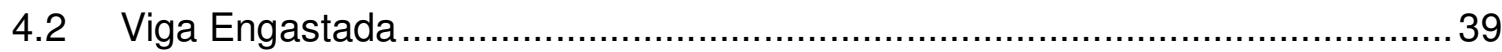

4.2.1 Modelagem analítica - Sistema de Massa Concentradas .....................40

4.2.2 Modelagem analítica - Viga Contínua ..............................................43

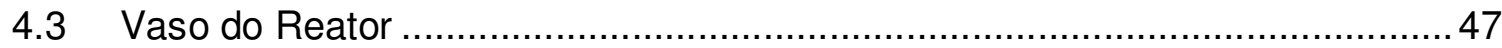

$5 \quad$ Simulações e Resultados..................................................................

5.1 Espectro de choque de projeto................................................................

5.2 Exemplo - Sistema com 1 grau de liberdade ............................................58

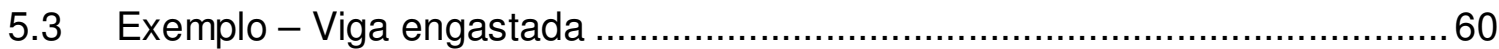

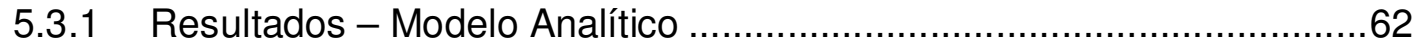

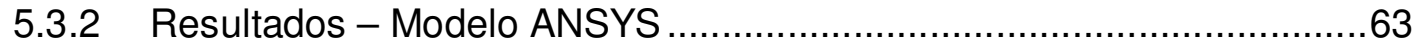

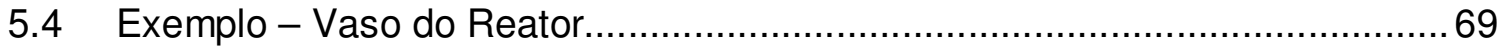

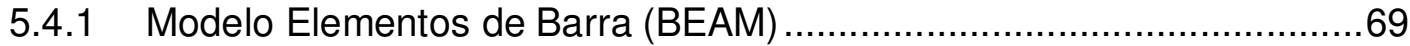

5.4.2 Modelo Vaso do Reator - Elementos Sólidos (SOLID) …….................74

5.5 Resultados - Comparação Modelo BEAM e Modelo SOLID .............................77

6 Comentários, Conclusões e Recomendações para Trabalhos Futuros ........89

$7 \quad$ Referências Bibliográficas................................................................... 


\section{Lista de Ilustrações}

Figura 1 - Representação das deflexões por uma soma dos modos de vibração. Extraído de Clough, $2003-220$ p.

Figura 2 - Sistema massa-mola com excitação de base - Adaptado Clough, 200319 p. 22

Figura 3 - Integral de Duhamel para um sistema massa-mola não-amortecido Adaptado Clough, 200387 p. 24

Figura 4 - Exemplo típico de resposta no tempo de um sistema sujeito a um choque - Cunniff \& O’Hara (1989) 26

Figura 5 - Exemplo de Espectro de Choque - O'Hara \& Cunniff (1984) - 314 p......26

Figura 6 - Exemplo de espectro de choque com o envelope dos mínimos e máximos. Cunniff \& O'Hara, 1989157 p. 32

Figura 7 - Esquema de obtenção do espectro de choque - adaptado de Alexander (2009) $5 p$. 33

Figura 8 - Características da viga - Adaptado de Abbey \& Weinberg. 40

Figura 9 - Exemplo de Vaso de um Reator PWR em corte - Extraído de Augusto (1985) 47

Figura 10 - Detalhe do apoio dos internos na região do flange superior do vaso.....48

Figura 11 - Exemplo de Elemento Combustível de um Reator PWR - online: http://en.wikipedia.org/wiki/Pressurized water reactor em 06/02/2012..... 49

Figura 12 - Esquema do Mecanismo de Acionamento das Barras de Controle 49

Figura 13 - Dimensões Adotadas do Vaso do Reator, segundo CTMSP 50

Figura 14 - Modelo de viga com 10 elementos no ANSYS 14.0 61

Figura 15 - DDAM ANSYS - Deslocamento total da viga 3 modos. 64

Figura 16 - DDAM ANSYS - Deslocamento total da viga 20 modos. 64

Figura 17 - DDAM ANSYS - Força cortante viga 3 modos 65

Figura 18 - DDAM ANSYS - Força cortante viga 20 modos 65

Figura 19 - DDAM ANSYS - Momento Fletor viga 3 modos 66 
Figura 20 - DDAM - Momento Fletor viga 20 modos .....................................66

Figura 21 - Modelo BEAM Vaso do Reator ANSYS - Line Body...........................70

Figura 22 - Modelo BEAM Vaso do Reator ANSYS - Elementos BEAM.................70

Figura 23 - Modelo BEAM Vaso do Reator ANSYS - Detalhe Calotas ...................71

Figura 24 - Modelo BEAM Vaso do Reator ANSYS - Detalhe Geometria Suporte ..72

Figura 25 - Modelo BEAM Vaso do Reator ANSYS - Massa Internos - 1 ponto ......72

Figura 26 - Modelo BEAM Vaso do Reator ANSYS - Detalhe Internos Inferiores ...73

Figura 27 - Modelo BEAM Vaso do Reator ANSYS - Massa Internos - 2 pontos ....73

Figura 28 - Modelo BEAM Vaso do Reator ANSYS - Restrição Deslocamento Axial .74

Figura 29 - Modelo SOLID Vaso do Reator no ANSYS - Suporte Anel Flange .......75

Figura 30 - Modelo SOLID Vaso do Reator no ANSYS - Detalhe Massa Internos em 1 região 76

Figura 31 - Modelo SOLID Vaso do Reator no ANSYS - Detalhe Massa Internos em 2 regiões. 76

Figura 32 - Modelo SOLID Vaso do Reator no ANSYS - Elementos SOLID ..........77

Figura 33 - Modelo Vaso do Reator BEAM - 1ำ Modo ...................................... 80

Figura 34 - Modelo Vaso do Reator SOLID - 1ำ Modo .................................... 80

Figura 35 - Modelo Vaso do Reator BEAM - 2ำ Modo .................................... 81

Figura 36 - Modelo Vaso do Reator SOLID $-2^{\circ}$ Modo ................................... 81

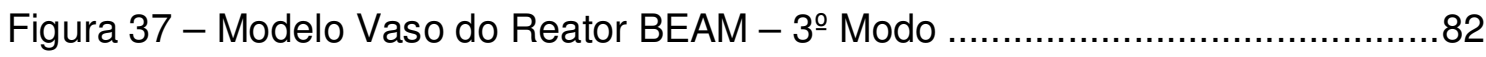

Figura 38 - Modelo Vaso do Reator SOLID - 3ํ․…................................. 82

Figura 39 - Modelo Vaso do Reator SOLID - 1ำ Modo de Casca...........................83

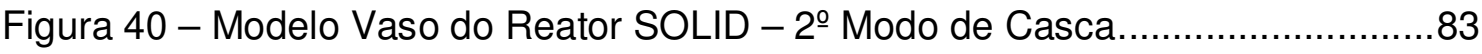

Figura 41 - Modelo Vaso do Reator BEAM - Internos em 1 Ponto - Deslocamento Final na Direção do Carregamento .85 
Figura 42 - Modelo Vaso do Reator BEAM - Internos em 2 Pontos - Deslocamento Final na Direção do Carregamento 85

Figura 43 - Modelo Vaso do Reator SOLID - Internos em 1 Ponto - Deslocamento Final na Direção do Carregamento 86

Figura 44 - Modelo Vaso do Reator SOLID - Internos em 2 Pontos - Deslocamento Final na Direção do Carregamento 86

Figura 45 - Modelo Vaso do Reator BEAM - Internos em 1 Ponto - Força Máxima na Direção do Carregamento 87

Figura 46 - Modelo Vaso do Reator BEAM - Internos em 2 Pontos - Força Máxima na Direção do Carregamento 87

Figura 47 - Modelo Vaso do Reator SOLID - Internos em 1 Ponto - Força Máxima na Direção do Carregamento 88

Figura 48 - Modelo Vaso do Reator SOLID - Internos em 2 Pontos - Força Máxima na Direção do Carregamento 88 


\section{Lista de Gráficos}

Gráfico 1 - Espectro de choque de projeto em termos de velocidade - Submarino Casco - Vertical ou Través

Gráfico 2 - Espectro de choque de projeto em termos de aceleração - Submarino Casco - Vertical ou Través 52

Gráfico 3 - Espectro de choque de projeto em termos de velocidade - Submarino Convés - Vertical 52

Gráfico 4 - Espectro de choque de projeto em termos de aceleração - Submarino Convés - Vertical 53

Gráfico 5 - Espectro de choque de projeto em termos de velocidade - Submarino Convés - Través 53

Gráfico 6 - Espectro de choque de projeto em termos de aceleração - Submarino Convés - Través 54

Gráfico 7 - Espectro de choque de projeto em termos de velocidade - Navio Casco - Vertical 54

Gráfico 8 - Espectro de choque de projeto em termos de aceleração - Navio Casco - Vertical 55

Gráfico 9 - Espectro de choque de projeto em termos de velocidade - Navio Casco - Través 55

Gráfico 10 - Espectro de choque de projeto em termos de aceleração - Navio Casco - Través .56

Gráfico 11 - Espectro de choque de projeto em termos de velocidade - Navio Convés - Vertical .56

Gráfico 12 - Espectro de choque de projeto em termos de aceleração - Navio Convés - Vertical

Gráfico 13 - Espectro de choque de projeto em termos de velocidade - Navio Convés - Través

Gráfico 14 - Espectro de choque de projeto em termos de aceleração - Navio Convés - Través 


\section{Lista de Tabelas}

Tabela 1 - Parâmetros do espectro de choque de projeto - Equipamentos no casco SUBMARINOS 35

Tabela 2 - Parâmetros do espectro de choque de projeto - Equipamentos no convés - SUBMARINOS 36

Tabela 3 - Parâmetros do espectro de choque de projeto - Equipamentos no chapeamento - SUBMARINOS 36

Tabela 4 - Parâmetros do espectro de choque de projeto - Equipamentos no casco NAVIOS 37

Tabela 5 - Parâmetros do espectro de choque de projeto - Equipamentos no convés - NAVIOS 37

Tabela 6 - Parâmetros do espectro de choque de projeto - Equipamentos no chapeamento - NAVIOS 38

Tabela 7 - Características da barra - O'Hara \& Belsheim, 196145 p.......................58

Tabela 8 - Resultados Modelos Viga Engastada - Deslocamento Máximo...............62

Tabela 9 - Resultados Modelos Viga Engastada - Força Cortante na base ............62

Tabela 10 - Resultados Modelos Viga Engastada - Momento Fletor na base .........63

Tabela 11 - Resultados Modelos Vaso do Reator ANSYS .....................................67

Tabela 12 - Comparação Frequências Naturais - Viga Engastada...........................68

Tabela 13 - Comparação Resultados - Viga Engastada.........................................68

Tabela 14 - Massa do Vaso e Seus Componentes ...............................................69

Tabela 15 - Frequências Naturais - Modelo BEAM.............................................78

Tabela 16 - Frequências Naturais - Modelo SOLID …………………………....78

Tabela 17 - Resultados Modelos do Vaso do Reator - Deslocamentos e Forças....79 


\section{Lista de Abreviaturas}

$\begin{array}{ll}\text { NRL } & \text { Naval Research Laboratory } \\ \text { DDAM } & \text { Dynamic Design Analysis Method } \\ \text { NSSC } & \text { Naval Ship Systems Command } \\ \text { CTMSP } & \text { Centro Técnológico da Marinha em São Paulo } \\ \text { PWR } & \text { Pressurized Water Reactor } \\ \text { NASTRAN } & \text { NASA Structural Analysis } \\ \text { DAA } & \text { Double Asymtoptic Aproximation } \\ \text { USA } & \text { Underwater Shock Analysis }\end{array}$




\section{Lista de Símbolos}

Em geral, se utiliza negrito para representar parâmetros ou funções vetoriais ou matriciais. Utilizam-se também as letras $i$ e $j$ para representar índices.

\section{Alfabeto Romano}

C

K

M

$\boldsymbol{v}, \dot{v}, \ddot{v}$

$p$

$f_{I}$

$f_{A}$

$f_{E}$

$k_{i j}$

$m_{i j}$

$c_{i j}$

$v_{i}$

$\widehat{v}$

$t$

$y_{n}$

$m^{*}{ }_{n}$

$k^{*}{ }_{n}$

$p_{n}^{*}$

$\ddot{v}_{g}$

$p_{\text {eff }}$
Matriz de amortecimento

Matriz de rigidez

Matriz de massa

Vetores deslocamento, velocidade e aceleração

Vetor carregamento externo

Força de inércia genérica

Força de amortecimento genérica

Força elástica genérica

Componentes da matriz de rigidez

Componentes da matriz de massa

Componentes da matriz de amortecimento

Componentes do vetor deslocamento

Vetor amplitude de deslocamento

Tempo

Componente do vetor deslocamento no modo $n$ em coordenadas generalizadas

Massa modal para modo $n$

Rigidez modal para modo $n$

Carregamento externo para modo $n$

Aceleração tomada a partir de um referencial inercial

Carregamento externo efetivo 


$\begin{array}{ll}v_{t} & \text { Deslocamento total } \\ g & \text { Aceleração da gravidade } \\ S a, S v, S d & \begin{array}{l}\text { Espectro de resposta (choque) em acelerações, velocidades e } \\ \text { deslocamentos }\end{array} \\ W_{a}, \bar{W}_{a}, W_{a_{-} \text {barra }} & \text { Peso modal (definição DDAM) } \\ \bar{X}_{i a} & \text { Deslocamento relativo do elemento } i \text { no modo } a \text { de vibração } \\ M_{i} & \text { Massa modal do elemento } i \\ A_{0}, A_{a} & \text { Pseudo-acelerações (espectro de choque de projeto) } \\ V_{0}, V_{\mathrm{a}} & \text { Pseudo-velocidades (espectro de choque de projeto) } \\ R_{i} & \text { Resposta final para a soma NRL do elemento } i \\ R_{i a} & \text { Maior valor de resposta do elemento } i \\ R_{i b} & \text { Demais valores de resposta do elemento } i \\ E & \text { Módulo de elasticidade } \\ I & \text { Momento de Inércia } \\ f_{S a_{n}} & \text { Vetor força calculado por análise espectral para o modo } n \\ \bar{m} & \text { Massa por unidade de comprimento } \\ V_{0_{n}} & \text { Momento fletor na base da estrutura para o modo } n \\ M_{0_{n}} & \end{array}$

\section{Alfabeto Grego}

$\omega$

$\theta$

$\phi_{n}$

$\Phi$

$\phi$
Frequência natural

Ângulo de fase

Vetor modo de vibração do modo $n$

Matriz de modos de vibração

Função de forma 
Constante de Poisson

Densidade do material

Coeficiente de amortecimento

Intervalo de integração da Integral de Duhamel 



\section{Introdução}

É de conhecimento geral que a Marinha do Brasil lançou em 2008 o Programa de Desenvolvimento de Submarino com Propulsão Nuclear (Prosub) cujo principal objetivo é desenvolver um submarino movido à energia nuclear. Atualmente, apenas seis países dominam a tecnologia de construção de submarinos nucleares e, com a realização desse projeto, o Brasil se incluiria nesse seleto grupo. Além disso, a soberania sobre seu território é de extrema importância para um país que acaba de descobrir uma enorme quantidade de riquezas em suas águas, as bacias petrolíferas do Pré-Sal.

Para tanto, são necessários investimentos na área de pesquisa e desenvolvimento de tecnologia para se tornar possível a viabilização de um projeto dessa magnitude. Sendo assim, em um convênio com a Escola Politécnica da Universidade de São Paulo, o Centro Tecnológico da Marinha em São Paulo (CTMSP) ofereceu incentivos à pesquisa para que engenheiros pudessem se especializar e estudar assuntos considerados importantes no projeto de desenvolvimento do submarino nuclear. Um desses temas de estudo levantados pelo CTMSP se direciona para a área de projeto estrutural, mais precisamente, para uma análise estrutural de um reator nuclear de submarino.

Para projetar e construir uma embarcação militar, deve-se levar em conta não só as condições normais de navegação e operação, mas também as situações em que a embarcação é submetida quando está em engajada em uma batalha. Nesse cenário, um navio ou um submarino são expostos a uma variedade de ataques que podem causar sérios danos.

Segundo Clements (1972), antes da Segunda Guerra Mundial, os danos causados aos equipamentos de bordo de uma embarcação eram provenientes, principalmente, de colisões diretas de embarcações inimigas e de seus torpedos, ou ainda, do impulso causado pelo disparo de suas próprias armas de bordo. As únicas medidas de proteção a esse tipo de dano eram a instalação dos equipamentos o mais longe possível do casco e a colocação da maior quantidade de blindagem possível. Durante a Segunda Guerra, esse problema se agravou, devido à evolução das bombas e minas antissubmarinas. Estas não explodiam em contato direto com a 
embarcação, mas sim causavam uma explosão submarina à distância gerando uma forte onda de choque. Essa onda de pressão era percebida por boa parte do submarino ou do navio e, embora o casco não sofresse danos graves, os equipamentos se danificavam. Nessa situação, equipamentos pesados, como os geralmente encontrados nas praças de máquinas se desalinhavam ou se tornavam inoperantes por fraturas em suas fundações, ou ainda, se desprendiam de sua base e se lançavam pelo compartimento.

Nesse contexto, a Marinha Norte Americana, no início da década de 50, passou a realizar uma série de testes em equipamentos de bordo de diversas dimensões a fim de se estudar o comportamento dinâmico de estruturas e máquinas quando submetidas a ondas de choque provenientes de carregamentos impulsivos, simulando uma explosão à distância. Os resultados experimentais possibilitaram a verificação da resistência dos equipamentos de bordo e de suas fundações ainda na fase de projeto.

Contudo, as máquinas de teste tinham, à época, uma limitação de peso do equipamento a ser avaliado (Clements, 1972) e, assim, a Marinha Norte Americana, por meio do Naval Research Laboratory - NRL, propôs um método analítico para estimar os esforços inerciais dos equipamentos de bordo que não podiam ser submetidos a testes reais. Segundo O'Hara \& Belsheim (1961), tal método foi denominado Dynamic Design Analysis Method - DDAM.

No decorrer dos anos 60 e 70, inúmeras pesquisas foram realizadas para se estudar com maior profundidade o comportamento de um equipamento a bordo de uma embarcação ou de um submarino quando submetido a um carregamento impulsivo. Estes estudos se alicerçavam na tese desenvolvida por Biot (1943), que trata da aplicação da análise espectral no cálculo da resposta dinâmica de estruturas submetidas a abalos sísmicos. Ele utilizou o conceito de espectro de resposta e definiu o espectro de choque (Shock Spectrum) e o espectro de choque de projeto (Design Shock Spectrum).

Sendo assim, o Naval Ship Systems Command - NSSC (1961), departamento da Marinha Norte Americana, divulgou o Dynamic Design Analysis Method - DDAM, um método concebido para avaliar o comportamento dinâmico de equipamentos de 
bordo a fim de integrar critérios de choque à fase de projeto destes equipamentos $\mathrm{e}$ de suas fundações. Nesse trabalho em específico foram focados equipamentos instalados em submarinos, mas a metodologia pode também ser aplicada a navios.

O método é simples e consequência dos recursos computacionais existentes na época de sua criação. Consiste em efetuar uma análise dinâmica por espectro de resposta, de um modelo com poucos graus de liberdade, para se estimar os esforços inerciais provenientes de vibrações causadas por uma onda de choque gerada por explosões submarinas à distância, sem a necessidade de se realizar testes em modelos ou em escala real. A estimativa é feita de acordo com parâmetros préestabelecidos e, segundo O'Hara \& Belsheim (1963), tais parâmetros foram obtidos experimentalmente com o apoio de testes em embarcações reais ou de ensaios em laboratório.

O equipamento, então, é modelado por um sistema massa-mola, dependendo obviamente de sua complexidade e de seus componentes. A análise dinâmica também é feita de acordo com sua importância no funcionamento pleno da embarcação. Para equipamentos críticos, como aqueles relacionados à propulsão e à geração de energia (motores, turbinas e eixos que são mais suscetíveis a falhas devido a deslocamentos de suas bases), o modelo a ser utilizado deve contemplar os componentes e suas respectivas massas de forma precisa e detalhada para que sua análise modal apresente resultados com menores graus de incerteza.

Mais tarde, o NSSC (1976) publicou mais um trabalho sobre a aplicação do método DDAM no cálculo da resposta dinâmica de embarcações de superfície. $\mathrm{Na}$ publicação exemplifica-se de maneira mais clara e detalhada o método em si e as aplicações em que pode ser usado. Nesse caso, ressaltou-se a análise estrutural das fundações de equipamentos de bordo de navios quando submetidas a carregamentos impulsivos gerados por ondas de choque.

Com o uso cada vez mais frequente do DDAM em projetos de equipamentos navais, e com o desenvolvimento de programas computacionais de análise estrutural através do Método dos Elementos Finitos, a análise se torna mais eficiente. Em 1982, Hurwitz (1982) apresenta os primeiros códigos desenvolvidos para essa incorporação do DDAM no código do NASTRAN - NASA Structural Analysis que 
buscavam justamente aperfeiçoar a análise dinâmica por esse método, uma vez que o NASTRAN poderia resolver um problema via DDAM, contudo sendo necessário a manipulação e tratamento de dados de maneira mais complicada. Em um trabalho mais recente, Tao et. al. (2009), utiliza o método DDAM juntamente com um modelo em elementos finitos para comparar a eficácia do método analítico para o método numérico. Esse estudo confirma a validade de se utilizar o DDAM para se estimar esforços inerciais originados de vibrações.

\subsection{Objetivos}

O presente estudo tem como principal objetivo mostrar a relevância do Dynamic Design Analysis Method - DDAM na análise estrutural de um equipamento complexo (reator nuclear) e avaliar sua capacidade de ser utilizado como ferramenta de projeto, tendo em vista o fato de que este equipamento e sua fundação estarem sujeitos a carregamentos impulsivos de grande magnitude.

Para tanto, um estudo aprofundado da dinâmica de estruturas com ênfase em vibrações, análise modal, e análise espectral foi feito e, com o auxílio do software ANSYS, um modelo em elementos finitos de um reator nuclear PWR foi construído, ao qual foi aplicado o DDAM para se estimar os esforços inerciais provenientes de vibrações causadas por choque. Apesar de ser um problema que também aborda conceitos de mecânica dos fluidos, como explosões submarinas e ainda, a interação fluido-estrutura, o foco desse trabalho reluziu sobre a análise dinâmica da estrutura, que é o cerne da metodologia proposta pela Marinha Norte Americana, o DDAM.

\subsection{Organização do texto}

Este trabalho foi organizado de forma a descrever um método de análise estrutural concebido pela Marinha Norte Americana, para se prever esforços em um equipamento naval de modo a otimizar seu projeto. No capítulo 2, o método estudado é contextualizado ao cenário atual, através de uma revisão bibliográfica e discussão dos principais trabalhos publicados. Por se tratar de um assunto que envolve sigilos militares, não há uma vasta fonte de pesquisa, contudo, diversas publicações foram reveladas no que diz respeito à concepção teórica dessa metodologia. Logicamente que ao longo do texto, outras discussões bibliográficas são inseridas de forma apropriada. 
No capítulo 3 é apresentado o método em si, o Dynamic Design Analysis Method - DDAM. Da seção 3.1 à seção 3.7 uma revisão da teoria linear de dinâmica das estruturas é realizada, com ênfase em análise modal e matrizes modais, que são os parâmetros principais utilizados por esse método. Em seguida, o método é exemplificado, bem como algumas melhorias agregadas à metodologia, ao longo dos anos.

No capítulo 4, os modelos desenvolvidos que incluem o vaso do reator nuclear PWR a ser analisado são apresentados qualitativamente, com suas características físicas, seus principais componentes. Além do vaso, uma estrutura simples também foi estudada para verificação da aplicação do DDAM.

Os parâmetros e resultados das simulações são apresentados e discutidos no capítulo 5. A aplicação do DDAM foi feita para um equipamento simples e espectros de choque de projeto foram levantados, de acordo com as normas da Naval Research Laboratory - NRL. Os resultados foram discutidos e analisados caso a caso.

Por fim, as conclusões e comentários finais são apresentados no capítulo 6. 


\section{Contextualização}

Neste capítulo, os principais temas da presente dissertação serão abordados no contexto atual dos estudos na área de análise dinâmica de estruturas quando submetidas a explosões submarinas. Para tanto, uma revisão bibliográfica e discussões acerca dos trabalhos desenvolvidos nesse assunto se fez necessária.

Embora as pesquisas relativas a explosões submarinas sejam anteriores à primeira guerra, o primeiro trabalho sistemático divulgado sobre o assunto foi realizado por Cole (1948). Naturalmente as pesquisas progrediram, porém, dado o interesse e patrocínio de agências militares a esses estudos, pouco material encontra-se divulgado.

$\mathrm{Na}$ área de dinâmica de estruturas, Biot (1933) publica uma tese que estudou o comportamento de estruturas submetidas a abalos sísmicos. Nesse trabalho, Biot desenvolve uma metodologia de predição de esforços em uma estrutura passível de ser atingida por um terremoto. Para tanto, se utiliza de um equipamento (Mechanical Analyzer) desenvolvido por ele na Universidade de Columbia, em 1940, que tem como função registrar acelerações do solo em função da frequência de vibração em que ele se encontra.

Sendo assim, em uma situação de terremoto, esse equipamento registraria as acelerações que uma estrutura alvo atingiria nesse cenário. Desse registro, um espectro de resposta de acelerações em função das frequências de vibração da estrutura é produzido. O movimento de uma estrutura era visto, então, como uma superposição de movimentos de vários sistemas massa-mola, e cada modo tem um peso para a resposta final, e com esses espectros podia se prever carregamentos em uma estrutura submetida a tal abalo sísmico.

Para aplicar esses conceitos da engenharia de terremotos (espectro de resposta) no estudo de vibrações em equipamentos a bordo de embarcações, O'Hara (1958) efetuou uma análise dos resultados de experimentos feitos com equipamentos de testes de impacto da Marinha Norte Americana, onde questiona a utilização do espectro de resposta para o projeto de equipamentos que serão submetidos a cargas de impacto geradas por explosões submarinas. 
Posteriormente, O'Hara (1959) divulgou seus estudos e conclusões a respeito da influência da interação equipamento/fundação (shock spectrum dip) no espectro de choque e o uso devido do espectro de choque como ferramenta de projeto de um equipamento ou de uma estrutura. Ele demonstrou que existe uma diferença significativa entre o espectro real de choque e aquele que deve ser utilizado para o projeto de um equipamento.

Então, em 1961, O'Hara \& Belsheim, por meio do Naval Ship Systems Command (1961), publicaram o Dynamic Design Analysis Method. Esse método tem como objetivo, incorporar ao projeto de máquinas e equipamentos de bordo no sentido de estimar os esforços em uma estrutura quando submetida a um carregamento impulsivo que the causa vibrações. Ou seja, os esforços inerciais provenientes das vibrações são calculados de forma empírica por esse método que foi desenvolvido através de análises de testes em escala real de equipamentos de bordo e em experimentos feitos em escala reduzida (Clements, 1972).

Em seguida, O'Hara \& Belsheim (1963) através do Naval Research Laboratory - NRL publicaram um relatório onde esse algoritmo de fórmulas empíricas é exemplificado. É especificado o parâmetro Shock Design Value que é o parâmetro que indica a grandeza do esforço inercial premeditado para um dado equipamento. É definido também o peso com que cada modo de vibração contribui com a dinâmica da estrutura. No documento estão propostos modelos para o cálculo elástico ou elasto-plástico da resposta de um equipamento, e tratamentos diferenciados destes de acordo com sua fundação, i.e., se está instalado na estrutura primária (hastilhas e/ou longarinas), ou em um convés não reforçado, por exemplo.

Em um amplo estudo, Clement (1972) divulgou os resultados de mais uma pesquisa sobre uma série de experimentos de simulação de ondas de choque em uma parte de estrutura ou de um equipamento com vistas à análise dinâmica, ou seja, testes reais foram realizados para se descrever as ondas de choque causadas por uma série de intensidades de impacto em estruturas de diferentes dimensões.

Os testes foram divididos em três categorias, de acordo com o peso do equipamento ou da estrutura. Dessa forma, foram obtidos os espectros de choque 
derivados de impactos de diferentes magnitudes para cada categoria. Esse estudo, porém, se mostrou limitado na medida em que os equipamentos testados teriam que ter até 27 toneladas aproximadamente, que era a capacidade da máquina de testes da marinha americana à época. Mas comprovou a eficiência do uso dos espectros de choque para auxiliar o projeto de máquinas e equipamentos de bordo. No trabalho cita-se ainda a importância do DDAM como alternativa eficaz em resolver esse problema de dinâmica estrutural.

Posteriormente, Barber P. e Arden K. (Newport News Shipbuilding), aplicaram o método no projeto do leme do submarino americano da classe SSN668 utilizando o DDAM implementado em um software comercial de elementos finitos. Outro exemplo foi estudado pela Noran Engineering (Abbey T.) onde o método foi aplicado também com o auxílio de um programa computacional para análise dinâmica de uma embarcação.

Remmers (1983) publicou um trabalho onde descreveu cronologicamente a evolução da análise dinâmica de estruturas por meio do espectro de choque até a época da publicação. Na realidade, essa publicação dá ênfase à aplicação da metodologia desenvolvida por Biot, pela Marinha Norte Americana, que é o desenvolvimento do método DDAM e os estudos consequentes para a melhoria de projetos de equipamentos de bordo.

Daquela época até o presente, o desenvolvimento dos computadores permitiu uma extraordinária evolução dos métodos numéricos, tanto para a modelagem de fluidos quanto para a modelagem de estruturas, as duas disciplinas fundamentais para se conduzir este tipo de estudo.

Kwon e Fox (1992) fazem a comparação entre resultados experimentais e os de uma simulação numérica para a resposta transitória de um cilindro submetido a uma explosão subaquática. A simulação numérica foi feita com o uso de elementos finitos para o cilindro e de elementos de contorno para a água (meio acústico). A interação fluido-estrutura também é modelada segundo uma técnica de aproximação chamada doubly asymptotic approximation (DAA) (Geers, 1971). Os resultados da simulação, quando comparados aos do ensaio experimental revelaram notável concordância. 
Bathe et. al. (1995) desenvolveram um elemento finito (three-field finite element) a ser utilizado em cálculos estruturais, onde a interação do fluido acústico e da estrutura deve ser modelada.

Ergin (1997) apresentou resultados experimentais e de cálculos numéricos da resposta transitória da estrutura de um cilindro submerso em água e submetido a um impacto impulsivo. Kwon e Cunningham (1998) efetuaram esse mesmo tipo de cálculo e ainda propõem uma metodologia para o posicionamento de reforçadores ao longo de um cilindro. Em ambos os trabalhos, a DAA foi utilizada para a modelagem da interação fluido-estrutura.

Shin Y. e Santiago L. (1998), apresentaram o cálculo da resposta transitória para um modelo bidimensional de uma seção transversal de uma embarcação de superfície da Marinha Americana (Destroyer DDG-51 Flight 1). Os autores consideraram os efeitos da cavitação do fluido e mostraram que ela é relevante no estudo dinâmico de estruturas de superfície sujeitas a explosões submarinas.

Liang (2000) publicou o cálculo da resposta dinâmica de uma casca esférica submetida ao impacto de uma forte onda de choque plana. Os resultados foram comparados aos dados encontrados na literatura e demonstraram que a metodologia de análise dinâmica de estruturas submetidas a cargas impulsivas pode ser aplicada a modelos lineares.

Shin Y. (2004) publicou os resultados da aplicação do método numérico de análise dinâmica para obtenção da resposta transitória da estrutura para um modelo 3-D de uma embarcação de superfície quando submetido a explosões submarinas. O trabalho valida a programação desenvolvida pela Marinha Americana (Underwater Shock Analysis - USA) para análise dinâmica de submarinos quando submetidos a cargas provenientes de explosões submarinas, e extrapola sua aplicação para navios de superfície, utilizando-se, obviamente, da modelagem de fenômenos peculiares a esse tipo de embarcação, como a cavitação, por exemplo.

Liang C.C. e Tai Y.S. (2006), apresentaram um modelo numérico para a simulação do comportamento de uma embarcação de superfície exposta a uma explosão submarina. O modelo numérico permite o cálculo do comportamento do fluido devido à explosão submarina, a subsequente interação fluido-estrutura com a 
resposta transitória da estrutura do casco (considerando não linearidades geométricas), e, o comportamento elasto-plástico do material. Vale ressaltar que a diversidade de modelos físicos para a simulação da mecânica das estruturas e da mecânica dos fluidos presentes no estudo só é possível com o uso de aplicativos computacionais de elementos finitos e de elementos de contorno de última geração, que, de per si, exigem para cada disciplina um trabalho de pesquisa mais aprofundado.

Por outro lado, houve publicações onde a aplicação do método DDAM foi feita de forma mais direta como exemplificado em dois trabalhos por Tao J. et al. (2009) onde em um deles $\mathrm{o}$ autor, a partir de um modelo em elementos finitos, realiza diversas simulações e faz uma comparação de resultados entre o método DDAM e ensaios numéricos de explosões em meio fluido, e verifica a validade do DDAM para se estimar esforços inerciais provenientes de ondas de choque.

Nestas condições, optou-se, para este trabalho de pesquisa, aprofundar-se no estudo da dinâmica e na modelagem da estrutura do reator PWR instalado em um submarino nuclear, com a aplicação direta do método DDAM em sua análise estrutural. 


\section{Metodologia}

Este capítulo irá tratar sobre a metodologia de análise estrutural de equipamentos a bordo de embarcações quando submetidos a excitações transientes, como uma onda de choque. Esse método foi desenvolvido pela Marinha Norte Americana no intuito de estimar esforços inerciais e inserir essas informações na fase de projeto desses equipamentos.

\subsection{Introdução}

É essencialmente uma análise por espectro de resposta onde são adicionados parâmetros de choque empíricos, obtidos de testes de explosões submarinas em navios e também de estudos teóricos e ensaios em laboratório (Clements, 1972; Remmers, 1983).

Na década de 70, a Marinha Norte Americana, através de seus laboratórios e centros de estudo, desenvolveu um programa de diminuição da vulnerabilidade de seus submarinos e navios aos ataques provenientes de explosões submarinas. Um dos resultados desse programa é o Dynamic Design Analysis Method - DDAM que, na prática, é um complemento de uma análise modal do equipamento com parâmetros de excitação de choque obtidos empiricamente de testes de explosões submarinas em instalações de navios e submarinos reais, estudos teóricos e testes em laboratório (O’Hara \& Belsheim, 1961).

Dessa forma, é admitido que o equipamento e sua fundação comportam-se como uma estrutura linearmente elástica em resposta à excitação, descrita como um espectro (espectro de resposta). É suposto também que a análise seja dividida em três direções ortogonais, correspondentes à localização das supostas cargas explosivas geradoras das ondas de choque, sendo elas, vertical, través e longitudinalmente à embarcação. Diferenciações na capacidade de absorção de energia para diferentes tipos de carregamento e cavernamento de seções são permitidas com uso de parâmetros como tensão de escoamento e critérios de falha adequados para cada caso.

Outra hipótese adotada por esse método é a classificação do equipamento por critérios da Marinha Norte Americana. Ela classifica os equipamentos em 
essenciais e não-essenciais, ou ainda em outra classe intermediária. Essa classificação em conjunto com as características físicas do equipamento irá determinar o modelo estrutural equivalente para se realizar esse estudo.

É importante ressaltar que esse método não elimina a análise de equilíbrio estático do equipamento. Esse estudo dinâmico serve para definir os carregamentos induzidos por efeitos inerciais. As questões inerentes à Teoria da Elasticidade que relacionam carregamentos com tensões, deformações ou deflexões ainda existem e devem ser resolvidos antes que uma análise dinâmica possa ser realizada.

Sendo assim, a análise dinâmica através desse método pode ser descrita sucintamente em quatro etapas:

1. Adota-se a estrutura inteira (casco + equipamento) como um sistema linear elástico;

2. Determinam-se os modos e as frequências naturais de vibração do sistema - Análise Modal;

3. Calculam-se as respostas (deslocamentos, velocidades) para cada modo natural devido aos carregamentos impulsivos - Análise espectral (Espectro de choque);

4. Superposição de efeitos - Respostas modais obtidas são combinadas para se obter a resposta total.

Pode se demonstrar que qualquer ponto (ou superfície) da estrutura pode ser definido como referência e, assim, pode ser considerado como uma "base fixa" para a outra parte da estrutura. Sendo assim, no caso de um submarino, o casco e seus reforçadores pesados são considerados a base fixa e, portanto, a resposta dinâmica do(s) equipamento(s) nele contido(s) é obtida através da resposta dele(s) à superposição dos modos naturais da base fixa. Ou seja, o movimento da base fixa servirá como carregamento imposto para a análise dinâmica do(s) equipamento(s) fixado(s) nela. Esse movimento da base pode ser representado por um espectro de choque equivalente, e deve ser conhecido. 


\subsection{Dinâmica de Estruturas - Sistema Linear de Massas Concentradas - Múltiplos Graus de Liberdade}

Em dinâmica estrutural existem diversas abordagens para se solucionar um problema. Uma delas é a descrição de uma estrutura por um sistema de massas concentradas que represente de forma mais precisa os seus múltiplos graus de liberdade.

Segundo Clough (2003), a equação de movimento de um sistema com múltiplos graus de liberdade é obtida através do equilíbrio das forças que atuam na estrutura, ou melhor, em cada um de seus graus de liberdade. Sendo assim, dada uma estrutura com $N$ graus de liberdade, terá para cada grau de liberdade $i$, quatro forças atuantes: força externa aplicada, $p_{i}(t)$; força de inércia, $f_{I_{i}}(t)$; força de amortecimento, $f_{A_{i}}(t)$; força elástica, $f_{E_{i}}(t)$. Logo, para cada um dos graus de liberdade, o equilíbrio dinâmico pode ser expresso por:

$$
\begin{gathered}
f_{I_{1}}(t)+f_{A_{1}}(t)+f_{E_{1}}(t)=p_{1}(t) \\
f_{I_{2}}(t)+f_{A_{2}}(t)+f_{E_{2}}(t)=p_{2}(t) \\
\vdots \\
f_{I_{N}}(t)+f_{A_{N}}(t)+f_{E_{N}}(t)=p_{N}(t)
\end{gathered}
$$

Essas forças resistentes podem ser representadas de outra maneira, através de um conjunto de coeficientes de influência. Para a força elástica, toma-se como exemplo a força elástica atuante no grau de liberdade 1. O deslocamento desse ponto dependerá, em geral, dos deslocamentos do resto da estrutura. Dessa forma,

$$
f_{E 1}=k_{11} v_{1}+k_{12} v_{2}+\cdots+k_{1 N} v_{N}
$$

De maneira análoga, a força elástica que atua no grau de liberdade 2 pode ser descrita como:

$$
f_{E 2}=k_{21} v_{1}+k_{22} v_{2}+\cdots+k_{2 N} v_{N}
$$

e assim, para o $i$-ésimo termo, a força elástica atuante é

$$
f_{E i}=k_{i 1} v_{1}+k_{i 2} v_{2}+\cdots+k_{i N} v_{N}
$$


onde $k_{i j}$ são os coeficientes de rigidez, definidos como sendo a força elástica correspondente ao grau de liberdade $i$ devido a um deslocamento unitário do grau de liberdade $j$.

Na forma matricial, o vetor de forças elásticas é expresso por:

$$
\left\{\begin{array}{c}
f_{E 1} \\
f_{E 2} \\
\vdots \\
f_{E N}
\end{array}\right\}=\left[\begin{array}{ccccc}
k_{11} & k_{12} & k_{13} & \cdots & k_{1 N} \\
k_{21} & k_{22} & k_{23} & \cdots & k_{2 N} \\
\cdots & \cdots & \cdots & \cdots & \cdots \\
k_{N 1} & k_{N 2} & k_{N 3} & \cdots & k_{N N}
\end{array}\right]\left\{\begin{array}{c}
v_{1} \\
v_{2} \\
\vdots \\
v_{N}
\end{array}\right\}
$$

ou

$$
\boldsymbol{f}_{E}=\boldsymbol{K v}
$$

onde $\boldsymbol{K}$ é a matriz de rigidez da estrutura e $\boldsymbol{v}$, o vetor de deslocamentos nodais.

Analogamente, para as forças de inércia, elas podem ser descritas como sendo:

$$
f_{I}=M \ddot{v}
$$

onde os coeficientes $m_{i j}$ da matriz de massa $\boldsymbol{M}$ são definidos como sendo a força inercial correspondente ao grau de liberdade $i$ devido a uma aceleração unitária do grau de liberdade $j$.

Finalmente, para as forças de amortecimento,

$$
\boldsymbol{f}_{A}=\boldsymbol{C} \dot{v}
$$

onde os coeficientes $c_{i j}$ da matriz de amortecimento $C$ são definidos como sendo a força de amortecimento correspondente ao grau de liberdade $i$ devido a velocidade unitária do grau de liberdade $j$.

Desse modo, a equação do movimento tem todos seus componentes descritos:

$$
\boldsymbol{M} \ddot{\boldsymbol{v}}(t)+\boldsymbol{C} \dot{\boldsymbol{v}}(t)+\boldsymbol{K} \boldsymbol{v}(t)=\boldsymbol{p}(t)
$$




\subsection{Dinâmica Linear de Estruturas - Análise Modal}

Para uma análise modal, considera-se um sistema em vibração livre nãoamortecida, e omite-se, assim, a parcela das forças de amortecimento e das forças externas aplicadas. A equação do movimento (3.1) fica:

$$
\boldsymbol{M} \ddot{\boldsymbol{v}}(t)+\boldsymbol{K} \boldsymbol{v}(t)=\mathbf{0}
$$

A solução desse tipo de análise consiste em se determinar as condições sob as quais o equilíbrio da equação de movimento é alcançado, isto é, os modos e suas respectivas frequências de vibração.

Para tanto, admite-se como resposta da vibração livre não-amortecida é harmônica e pode ser escrita da seguinte forma.

$$
\boldsymbol{v}(t)=\widehat{\boldsymbol{v}} \operatorname{sen}(\omega t+\theta)
$$

Obtendo a segunda derivada e substituindo na equação diferencial:

$$
\ddot{\boldsymbol{v}}(t)=-\omega^{2} \widehat{\boldsymbol{v}} \operatorname{sen}(\omega t+\theta)=-\omega^{2} \boldsymbol{v}(t)
$$

A equação diferencial fica:

$$
-\omega^{2} \boldsymbol{M} \hat{\boldsymbol{v}} \operatorname{sen}(\omega t+\theta)+\boldsymbol{K} \widehat{\boldsymbol{v}} \operatorname{sen}(\omega t+\theta)=\mathbf{0}
$$

Como o termo em sen é arbitrário, ele pode ser omitido, e a equação diferencial é reescrita da seguinte forma:

$$
\left[\boldsymbol{K}-\omega^{2} \boldsymbol{M}\right] \widehat{\boldsymbol{v}}=\mathbf{0}
$$

Encontrar os valores para $\omega$ significa encontrar os autovalores desse sistema e estes correspondem às frequências naturais de vibração. Para isso, é necessário resolver o seguinte determinante:

$$
\left\|\boldsymbol{K}-\omega^{2} \boldsymbol{M}\right\|=0
$$

que leva à equação característica do sistema.

As raízes da equação característica correspondem às frequências naturais de vibração, sendo a menor delas a frequência do primeiro modo, a próxima mais alta, 
ao segundo, e assim por diante, e são arranjadas em sequência no vetor de frequência $\omega$ :

$$
\boldsymbol{\omega}=\left\{\begin{array}{c}
\omega_{1} \\
\omega_{2} \\
\omega_{3} \\
\vdots \\
\omega_{n}
\end{array}\right\}
$$

Segundo Clough (2003), pode-se demonstrar que para matrizes de massa, e rigidez reais, simétricas, positivas e definidas (matrizes para sistemas estruturais estáveis), todas as frequências terão valores reais e positivos.

Uma vez determinadas as frequências de vibração do sistema, podem-se obter os modos de vibração associado a cada frequência. É necessário então resolver a equação matricial (3.6) para $\omega$ igual a um valor de freqüência natural obtida. Como a eq. (3.6) é uma identidade, ou seja, as frequências das vibrações foram obtidas por tal condição, os valores de deslocamento $\widehat{\boldsymbol{v}}_{n}$ são indeterminados. Porém, as amplitudes relativas dos $N$ graus de liberdade podem ser determinadas em termos de qualquer coordenada. Sendo assim, para um modo $n$, adota-se um valor unitário para um grau de liberdade, o primeiro por exemplo, e resolve-se a equação de modo a determinar os outros valores de deslocamentos.

$$
\widehat{\boldsymbol{v}}_{n}=\left\{\begin{array}{c}
\hat{v}_{1 n} \\
\hat{v}_{2 n} \\
\hat{v}_{3 n} \\
\vdots \\
\hat{v}_{N n}
\end{array}\right\}=\left\{\begin{array}{c}
1 \\
\hat{v}_{2 n} \\
\hat{v}_{3 n} \\
\vdots \\
\hat{v}_{N n}
\end{array}\right\}
$$

Substituindo em (3.6), a forma matricial pode ser escrita como:

$$
\boldsymbol{E}_{n} \widehat{\boldsymbol{v}}_{n}=\mathbf{0}
$$

onde $\boldsymbol{E}_{n}=\boldsymbol{K}-\omega^{2} \boldsymbol{M}$. Expandindo a eq. (3.9), tem-se: 


$$
\left[\begin{array}{c|ccccc}
e_{11} & \mid & e_{12} & e_{13} & \ldots & e_{1 N} \\
- & \mid & - & - & - & - \\
e_{21} & \mid & e_{22} & e_{23} & \ldots & e_{2 N} \\
e_{31} & \mid & e_{32} & e_{33} & \ldots & e_{3 N} \\
\ldots & \ldots & \ldots & \ldots & \ldots & \ldots \\
e_{N 1} & \mid & e_{N 2} & e_{N 3} & \ldots & e_{N N}
\end{array}\right]\left\{\begin{array}{c}
1 \\
\hat{v}_{2 n} \\
\hat{v}_{3 n} \\
\ldots \\
\hat{v}_{N n}
\end{array}\right\}=\left\{\begin{array}{c}
0 \\
0 \\
0 \\
\ldots \\
0
\end{array}\right\}
$$

na qual se "elimina" a primeira linha e coluna, e, resolvendo para $\widehat{\boldsymbol{v}}_{n}$, obtêm-se os deslocamentos proporcionais de todos os outros graus de liberdade para um determinado modo $n$. O mesmo procedimento é repetido substituindo os outros valores de frequência natural na equação (3.6). Assim, neste exemplo, para o modo $n$, o vetor deslocamento fica:

$$
\widehat{\boldsymbol{v}}_{n}=\left\{\begin{array}{c}
1 \\
\hat{v}_{21} \\
\hat{v}_{31} \\
\vdots \\
\hat{v}_{n 1}
\end{array}\right\}
$$

Pode se definir $\boldsymbol{\phi}_{n}$ como o modo normal de vibração, onde

$$
\boldsymbol{\phi}_{n}=\hat{\boldsymbol{v}}_{n} /\left\|\hat{\boldsymbol{v}}_{n}\right\|
$$

e $\left\|\widehat{\boldsymbol{v}}_{n}\right\|$ é a norma euclidiana de $\widehat{\boldsymbol{v}}_{n}$.

Dessa forma, a matriz dos modos de vibração é definida como:

$$
\boldsymbol{\Phi}=\left[\begin{array}{lllll}
\boldsymbol{\phi}_{1} & \boldsymbol{\phi}_{2} & \boldsymbol{\phi}_{3} & \cdots & \boldsymbol{\phi}_{n}
\end{array}\right]
$$

que é a matriz de autovetores utilizada na aplicação da superposição modal na análise dinâmica linear de um sistema.

\subsection{Dinâmica Linear de Estruturas - Superposição Modal - Ortogonalidade entre os modos}

Para ser possível representar a resposta do sistema dinâmico através da combinação linear dos modos de vibração, ou seja, utilizar o método da superposição na resolução do sistema dinâmico linear, é necessário provar que os modos de vibração são ortogonais às matrizes de massa e de rigidez. Para tanto, 
considera-se dois modos de vibrar de uma estrutura $\phi_{i}$ e $\phi_{j}$, que correspondem respectivamente às freqüências de vibração $\omega_{i}$ e $\omega_{j}$.

Cada modo deve satisfazer a equação de equilíbrio (3.6), de modo que:

$$
\begin{aligned}
\boldsymbol{K} \boldsymbol{\phi}_{i} & =\omega_{i}^{2} \boldsymbol{M} \boldsymbol{\phi}_{i} \\
\boldsymbol{K} \boldsymbol{\phi}_{j} & =\omega_{j}^{2} \boldsymbol{M} \boldsymbol{\phi}_{j}
\end{aligned}
$$

Multiplicando a eq. (3.13) por $\boldsymbol{\phi}_{j}{ }^{T}$ eq. (3.14) por $\boldsymbol{\phi}_{i}{ }^{T}$, tem-se:

$$
\begin{aligned}
\boldsymbol{\phi}_{j}{ }^{T} \boldsymbol{K} \boldsymbol{\phi}_{i} & =\omega_{i}{ }^{2} \boldsymbol{\phi}_{j}{ }^{T} \boldsymbol{M} \boldsymbol{\phi}_{i} \\
\boldsymbol{\phi}_{i}{ }^{T} \boldsymbol{K} \boldsymbol{\phi}_{j} & =\omega_{j}{ }^{2} \boldsymbol{\phi}_{i}{ }^{T} \boldsymbol{M} \boldsymbol{\phi}_{j}
\end{aligned}
$$

Como $\boldsymbol{K}$ e $\boldsymbol{M}$ são simétricas, ou seja, $\boldsymbol{K}^{T}=\boldsymbol{K}$ e $\boldsymbol{M}^{T}=\boldsymbol{M}$, lembrando que o produto de matrizes das equações (3.15) e (3.16) são escalares e podem ser transpostas arbitrariamente, e, ainda, observando as regras de transposição, e o teorema da reciprocidade de Betti, tem-se que:

$$
\omega_{i}^{2} \boldsymbol{\phi}_{j}^{T} \boldsymbol{M} \boldsymbol{\phi}_{i}=\omega_{j}^{2} \boldsymbol{\phi}_{i}^{T} \boldsymbol{M} \boldsymbol{\phi}_{j}
$$

termos que representam as forças inerciais dos modos $i$ e $j$, respectivamente. É evidente que,

$$
\left(\omega_{i}^{2}-\omega_{j}^{2}\right) \boldsymbol{\phi}_{j}^{T} \boldsymbol{M} \boldsymbol{\phi}_{i}=0
$$

Como $\omega_{j} \neq \omega_{i}$, a eq. (3.18) resulta na primeira condição de ortogonalidade:

$$
\phi_{j}{ }^{T} M \phi_{i}=0
$$

A segunda condição de ortogonalidade pode ser obtida pré-multiplicando a eq. (3.14) por $\boldsymbol{\phi}_{i}{ }^{T}$, e aplicando a primeira condição. Assim, tem-se:

$$
\boldsymbol{\phi}_{j}{ }^{T} \boldsymbol{K} \boldsymbol{\phi}_{i}=0
$$

$\operatorname{com} j \neq i$. 
As equações (3.19) e (3.20) representam a ortogonalidade entre os modos naturais, com relação às matrizes de massa e de rigidez.

\subsection{Dinâmica Linear de Estruturas - Superposição Modal - Autovetores}

Uma vez encontrada a matriz dos modos de vibração, o vetor deslocamento $v$ pode ser escrito como uma superposição das deflexões dos modos de vibração, como mostra a Figura 1. Isto é:

$$
\boldsymbol{v}=\boldsymbol{\phi}_{1} y_{1}+\boldsymbol{\phi}_{2} y_{2}+\cdots+\boldsymbol{\phi}_{N} y_{N}=\sum \boldsymbol{\phi}_{n} y_{n}
$$

Em forma matricial:

$$
\boldsymbol{v}=\boldsymbol{\Phi} * \boldsymbol{y}(t)
$$

onde $\boldsymbol{y}(t)$ é o vetor de amplitude modal, função do tempo.
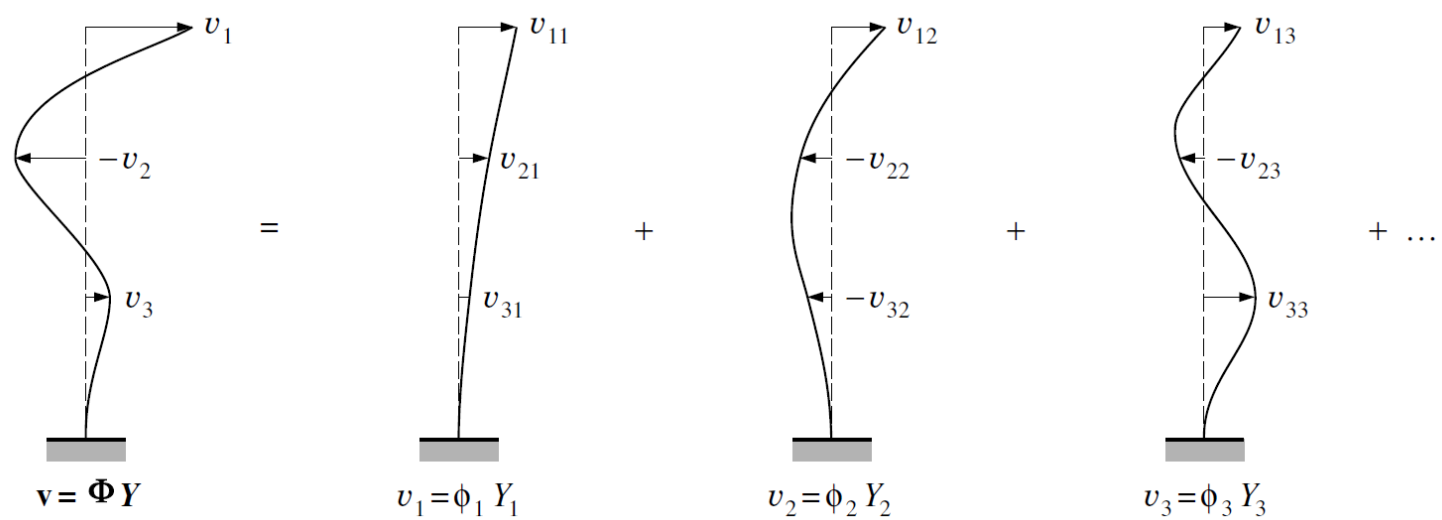

Figura 1 - Representação das deflexões por uma soma dos modos de vibração.

Extraído de Clough, $2003-220$ p.

Substituindo a eq. (3.22) na equação do movimento, tem-se

$$
\boldsymbol{M} \boldsymbol{\Phi} \ddot{\boldsymbol{y}}(t)+\boldsymbol{K} \boldsymbol{\Phi} \mathbf{y}(t)=\mathbf{0}
$$

Multiplicando a esquerda a equação (3.23) por $\boldsymbol{\phi}_{n}^{T}$ e, devido à ortogonalidade com respeito à massa, ou seja, $\boldsymbol{\phi}_{n}^{T} \boldsymbol{M} \boldsymbol{\phi}_{m}=0$ para $m \neq n$, todos os termos da somatória implícita na equação (3.23) se anulam exceto o termo $\boldsymbol{\phi}_{n}^{T} \boldsymbol{M} \boldsymbol{\phi}_{n}$, e a equação se resume a: 


$$
\boldsymbol{\phi}_{n}^{T} \boldsymbol{M} \boldsymbol{\phi}_{n} \ddot{y}_{n}+\boldsymbol{\phi}_{n}^{T} \boldsymbol{K} \boldsymbol{\phi}_{n} y_{n}=\mathbf{0}
$$

que é semelhante à equação de equilíbrio dinâmico de um sistema não-amortecido com um único grau de liberdade.

Concluindo, com o método se calcula a resposta de um sistema linear $\operatorname{com} n$ graus de liberdade com a soma da resposta de $n$ sistemas lineares com um único grau de liberdade.

Sendo $\boldsymbol{v}(0)$ e $\dot{\boldsymbol{v}}(0)$ as condições iniciais para o sistema livre, pode-se, utilizando-se uma das condições de ortogonalidade dos modos de vibração, determinar as condições iniciais para cada equação diferencial dos modos desacoplados. Assim,

$$
\begin{aligned}
& y_{n}=\frac{\boldsymbol{\phi}_{n}^{T} \boldsymbol{M} \boldsymbol{v}}{\boldsymbol{\phi}_{n}^{T} \boldsymbol{M} \boldsymbol{\phi}_{n}} \\
& y_{n}(0)=\frac{\boldsymbol{\phi}_{n}^{T} \boldsymbol{M} \boldsymbol{v}(0)}{\boldsymbol{\phi}_{n}^{T} \boldsymbol{M} \boldsymbol{\phi}_{n}} \\
& \dot{y}_{n}(0)=\frac{\boldsymbol{\phi}_{n}^{T} \boldsymbol{M} \dot{\boldsymbol{v}}(0)}{\boldsymbol{\phi}_{n}^{T} \boldsymbol{M} \boldsymbol{\phi}_{n}}
\end{aligned}
$$

Uma vez conhecidas as condições iniciais, basta resolver a equação de movimento para as coordenadas generalizadas $\boldsymbol{y}$.

\subsection{Dinâmica Linear de Estruturas - Vibrações Forçadas}

O método da superposição pode ser utilizado para o cálculo da resposta de um sistema submetido a um esforço externo. Considere a equação do movimento de um sistema massa-mola forçado não amortecido de múltiplos graus de liberdade:

$$
\boldsymbol{M} \ddot{\boldsymbol{v}}+\boldsymbol{K} \boldsymbol{v}=\boldsymbol{p}(t)
$$

Introduzindo a equação (3.22) na equação do movimento tem-se:

$$
\boldsymbol{M \Phi} \ddot{\boldsymbol{y}}(t)+\boldsymbol{K} \boldsymbol{\Phi} \boldsymbol{y}(t)=\boldsymbol{p}(t)
$$


Observa-se que o modo de vibração não depende do tempo $(\ddot{\boldsymbol{u}}=\boldsymbol{\Phi} \ddot{\boldsymbol{Y}})$. Multiplicando a esquerda pelo vetor $\boldsymbol{\phi}_{n}^{T}$, a equação fica:

$$
\boldsymbol{\phi}_{n}^{T} \boldsymbol{M} \boldsymbol{\Phi} \ddot{\boldsymbol{y}}(t)+\boldsymbol{\phi}_{n}^{T} \boldsymbol{K} \boldsymbol{\Phi} \boldsymbol{y}(t)=\boldsymbol{\phi}_{n}^{T} \boldsymbol{p}(t)
$$

Mas expandindo os dois termos do lado esquerdo da equação (3.30), observa-se que todos eles se anulam exceto pelo $n$-ésimo termo, devido à ortogonalidade da matriz dos modos de vibração. Assim, a equação resulta em:

$$
\boldsymbol{\phi}_{n}^{T} \boldsymbol{M} \boldsymbol{\phi}_{n} \ddot{y}_{n}(t)+\boldsymbol{\phi}_{n}^{T} \boldsymbol{K} \boldsymbol{\phi}_{n} y_{n}(t)=\boldsymbol{\phi}_{n}^{T} \boldsymbol{p}(t)
$$

Redefinindo os coeficientes da equação do movimento para $n$-ésimo modo de vibração:

$$
\begin{gathered}
m^{*}{ }_{n}=\boldsymbol{\phi}_{n}^{T} \boldsymbol{M} \boldsymbol{\phi}^{n} \\
k^{*}{ }_{n}=\boldsymbol{\phi}_{n}^{T} \boldsymbol{K} \boldsymbol{\phi}^{n} \\
p^{*}{ }_{n}(t)=\boldsymbol{\phi}_{n}^{T} \boldsymbol{p}(t)
\end{gathered}
$$

E a equação do movimento em coordenadas generalizadas, para um modo $n$ pode ser escrita como:

$$
m^{*}{ }_{n} \ddot{y}_{n}(t)+k^{*}{ }_{n} y_{n}(t)=p^{*}{ }_{n}(t)
$$

que é uma equação de um grau de liberdade para o modo $n$, onde os coeficientes $m_{n}^{*}$ e $k_{n}^{*}$, são denominados de massa e rigidez modal equivalente.

Dessa forma, cada modo de vibração tem uma equação do movimento independente. Para se alcançar a resposta dinâmica, podem-se obter as soluções de cada modo e sobrepô-las utilizando a equação (3.22). Existem ainda outros métodos de combinar as respostas modais Denomina-se tal procedimento de Método de Superposição Modal.

\subsection{Dinâmica Linear de Estruturas - Resposta a uma excitação de base}

A equação do movimento para um sistema linear massa-mola amortecedor de um grau de liberdade pode ser escrita da seguinte forma.

$$
m \ddot{v}(t)+c \dot{v}(t)+k v(t)=p(t)
$$


onde $m$ é a massa, $c$ é a constante de amortecimento, $k$ é a rigidez e $v(t)$ é o deslocamento que o sistema sofre em função do tempo. $p(t)$ é a excitação do sistema.

No caso particular de um sistema massa-mola que sofre excitação de base, a equação (3.36) pode ser reescrita como:

$$
m\left(\ddot{v}(t)+\ddot{v}_{g}(t)\right)+c \dot{v}(t)+k v(t)=0
$$

onde $\ddot{v}_{g}(t)$ é a aceleração da base do sistema (sempre tomada em relação a um referêncial inercial) e $v_{t}(t)=v(t)+v_{g}(t)$ é o deslocamento total da estrutura, como mostra a Figura 2.

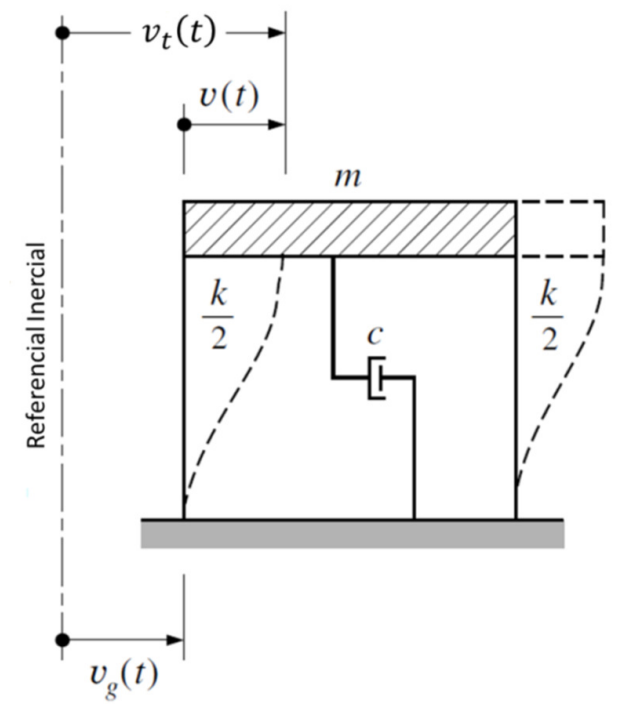

Figura 2 - Sistema massa-mola com excitação de base - Adaptado Clough, 200319 p.

Como a aceleração da base pode ser vista como uma excitação dinâmica do sistema, a eq. (3.37) pode ser reescrita como:

$$
m \ddot{v}(t)+c \dot{v}(t)+k v(t)=-m \ddot{v}_{g}(t)
$$

onde o termo $-m \ddot{v}_{g}(t)$ é o carregamento efetivo devido ao movimento da base do sistema. Ou seja, as deformações estruturais causadas pela aceleração $\ddot{v}_{g}(t)$ serão as mesmas produzidas se houvesse uma carga externa $p_{\text {eff }}(t)=-m \ddot{v}_{g}(t)$. O sinal negativo dessa carga se deve ao fato de que sua direção se opõe ao sentido de aceleração da base. 
No estudo de terremotos, a aceleração de base $\ddot{v}_{g}(t)$ é obtida por meio de aferições realizadas em estruturas submetidas a abalos sísmicos. Com essas aferições, é possível se obter um espectro de carregamentos de excitação e, assim, todas as variáveis do problema se tornam conhecidas. Essa abordagem pode ser utilizada também na análise dinâmica de estruturas submetidas a carregamentos impulsivos, como ondas de choque provenientes de explosões submarinas.

No entanto, a resposta de um sistema massa-mola amortecido para um carregamento genérico deriva da resposta de um sistema massa-mola nãoamortecido. Sendo assim, desconsiderando o amortecimento a equação do movimento fica:

$$
m \ddot{v}(t)+k v(t)=p(t)
$$

Pelo teorema do impulso, em um sistema massa-mola linear elástico submetido a um carregamento $F(t)$, partindo do repouso, tem-se que:

$$
\int_{0}^{t_{1}} F(t) d t=m \dot{v}\left(t_{1}\right)-m \dot{v}(0)
$$

onde $t_{1}$ é a duração do carregamento.

Tomando $F(t)=p(t)-k v(t)$, tem-se que, para valores de $t_{1}$ pequenos, a variação da velocidade $\dot{v}(t)$ é muito maior que o deslocamento $v\left(t_{1}\right)$. Logo, a eq. (3.40) pode ser reescrita como:

$$
\int_{0}^{t_{1}} p(t) d t=m \dot{v}\left(t_{1}\right)
$$

Assim,

$$
\dot{v}\left(t_{1}\right)=\frac{1}{m} \int_{0}^{t_{1}} p(t) d t
$$

A resposta do sistema após o término do carregamento é uma vibração livre não-amortecida, com condições iniciais $v\left(t_{1}\right)$ e $\dot{v}\left(t_{1}\right)$,

$$
v(\bar{t})=\frac{\dot{v}\left(t_{1}\right)}{\omega} \operatorname{sen}(\omega \bar{t})+v\left(t_{1}\right) \cos (\omega \bar{t})
$$


onde $\bar{t}=t-t_{1}$. Mas como $v\left(t_{1}\right)$ é desprezível, a eq. (3.42) fica,

$$
v(\bar{t})=\frac{1}{m \omega}\left(\int_{0}^{t_{1}} p(t) d t\right) \operatorname{sen}(\omega \bar{t})
$$

Uma maneira de se resolver o problema é utilizando a integral de Duhamel. Segundo Clough (2003), dado um carregamento genérico $p(t)$ aplicado a um sistema linear elástico e não-amortecido (na dinâmica de um sistema submetido a um carregamento impulsivo de curta duração, o amortecimento pode ser desprezado, pois pouco influenciará na resposta), e considerando um instante $\tau$ neste espectro, tem-se que em um intervalo $d \tau, p(\tau) d \tau$ representa um impulso de curta duração que age na estrutura, como mostra a Figura 3.

Sendo assim, pode se utilizar o procedimento de aproximação da resposta de um sistema de um grau de liberdade submetida a um carregamento impulsivo, para se avaliar os deslocamentos provenientes de um carregamento genérico.

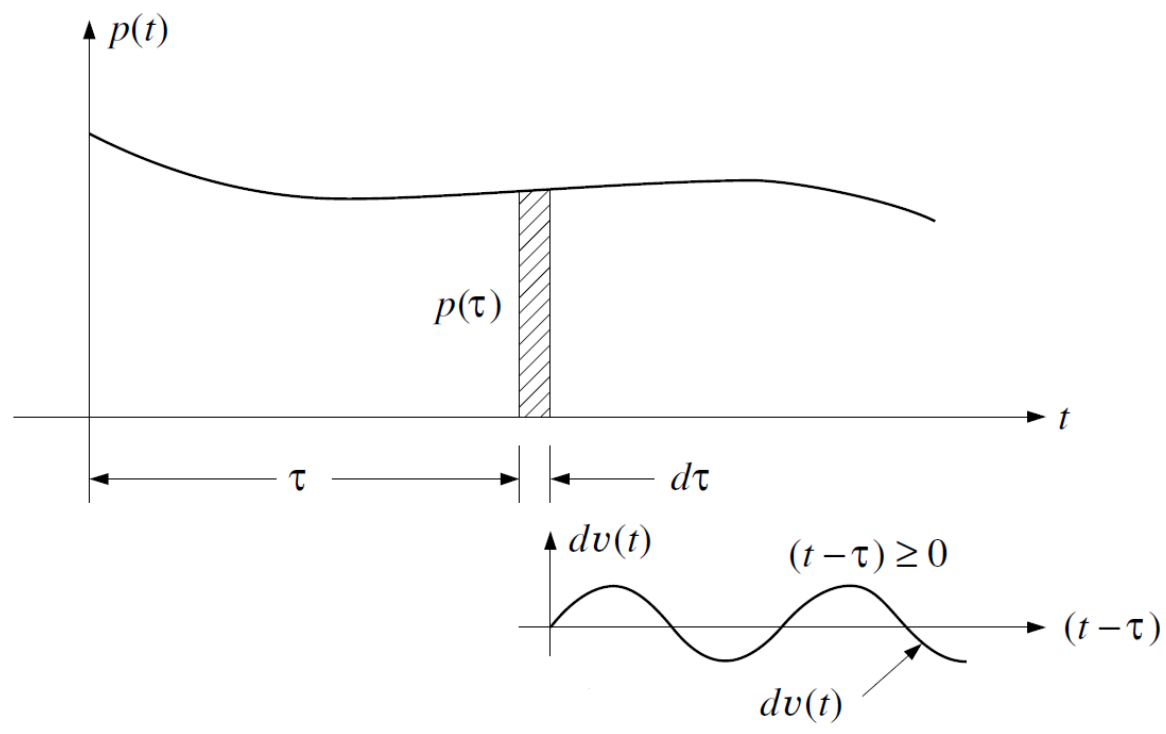

Figura 3 - Integral de Duhamel para um sistema massa-mola não-amortecido Adaptado Clough, 200387 p. 
Usando a eq. (3.44), tem-se que, no intervalo infinitesimal $d \tau$, a resposta produzida pelo impulso $p(\tau) d \tau$ é igual a:

$$
d v(t)=\frac{p(\tau) d \tau}{m \omega} \operatorname{sen} \omega(t-\tau)
$$

$\operatorname{com} t \geq \tau$.

Nessa expressão, $d v(t)$ representa a resposta no tempo do sistema para todo intervalo $t \geq \tau$. Não é a variação de $v$ durante o intervalo de tempo $d t$.

Para se determinar a resposta $v(t)$, basta considerar o carregamento no tempo como uma sucessão de impulsos de curta duração, cada um deles produzindo sua própria resposta diferencial, da forma de (3.45). Logo, para esse sistema massa-mola linear elástico, a resposta total pode ser obtida somando-se as respostas diferenciais, ou seja, integrando a eq. (3.45) de modo que:

$$
v(t)=\frac{1}{m \omega}\left(\int_{0}^{t} p(\tau) \operatorname{sen} \omega(t-\tau) d \tau\right)
$$

$\operatorname{com} t \geq 0$.

$$
v(t)=\frac{1}{m \omega_{D}}\left(\int_{0}^{t} p(\tau) \operatorname{sen} \omega_{D}(t-\tau) e^{-\xi \omega(t-\tau)} d \tau\right)
$$

Essa equação é conhecida como Integral de Duhamel, e descreve a resposta de um sistema linear elástico a um carregamento qualquer. E uma vez conhecida a resposta, pode-se construir o espectro de resposta, que consiste na descrição dos máximos deslocamentos em função da frequência de vibração da estrutura.

\subsection{Espectro de choque - Definição}

Segundo Clements (1972), dentro do contexto do DDAM, um espectro de choque é definido com sendo um espectro de resposta específico onde estão expressos os máximos valores absolutos de deslocamentos, velocidades ou acelerações de uma estrutura sujeita a um carregamento de choque como excitação de base em função das diferentes frequências de vibração. Ou seja, dada uma resposta de um sistema a esse carregamento, nesse caso específico, um choque 
(Figura 4), o espectro de choque é a representação dessa resposta em termos das máximas amplitudes absolutas de deslocamentos, velocidades ou acelerações em função da frequência, como mostra a Figura 5.

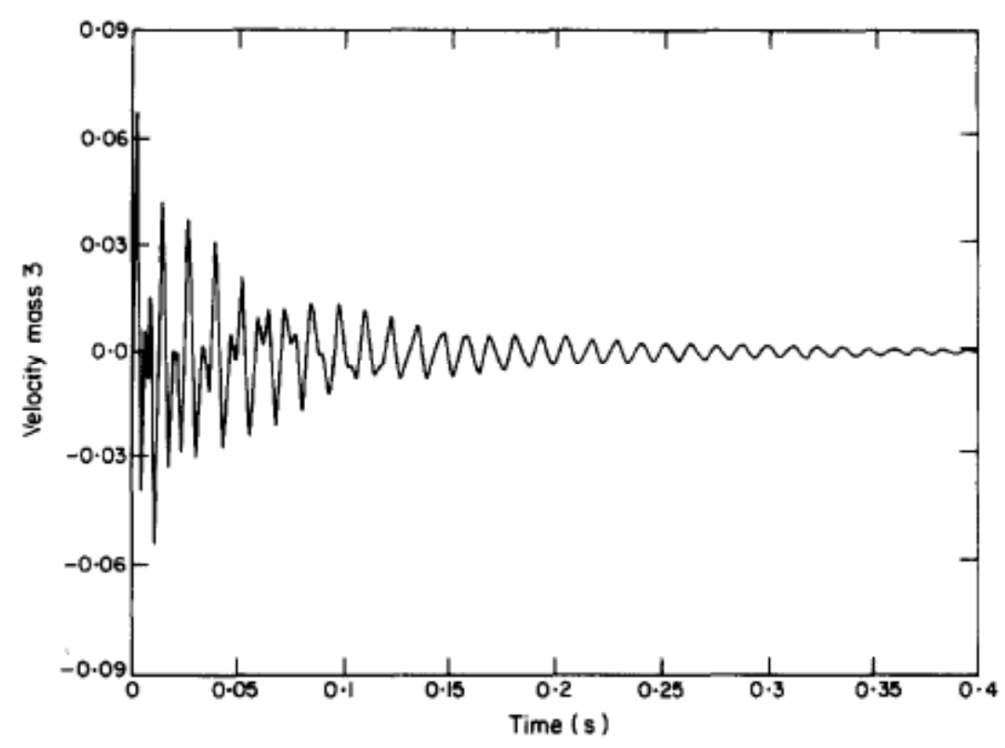

Figura 4 - Exemplo típico de resposta no tempo de um sistema sujeito a um choque - Cunniff \& O’Hara (1989)

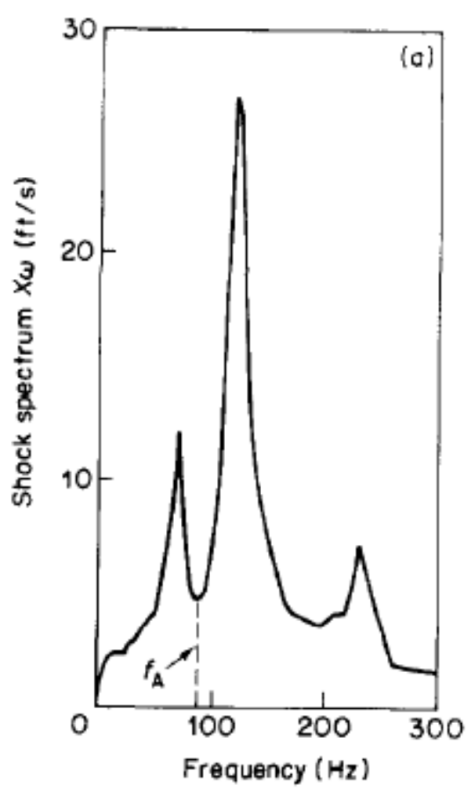

Figura 5 - Exemplo de Espectro de Choque - O’Hara \& Cunniff (1984) - 314 p. 


\subsection{Espectro de choque - Análise Espectral}

A definição matemática de um espectro de choque é apresentada a seguir. Considerando um oscilador de massa $m$ e rigidez $k$ sua freqüência natural $\omega=$ $\sqrt{k / m}$. A resolução desse problema é similar àquela desenvolvida no capítulo 3.7.

Adaptando a eq. (3.38) para esse oscilador desprezando o amortecimento, tem-se:

$$
m \ddot{v}(t)+k v(t)=-m \ddot{v}_{g}(t)
$$

onde $v(t)$ é o deslocamento relativo do oscilador e $\ddot{v}_{g}(t)$ é a aceleração imposta na base do sistema.

Resolvendo a eq. (3.48) pela Integral de Duhamel, tem-se:

$$
v(t)=-\frac{1}{m \omega}\left(\int_{0}^{t} m \ddot{v}_{g}(\tau) \operatorname{sen} \omega(t-\tau) d \tau\right)
$$

Usando a relação (3.54),

$$
\ddot{v}_{t}(t)=\omega\left(\int_{0}^{t} \ddot{v}_{g}(\tau) \operatorname{sen} \omega(t-\tau) d \tau\right)
$$

Assim, a relação entre a aceleração total do sistema e a excitação fica estabelecida. É definido então o espectro de choque de acelerações como sendo:

$$
S a=\left|\omega\left(\int_{0}^{t} \ddot{v}_{g}(\tau) \operatorname{sen} \omega(t-\tau) d \tau\right)\right|_{\max }
$$

É definido também o espectro de choque de velocidades:

$$
S v=\left|\left(\int_{0}^{t} \ddot{v}_{g}(\tau) \operatorname{sen} \omega(t-\tau) d \tau\right)\right|_{\max }
$$

E, da equação (3.49), tem-se a definição do espectro de choque de deslocamentos:

$$
S d=S v / \omega
$$




\subsection{Dynamic Design Analysis Method - DDAM}

Segundo O'Hara \& Belsheim (1961), uma das tarefas mais complicadas para se realizar uma análise estrutural é a escolha e criação de um modelo que represente dinamicamente o equipamento a ser estudado. E para tanto, deve se ter em mente que, na maioria dos casos, apenas os primeiros modos de vibração de um sistema contribuem significativamente para as tensões e deformações resultantes dos esforços inerciais. Essa afirmação é tão mais exata na medida em que todos os componentes de um sistema, ou a maior parte deles, podem ser considerados como corpos rígidos, ou seja, sua própria estrutura não é relevante frente aos esforços solicitantes e, desse modo, apenas sua contribuição dinâmica (inércia) se torna importante para a análise.

A abordagem do problema se inicia com a classificação do equipamento a ser analisado. Essa classificação deve ser feita de acordo com a importância do equipamento para a operação contínua seja do submarino ou do navio. O'Hara \& Belsheim (1961), sugerem a classificação da seguinte forma:

Categoria A - Itens não necessários para a operabilidade da embarcação, ou seja, equipamentos supérfluos;

Categoria B - Itens cuja perda na prejudicaria de forma grave a operação da embarcação;

Categoria C - Itens cuja perda implicaria em sérias falhas de operação do navio, ou até a perda total da embarcação.

Assim sendo, um modo adequado para se modelar um equipamento é representar regiões dele que se comportam como rígidas (dinamicamente) por massas concentradas em seu centro de gravidade. Dessa forma, a análise matricial dos modos naturais da estrutura é realizada de forma direta, porém, a precisão nas repostas é reduzida na medida em que toda uma região é descrita por um único ponto.

O`Hara \& Belsheim (1961), sugerem, então, que o equipamento seja modelado por um sistema massa-mola não-amortecido de forma a simplificar os cálculos. O número de graus de liberdade desse sistema dá uma noção de quão 
complicada será a análise modal desse sistema. À época da criação desse algoritmo, os recursos computacionais eram mais limitados, que implicava em maiores simplificações na modelagem do equipamento.

Deve-se então obter as propriedades do equipamento através de suas matrizes características, as matrizes de massa e de rigidez, que são utilizados para se calcular as frequências e modos naturais de vibração do equipamento em estudo. Além disso, sua fundação de vê ser especificada como: casco, deck ou chapeamento. Os esforços estimados variam de acordo com a estrutura a qual o equipamento é fixado (O’Hara \& Belsheim, 1963)

Construído o modelo físico do sistema, a próxima etapa é a atribuição dos carregamentos para esse sistema. Os conceitos de espectro de choque e espectro de choque para projeto são utilizados na montagem desse tipo de análise estrutural. Como já comentado na introdução, esses parâmetros foram concebidos e inseridos na engenharia de estruturas por Biot (1943) que desenvolveu uma tese sobre predição de esforços em estruturas submetidas a abalos sísmicos.

Em sua tese, Biot se utilizou do espectro de choque como principal parâmetro de cálculo para os esforços inerciais, e o definiu como sendo os valores de máxima resposta ao movimento gerado pela excitação do abalo sísmico.

Reescrevendo a equação do movimento para um sistema dinâmico em vibração forçada:

$$
m \ddot{v_{t}}+k\left(v_{t}-v_{g}\right)=0
$$

Como $\omega=\sqrt{k / m}$, reescreve-se a equação:

$$
\ddot{v_{t}}=-\omega^{2} v
$$

onde $v=v_{t}-v_{g}$.

A definição de espectro de choque resulta da expressão (3.54), que é dividida pela aceleração da gravidade $g$ para se chegar a um valor adimensional. Como os valores podem variar de sinal dependendo da direção em que ocorre o movimento, a expressão que define os valores do espectro de choque resulta em: 


$$
\left|\frac{\ddot{v}_{t}}{g}\right|_{\max }=\left|\frac{\omega^{2} v}{g}\right|
$$

Isto é, a máxima aceleração absoluta (medida em $g$ ) é igual ao máximo deslocamento relativo entre o oscilador e a base (variação de comprimento da mola). É importante ressaltar que essa equação mostra que o valor do espectro de choque independe da massa do oscilador, contanto que tenha a frequência $\omega$.

Segundo Remmers (1983), essas acelerações e deslocamentos podiam ser medidos por um pêndulo torsional e registrados por um equipamento desenvolvido pelo próprio Biot (1941). Dessa forma, os cálculos da integral de Duhamel que estimavam os deslocamentos da estrutura analisada, eram substituídos por uma simples leitura do espectro registrado pelo equipamento, no intervalo em que ela está sendo excitada por um abalo sísmico.

Biot (1941) se utiliza do fato que, quando um sistema massa-mola nãoamortecido é excitado por um impulso transiente, a resposta final pode ser representada pela superposição de oscilações livres, cada qual com amplitude proporcional a uma deformação estática e proporcional ao valor da intensidade espectral da frequência correspondente, isto é, a amplitude de vibração do impulso em uma dada frequência.

A vantagem dessa abordagem é que, para o cálculo da resposta do sistema, ele substitui a resposta no tempo que possui uma forma complicada, por uma distribuição espectral que é sempre uma função analítica da frequência.

Este conceito de espectro de choque foi aplicado em testes de equipamentos de submarinos e navios visando a melhora de seus projetos. Equipamentos de dimensões variadas foram submetidos a testes de campo com embarcações reais ou em ensaios em laboratório com máquinas que simulam ondas de choque (Clements, 1972). Com esses dados, a Marinha Norte Americana, desenvolveu um algoritmo que estima os esforços inerciais provenientes de uma onda de choque a partir das características do equipamento e de suas fundações (O'Hara \& Belsheim, 1963). 
A grande vantagem deste procedimento é que ele necessita apenas das características do equipamento em estudo para se modelar um problema. Os carregamentos de uma análise estrutural são estimados de acordo com uma extrapolação dos dados coletados de testes reais em embarcações ou experimentos em laboratórios com equipamentos específicos (O’Hara \& Belsheim, 1961; O’Hara, 1963; Clements, 1972).

\subsection{DDAM - Espectro de choque de projeto}

Como já mencionado espectro de choque é um espectro de resposta de um equipamento quando submetido a uma onda de choque. Consiste em, a partir de um experimento controlado ou de dados reais obtidos de abalos sísmicos, computar os deslocamentos, velocidades ou acelerações de um equipamento quando submetido a um carregamento impulsivo em função das suas frequências de vibração.

É a partir de um conjunto de espectros de choque que o design shock spectrum é estabelecido. O design shock spectrum ou espectro de choque de projeto é uma extrapolação do espectro de choque. É um gráfico que, dado o modo de vibração, contém os valores de máximo deslocamento, velocidade ou aceleração que um equipamento responde a uma excitação, mas agora em função da sua massa. Assim, o estudo desse equipamento pode ser feito se utilizando somente das características físicas, não sendo necessários parâmetros de excitação.

Esse conceito foi criado, pois o cálculo do espectro de choque se mostra trabalhoso se for levado em conta que este procedimento seria feito para cada um dos equipamentos de bordo. Outro problema relacionado ao desenvolvimento do espectro de choque é o carregamento utilizado para excitar o sistema. Simular uma explosão submarina, ou ainda, realizar testes de explosões reais em embarcações se mostrou trabalhoso e dispendioso (Clements, 1972). 


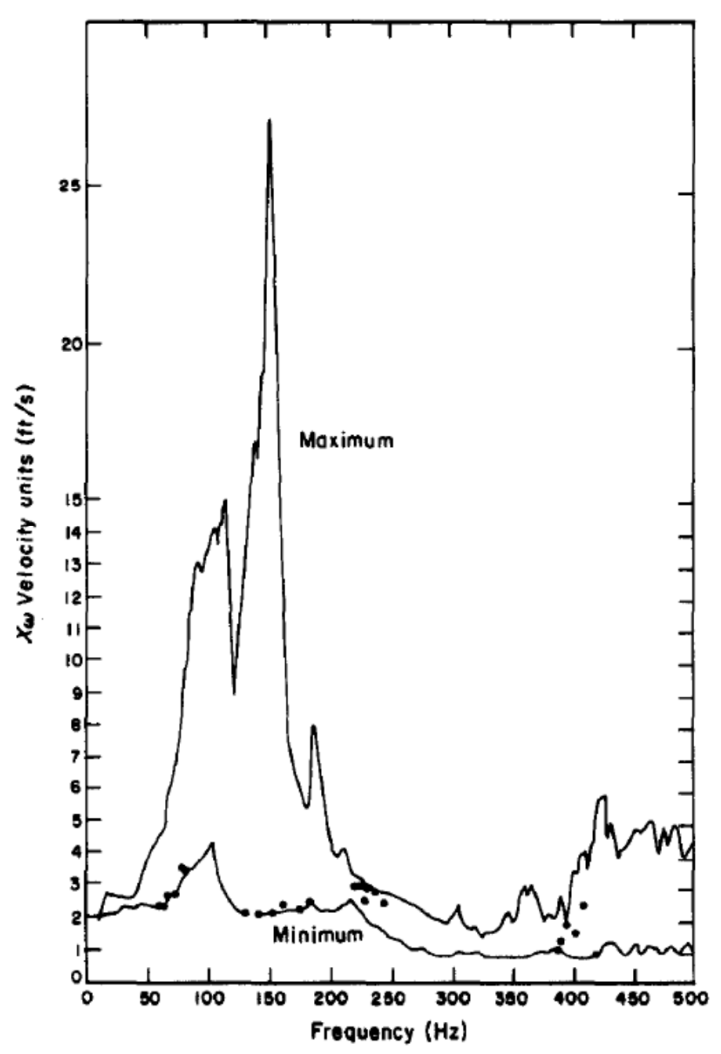

Figura 6 - Exemplo de espectro de choque com o envelope dos mínimos e máximos. Cunniff \& O’Hara, 1989157 p.

Então, a partir de conceitos da engenharia de terremotos (Biot, 1948), foram desenvolvidos equipamentos que pudessem construir esse espectro de forma experimental, através da aplicação de uma onda de choque, como carregamento na fundação onde deve estar montado um conjunto de osciladores de massa desprezível e de diferentes frequências naturais conhecidas. Dessa forma, ter-se-á o registro dos máximos deslocamentos, velocidades ou acelerações de cada oscilador em função de suas frequências naturais de vibração, e, assim, o espectro de choque é construído. A Figura 7 resume qualitativamente o procedimento de obtenção do espectro de choque a partir de um carregamento de choque conhecido. 

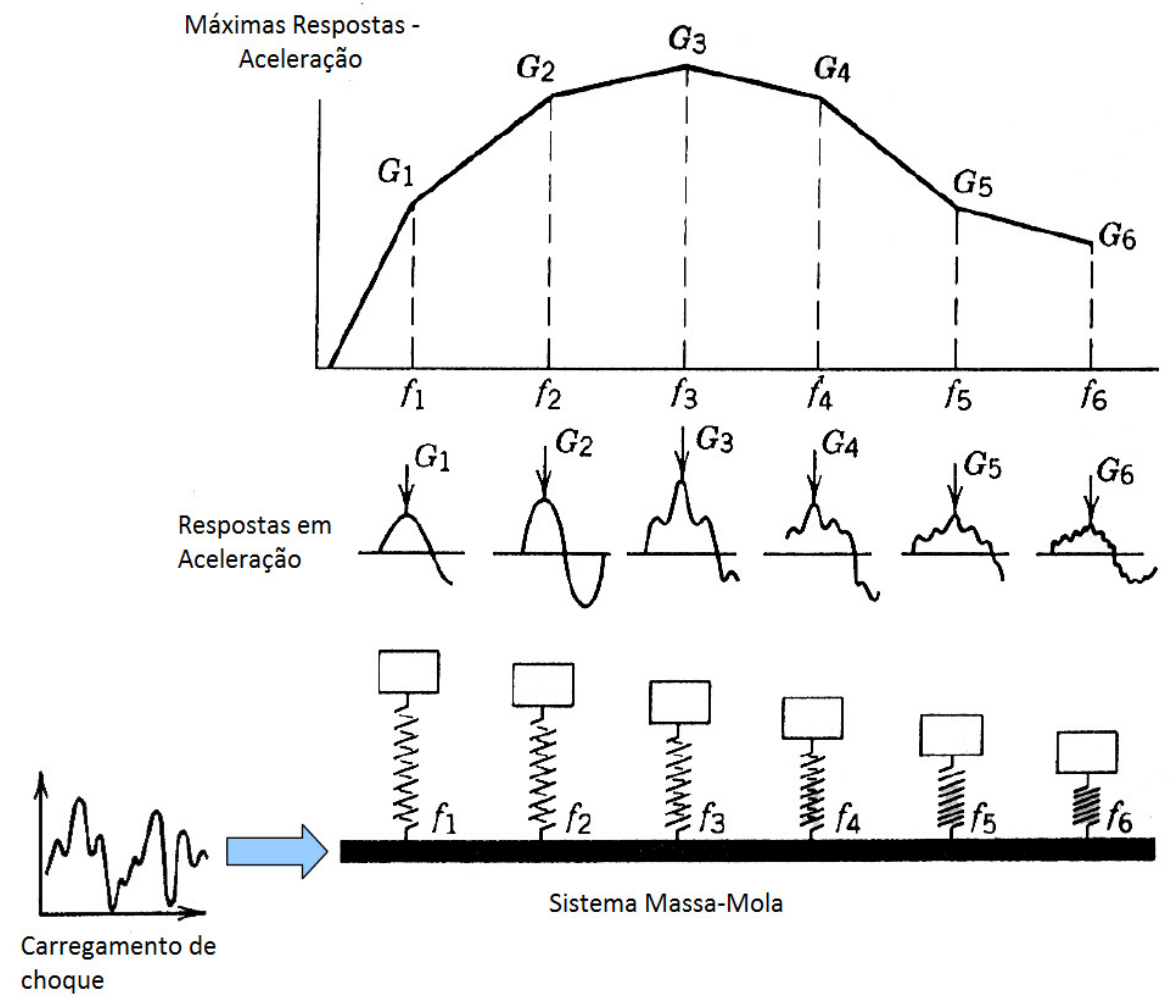

Figura 7 - Esquema de obtenção do espectro de choque - adaptado de Alexander (2009) 5p.

O espectro de choque de projeto pode ser obtido então a partir de um conjunto de espectros de choque conhecidos na medida em que esse conjunto de espectros é utilizado (O'Hara, 1958, 1959, 1984) para se gerar outro espectro (espectro de choque de projeto) que contenha agora os valores de resposta em deslocamentos, velocidades ou acelerações em função do peso do equipamento ou estrutura analisado (Cunniff \& O'Hara, 1989). Desse modo, equipamentos ou estruturas que não possuem um espectro de choque conhecido, mas que têm seu peso na mesma faixa de outros sistemas que já o possuem, podem ser estudados dinamicamente pelo DDAM.

Sendo assim, o espectro de choque de projeto se mostra como uma alternativa para estimar esforços inerciais devido a um carregamento impulsivo em outros equipamentos que não possuem um espectro de choque calculado.

A Figura 6 mostra um exemplo de um envelope de espectro de choque onde estão plotados os máximos e os mínimos valores de velocidade em função da 
frequência. Os pontos correspondem aos valores de choque de projeto considerados para o cálculo de esforços inerciais na fundação, provenientes do carregamento impulsivo do qual esse espectro foi construído. Foi demonstrado que, para utilizar um espectro de choque na estimativa de esforços inerciais de uma estrutura ou equipamento, deve-se levar em conta apenas os valores do espectro de choque correspondentes às frequências naturais de vibração da fundação/base dessa estrutura ou equipamento (O'Hara, 1959; O’Hara \& Cunniff, 1984).

Como já comentado, o algoritmo desenvolvido para estimar os esforços inerciais provenientes de carregamentos impulsivos se utiliza apenas das características dinâmicas da estrutura em estudo.

Para um sistema de 1 grau de liberdade, basta calcular a frequência natural $\omega=\sqrt{k / m}$, onde, em geral, $k$ é considerada a rigidez da fundação e $m$, a massa do equipamento somado a uma parte da fundação. O peso modal é definido como o peso do equipamento.

Já para um sistema de múltiplos graus de liberdade, deve-se calcular as matrizes de massa, bem como os modos e frequências de vibração, para se obter os pesos modais.

Sendo assim, estritamente para a aplicação do DDAM, o peso modal $W_{a}$ é definido como:

$$
W_{a}=\frac{g\left(\sum_{i} M_{i} \bar{X}_{i a}\right)^{2}}{\sum_{i} M_{i} \bar{X}_{i a}^{2}}[l b]
$$

onde $M_{i}$ é a massa modal do elemento $i, \bar{X}_{i a}$ é o deslocamento relativo do elemento $i$ no modo a de vibração. Será mostrado adiante que o denominador dessa expressão $\left(\sum_{i} M_{i} \bar{X}_{i a}^{2}\right)$ é definido como sendo a massa modal do modo $a$.

Com esses valores $W_{a}$, os valores do espectro de choque de projeto podem ser estimados. Contudo, o DDAM divide os equipamentos a serem estudados em 2 categorias, de acordo com seu comportamento estrutural, definido pela sua importância e/ou características: 
Regime Elástico - o equipamento e fundação a serem estudados devem se comportar dentro do limite de deformações elásticas, ou seja, não devem haver deformações plásticas residuais.

Regime Elasto-plástico - o equipamento e fundação a serem estudados podem ter pequenas deformações plásticas residuais após a aplicação do esforço calculado.

O método ainda exige que se determine o tipo da fundação onde 0 equipamento será fixado, se no casco, em um convés, ou no chapeamento da embarcação ou do submarino. São essas as definições dos tipos de fundação, segundo O'Hara \& Belsheim (1963):

- Casco (Hull) - Equipamentos fixados diretamente na estrutura primária, como cavernas, anteparas estruturais abaixo da linha d'água, e no chapeamento acima da linha d’água;

- Convés (Deck) - Equipamentos fixados diretamente em convéses, anteparas não estruturais ou anteparas estruturais acima da linha d'água;

- Chapeamento (Shell Plating) - Equipamentos fixados diretamente no chapeamento.

Segue, então, o algoritmo para o cálculo dos valores de espectro. É necessário ressaltar que o sistema de unidades utilizado no desenvolvimento desse algoritmo é o inglês, sendo obrigatória sua utilização. Esse algoritmo fornece o espectro de choque de projeto em termos de velocidade $\left(V_{a}\right)$ e aceleração $\left(A_{a}\right)$, a partir do peso modal $\bar{W}_{a}$. O'Hara \& Belsheim $(1961,1963)$ definem como pseudovelocidades e pseudo-acelerações esses valores calculados pelo algoritmo.

Tabela 1 - Espectro de choque de projeto - Equipamentos no casco - SUBMARINOS

\begin{tabular}{cllc|cc}
\hline \multirow{2}{*}{ Localização } & \multicolumn{2}{c|}{ Direção } & \multicolumn{2}{c|}{ Elástico } & \multicolumn{2}{c}{ Elasto-Plástico } \\
\cline { 3 - 6 } & \multirow{3}{*}{ Casco } & Va & Aa & Va \\
\cline { 2 - 6 } & Vertical & $1,0 \mathrm{~A}_{0}$ & $1,0 \mathrm{~A}_{0}$ & $1,0 \mathrm{~A}_{0}$ & $0,5 \mathrm{~A}_{0}$ \\
\cline { 2 - 6 } & Través & $1,0 \mathrm{~A}_{0}$ & $1,0 \mathrm{~A}_{0}$ & $1,0 \mathrm{~A}_{0}$ & $0,5 \mathrm{~A}_{0}$ \\
\cline { 2 - 6 } & Longitudinal & $0,4 \mathrm{~A}_{0}$ & $0,4 \mathrm{~A}_{0}$ & $0,4 \mathrm{~A}_{0}$ & $0,2 \mathrm{~A}_{0}$ \\
\hline
\end{tabular}




$$
\begin{aligned}
& A_{0}=10,4\left(\frac{480+\bar{W}_{a}}{20+\bar{W}_{a}}\right)\left[\frac{i n}{s^{2}}\right] \\
& V_{0}=20\left(\frac{480+\bar{W}_{a}}{100+\bar{W}_{a}}\right)\left[\frac{i n}{s}\right] \\
& \bar{W}_{a}=\frac{W_{a}}{1000}
\end{aligned}
$$

É importante observar que esses valores da Tabela 1 são específicos para serem utilizados no estudo de equipamentos de submarinos e aqueles classificados como fixados ao casco da embarcação, ou seja, em sua estrutura primária. Esse é o caso do reator PWR de propulsão do submarino.

Para um equipamento preso a um convés, o espectro de choque de projeto pode ser descrito na Tabela 2. A Tabela 3 mostra o espectro de choque de projeto para um equipamento de submarino fixado ao chapeamento.

Tabela 2 - Espectro de choque de projeto - Equipamentos no convés - SUBMARINOS

\begin{tabular}{cllcc|cc}
\hline \multirow{2}{*}{ Localização } & \multicolumn{2}{c|}{ Elástico } & \multicolumn{2}{c}{ Elasto-Plástico } \\
\cline { 3 - 7 } & \multicolumn{1}{c}{ Direção } & \multicolumn{1}{c}{$\mathrm{Aa}$} & $\mathrm{Va}$ & \multicolumn{2}{c}{$\mathrm{Aa}$} & $\mathrm{Va}$ \\
\hline \multirow{3}{*}{ Deck } & Vertical & $1,0 \mathrm{~A}_{0}$ & $1,0 \mathrm{~A}_{0}$ & $1,0 \mathrm{~A}_{0}$ & $0,5 \mathrm{~A}_{0}$ \\
\cline { 2 - 6 } & Través & $2,0 \mathrm{~A}_{0}$ & $2,0 \mathrm{~A}_{0}$ & $2,0 \mathrm{~A}_{0}$ & $1,0 \mathrm{~A}_{0}$ \\
\cline { 2 - 6 } & Longitudinal & $0,8 \mathrm{~A}_{0}$ & $0,8 \mathrm{~A}_{0}$ & $0,8 \mathrm{~A}_{0}$ & $0,4 \mathrm{~A}_{0}$ \\
\hline
\end{tabular}

$$
\begin{aligned}
& A_{0}=5,2\left(\frac{480+\bar{W}_{a}}{20+\bar{W}_{a}}\right)\left[\frac{i n}{s^{2}}\right] \\
& V_{0}=10\left(\frac{480+\bar{W}_{a}}{100+\bar{W}_{a}}\right)\left[\frac{i n}{s}\right]
\end{aligned}
$$

Tabela 3 - Espectro de choque de projeto - Equipamentos no chapeamento - SUBMARINOS

\begin{tabular}{clcc}
\hline \multirow{2}{*}{ Localização } & \multicolumn{1}{c}{ Direção } & \multicolumn{2}{c}{ Elástico } \\
\cline { 2 - 4 } Chapeamento & \multicolumn{1}{c}{ Va } \\
\cline { 2 - 4 } & Vertical & $1,0 \mathrm{~A}_{0}$ & $1,0 \mathrm{~A}_{0}$ \\
\cline { 2 - 4 } & Través & $0,2 \mathrm{~A}_{0}$ & $0,2 \mathrm{~A}_{0}$ \\
\cline { 2 - 4 } & Longitudinal & $0,08 \mathrm{~A}_{0}$ & $0,08 \mathrm{~A}_{0}$ \\
\hline
\end{tabular}




$$
\begin{aligned}
& A_{0}=52\left(\frac{480+\bar{W}_{a}}{20+\bar{W}_{a}}\right)\left[\frac{i n}{s^{2}}\right] \\
& V_{0}=100\left(\frac{480+\bar{W}_{a}}{100+\bar{W}_{a}}\right)\left[\frac{i n}{s}\right]
\end{aligned}
$$

Já para embarcações de superfície, a Tabela 4, a Tabela 5 e a Tabela 6 e as equações de (3.64) à (3.69) mostram como os valores do espectro de choque de projeto são calculados.

Tabela 4 - Espectro de choque de projeto - Equipamentos no casco - NAVIOS

\begin{tabular}{clcc|cc}
\hline \multirow{2}{*}{ Localização } & \multicolumn{2}{c|}{ Direção } & \multicolumn{2}{c}{ Elástico } & \multicolumn{2}{c}{ Elasto-Plástico } \\
\cline { 2 - 6 } Casco & Vertical & $1,0 \mathrm{~A}_{0}$ & $1,0 \mathrm{~A}_{0}$ & $1,0 \mathrm{~A}_{0}$ & $0,5 \mathrm{~A}_{0}$ \\
\cline { 2 - 6 } & Través & $0,4 \mathrm{~A}_{0}$ & $0,4 \mathrm{~A}_{0}$ & $0,4 \mathrm{~A}_{0}$ & $0,2 \mathrm{~A}_{0}$ \\
\hline \hline Longitudinal & $0,2 \mathrm{~A}_{0}$ & $0,2 \mathrm{~A}_{0}$ & $0,2 \mathrm{~A}_{0}$ & $0,1 \mathrm{~A}_{0}$ \\
\hline
\end{tabular}

\begin{tabular}{|c|c|c|c|c|c|}
\hline \multirow[b]{2}{*}{ Localização } & \multirow[b]{2}{*}{ Direção } & \multicolumn{2}{|c|}{ Elástico } & \multicolumn{2}{|c|}{ Elasto-Plástico } \\
\hline & & $\mathrm{Aa}$ & $\mathrm{Va}$ & $\mathrm{Aa}$ & $\mathrm{Va}$ \\
\hline \multirow{3}{*}{ Deck } & Vertical & $1,0 A_{0}$ & $1,0 \mathrm{~A}_{0}$ & $1,0 \mathrm{~A}_{0}$ & $0,5 \mathrm{~A}_{0}$ \\
\hline & Través & $0,4 A_{0}$ & $0,4 \mathrm{~A}_{0}$ & $0,4 \mathrm{~A}_{0}$ & $0,2 \mathrm{~A}_{0}$ \\
\hline & Longitudinal & $0,4 \mathrm{~A}_{0}$ & $0,4 A_{0}$ & $0,4 \mathrm{~A}_{0}$ & $0,2 \mathrm{~A}_{0}$ \\
\hline & \multicolumn{5}{|c|}{$0\left(\frac{\left(37,5+\bar{W}_{a}\right)\left(12+\bar{W}_{a}\right)}{\left(6+\bar{W}_{a}\right)^{2}}\right)\left[\frac{i n}{s^{2}}\right]$} \\
\hline & $V_{0}=30$ & \multicolumn{4}{|c|}{$\left(\frac{12+\bar{W}_{a}}{6+\bar{W}_{a}}\right)\left[\frac{i n}{s}\right]$} \\
\hline
\end{tabular}

Tabela 5 - Espectro de choque de projeto - Equipamentos no convés - NAVIOS 
Tabela 6 - Espectro de choque de projeto - Equipamentos no chapeamento - NAVIOS

\begin{tabular}{|c|c|c|c|}
\hline \multirow[b]{2}{*}{ Localização } & \multirow[b]{2}{*}{ Direção } & \multicolumn{2}{|c|}{ Elástico } \\
\hline & & $\mathrm{Aa}$ & $\mathrm{Va}$ \\
\hline \multirow{3}{*}{ Chapeamento } & Vertical & $1,0 \mathrm{~A}_{0}$ & $1,0 \mathrm{~A}_{0}$ \\
\hline & Través & $0,2 A_{0}$ & $0,2 A_{0}$ \\
\hline & Longitudinal & $0,1 A_{0}$ & $0,1 A_{0}$ \\
\hline \multicolumn{4}{|c|}{$A_{0}=40$} \\
\hline \multicolumn{4}{|c|}{$V_{0}=120\left(\frac{12+}{6+}\right.$} \\
\hline
\end{tabular}

Sendo assim, obtêm-se os valores de $V_{a}$ e $A_{a}$. São as máximas pseudovelocidades e acelerações em cada modo de vibração causadas por uma onda de choque. O menor valor entre $V_{a} \omega_{a}$ e $A_{a} g$ é utilizado na estimativa de esforços inerciais sobre a estrutura como o valor do espectro de choque $(S a)$ definido em 3.9, até o limite inferior de $2316 \mathrm{in} / \mathrm{s}^{2}(6 \mathrm{~g})$. Vale ressaltar que os dados das ondas de choque que geraram esses valores não foram divulgados pela Marinha Norte Americana.

\subsection{DDAM - Superposição Modal}

Com os valores dos espectros de choque definidos bem como os deslocamentos e tensões de cada elemento $i$ em cada modo $a$, é necessária a superposição dos resultados para se obter a resposta final da estrutura. Para tanto, a Soma NRL é utilizada e os deslocamentos e tensões podem ser superpostos da seguinte forma:

$$
R_{i}=\left|R_{i a}\right|+\sqrt{\sum_{b}\left(R_{i b}\right)^{2}}
$$

onde $R_{i a}$ é maior valor de resposta do elemento $i$ dentre os modos considerados e $R_{i b}$ são os demais valores de resposta do elemento $i$. 


\section{Modelos}

Este capítulo irá tratar da caracterização das estruturas estudadas. Um modelo simplificado de 1 grau de liberdade foi feito a fim de se verificar a aplicação do DDAM. Em seguida, um modelo de viga engastada foi avaliado dinamicamente por 2 abordagens distintas, uma analítica e outra pelo método de elementos finitos (ANSYS) para se avaliar novamente a aplicação do DDAM. Por fim, um modelo simplificado do vaso do reator foi feito no software ANSYS com a aplicação do DDAM.

\subsection{Aplicações do DDAM}

Primeiramente, foram criados os espectros de choque de projeto definidos $\mathrm{NRL}$, e, uma vez conhecidos os modos e frequências naturais, pode se calcular os espectros de resposta provenientes de um choque. Em um primeiro momento o modelo estudado foi um modelo analítico de um sistema de 1 grau de liberdade qualquer fixado no casco, descrito pela NSSC.

Em seguida, o DDAM foi aplicado a um modelo em elementos finitos de viga engastada (ANSYS) para uma comparação de resultados com exemplos da literatura e com um modelo analítico. Os conceitos teóricos que fundamentam essa solução analítica da dinâmica de uma viga serão explicitadas nesse capítulo também.

Por fim, o vaso do reator foi modelado no ANSYS, através de 2 abordagens diferentes a fim de se conhecer a dinâmica do vaso, e se verificar a aplicação do DDAM em uma estrutura mais complexa. Em uma delas, o vaso foi representado por elementos de viga tubulares, enquanto o outro modelo utilizou-se de elementos sólidos para compor a geometria da estrutura.

\subsection{Viga Engastada}

Um dos casos estudados foi a análise de uma viga engastada submetida a uma excitação transversal em sua base. Este exemplo foi realizado de acordo com o trabalho de Abbey, T. \& Weinberg, D., da Noran Engeneering. 


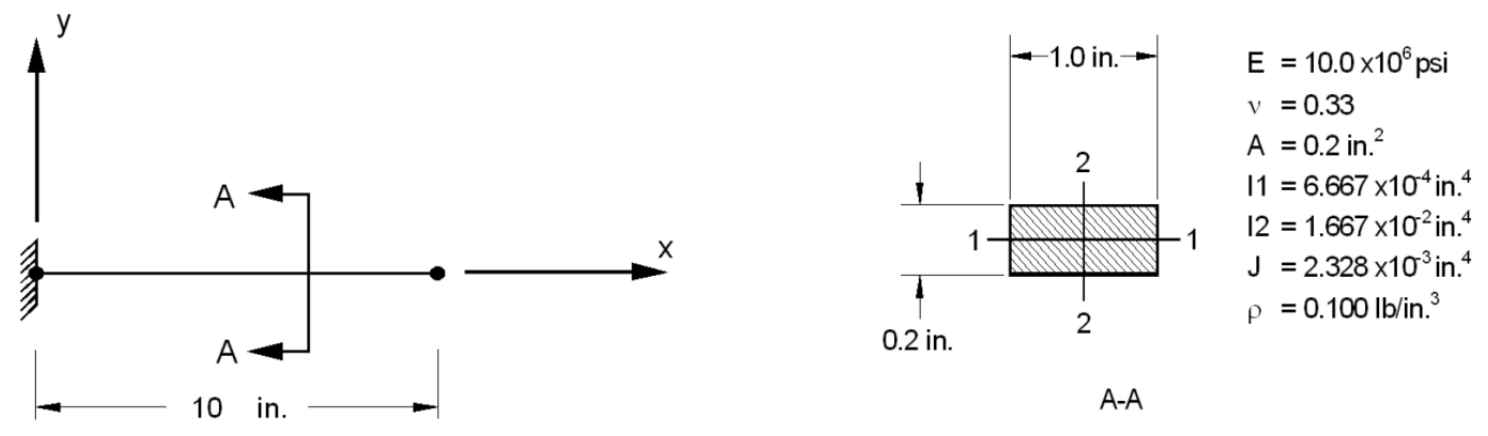

Figura 8 - Características da viga - Adaptado de Abbey \& Weinberg

O trabalho faz uma aplicação direta do DDAM em uma viga engastada a fim de se verificar a aplicação do método e os resultados que ele gera. Sendo assim, um estudo analítico da dinâmica da viga foi feito para dar sustentação ao modelo em elementos finitos que também foi desenvolvido no ANSYS.

A abordagem analítica desse problema foi realizada de duas formas. A primeira delas foi considerando a viga como uma estrutura contínua e a segunda, como um sistema de massas concentradas. Seguem as modelagens matemáticas para ambos os casos.

\subsubsection{Modelagem analítica - Sistema de Massa Concentradas}

Levando essa definição para um sistema com múltiplos graus de liberdade não-amortecido, considera-se a equação do movimento:

$$
\boldsymbol{M} \ddot{\boldsymbol{v}}(t)+\boldsymbol{K} \boldsymbol{v}(t)=\boldsymbol{p}(t)
$$

onde o carregamento, nesse caso, é uma aceleração na base da estrutura

$$
\boldsymbol{p}(t)=\boldsymbol{M}\{\mathbf{1}\} \ddot{v}_{g}(t)
$$

e o vetor $\{\mathbf{1}\}$ representa a direção na qual se dá a aceleração da base.

Relembrando o capítulo 3.6, transforma-se a equação do movimento para coordenadas generalizadas que, para o modo $n$, resulta em:

$$
m^{*}{ }_{n} \ddot{y}_{n}(t)+k^{*}{ }_{n} y_{n}(t)=p^{*}{ }_{n}(t)
$$


onde $m^{*}{ }_{n}=\boldsymbol{\phi}_{n}^{T} \boldsymbol{M} \boldsymbol{\phi}_{n}, k^{*}{ }_{n}=\boldsymbol{\phi}_{n}^{T} \boldsymbol{K} \boldsymbol{\phi}_{n}$ e $p_{n}^{*}(t)=\boldsymbol{\phi}_{n}^{T} \boldsymbol{M}\{\mathbf{1}\} \ddot{v}_{g}(t)$.

Dessa forma, determina-se a resposta de cada modo $n$ a partir dos resultados para um sistema de 1 G.L. Utilizando a resposta de um sistema pela Integral de Duhamel tem-se :

$$
y_{n}(t)=\frac{1}{m^{*}{ }_{n} \omega_{n}}\left(\int_{0}^{t} p^{*}{ }_{n}(\tau) \operatorname{sen} \omega(t-\tau) d \tau\right)
$$

Substituindo o valor de $p_{n}^{*}$, a resposta do sistema em coordenadas generalizadas fica:

$$
y_{n}(t)=\frac{\boldsymbol{\phi}_{n}^{T} \boldsymbol{M}\{\mathbf{1}\}}{m^{*}{ }_{n} \omega_{n}}\left(\int_{0}^{t} \ddot{v}_{g}(\tau) \operatorname{sen} \omega(t-\tau) d \tau\right)
$$

Utilizando agora a definição de espectro de choque (3.52), a resposta em coordenadas generalizadas, para o modo $n$, é obtida:

$$
y_{n}=\frac{\mathcal{L}_{n}}{m^{*}{ }_{n} * \omega_{n}} S v_{n}
$$

onde $S v_{n}$ é o espectro de choque de velocidade do modo $n$, e $\mathcal{L}_{n}=\boldsymbol{\phi}_{n}^{T} \boldsymbol{M}\{\mathbf{1}\}$. Utilizando um espectro de aceleração, a equação fica:

$$
y_{n}=\frac{\mathcal{L}_{n}}{m_{n}^{*}} * S a_{n}
$$

E, portanto, o vetor deslocamento da estrutura, no modo $n$, é obtido pela multiplicação do modo de vibração $\phi_{\boldsymbol{n}}$.

$$
\boldsymbol{v}_{n}(t)=\boldsymbol{\phi}_{\boldsymbol{n}} y_{n}(t)
$$

É importante ressaltar que o autovetor, nesse caso, é normalizado pela matriz de massa, ou seja:

$$
\boldsymbol{\phi}_{n_{\text {norm }}^{T}}^{T} \boldsymbol{M} \boldsymbol{\phi}_{n_{\text {norm }}}=1
$$

onde $\boldsymbol{\phi}_{n_{n o r m}}=A * \boldsymbol{\phi}_{n}$ é o autovetor normalizado pela matriz de massa. 
Dessa forma, a massa modal $m_{n}^{*}$ é unitária em todos os modos, simplificando os cálculos das respostas. Sendo assim, deve-se multiplicar o autovetor $\boldsymbol{\phi}_{n}$ por uma constante $A$, de modo que a massa modal seja unitária.

Assim,

$$
A_{n}=\sqrt{1 / \phi_{n} * \boldsymbol{M} * \boldsymbol{\phi}_{n}}
$$

Uma vez calculado os autovetores normalizados, pode-se obter não só os vetores deslocamento, mas também as forças e momentos que atuam na estrutura quando esta é submetida a um carregamento de choque e tem seu espectro de resposta conhecido.

Nesse caso, as forças elásticas provenientes do carregamento podem ser calculadas a partir dos deslocamentos e da rigidez da estrutura:

$$
\boldsymbol{f}_{E}(t)=\boldsymbol{K} * \boldsymbol{v}(t)=\boldsymbol{K} * \boldsymbol{\Phi} * \boldsymbol{y}(t)
$$

Mas, as forças elásticas também podem ser expressas em função das forças de inércia do sistema, segundo a relação imposta na equação (3.6):

$$
\boldsymbol{K} * \boldsymbol{\Phi}=\mathbf{M} * \boldsymbol{\Phi} * \mathbf{\Omega}^{2}
$$

onde $\boldsymbol{\Omega}^{2}$ é a matriz diagonal das frequências quadráticas $\omega_{n}{ }^{2}$. Logo,

$$
\boldsymbol{f}_{E}(t)=\mathbf{M} * \boldsymbol{\Phi} * \boldsymbol{\Omega}^{2} * \boldsymbol{y}(t)=\mathbf{M} * \boldsymbol{\Phi} *\left(\frac{\mathcal{L}_{n}}{m^{*}{ }_{n} * \omega_{n}} S v_{n}(t)\right)
$$

Mas, o espectro utilizado no DDAM é um valor máximo e não depende do tempo. Além disso, o método fornece como parâmetro o espectro de aceleração para o cálculo da resposta dinâmica do sistema. Logo, o vetor força elástica do modo $n$ pode ser calculado como sendo:

$$
\boldsymbol{f}_{E_{n}}=\boldsymbol{M} * \boldsymbol{\phi}_{n} * \mathcal{L}_{n} /_{m_{n}^{*}} * S a_{n}=\boldsymbol{f}_{S a_{n}}
$$

Uma vez conhecida a distribuição das forças pelos $i$ elementos do sistema, a força cortante $V_{0}$ na base da estrutura é calculada por: 


$$
V_{0}=\sum_{i=1}^{N} f_{S a_{i}}=\langle\mathbf{1}\rangle * \boldsymbol{f}_{S a}
$$

onde $\langle\mathbf{1}\rangle$ é um vetor linha de valores unitários. Nota-se também que:

$$
\langle\mathbf{1}\rangle * \mathbf{M} * \mathbf{\Phi}=\left\langle\mathcal{L}_{1} \mathcal{L}_{2} \cdots \mathcal{L}_{n}\right\rangle
$$

Logo, a força cortante $V_{0}$ pode ser expressa como:

$$
V_{0}=\sum_{n=1}^{N} \frac{\mathcal{L}_{n}{ }^{2}}{m_{n}^{*}} * S a_{n}
$$

E o momento fletor $M_{0}$ no engaste da viga é:

$$
M_{0}=\langle\boldsymbol{x}\rangle * \boldsymbol{f}_{S a_{n}}=\langle\boldsymbol{x}\rangle * \boldsymbol{M} * \boldsymbol{\phi}_{n} *\left\{\frac{\mathcal{L}_{n}}{m_{n}^{*}} * S a_{n}\right\}
$$

onde $\langle\boldsymbol{x}\rangle$ é um vetor linha composto pelas distâncias $x_{i}$ da massa em relação à base.

\subsubsection{Modelagem analítica - Viga Contínua}

Segundo Clough (2003), a equação do movimento que rege a dinâmica de um sistema contínuo em vibração livre é escrita da seguinte forma:

$$
E I \frac{\partial^{4} v(x, t)}{\partial x^{4}}+\bar{m} \frac{\partial^{2} v(x, t)}{\partial t^{2}}=0
$$

onde $E I$ é a rigidez a flexão do sistema e $\bar{m}$ é a massa por unidade de comprimento, que, nesse caso, são constantes. Essa equação é obtida pelo equilíbrio de forças e momentos de um elemento infinitesimal $d x$ da viga analisada.

Dividindo a equação por EI, e adotando outra notação, a eq. (4.4) fica:

$$
v^{i v}(x, t)+\frac{\bar{m}}{E I} \ddot{v}(x, t)=0
$$

Mas, como $\bar{m} / E$ I é constante, uma forma de se obter a solução para essa equação é separando as variáveis da função $v(x, t)$. Assim:

$$
v(x, t)=\phi(x) y(t)
$$


onde $\phi(x)$ é uma função de forma e $y(t)$ é uma amplitude que varia no tempo. Substituindo na eq. (4.5), tem-se:

$$
\phi^{i v}(x) y(t)+\frac{\bar{m}}{E I} \phi(x) \ddot{y}(t)=0
$$

Dividindo por $\phi(x) y(t)$, a eq. (4.7) resulta em:

$$
\frac{\phi^{i v}(x)}{\phi(x)}+\frac{\bar{m}}{E I} \frac{\ddot{y}(t)}{y(t)}=0
$$

Como o primeiro termo da equação (4.8) depende apenas de $x$ e o segundo termo é uma função de $t$ apenas, a solução dessa equação pode ser satisfeita por valores arbitrários de $x$ e $t$ somente se cada um dos termos forem constantes e de acordo com:

$$
\frac{\phi^{i v}(x)}{\phi(x)}=-\frac{\bar{m}}{E I} \frac{\ddot{y}(t)}{y(t)}=a^{4}
$$

onde a constante é designada na forma $a^{4}$ por conveniência matemática. Essa equação resulta em duas equações diferenciais ordinárias:

$$
\begin{gathered}
\ddot{y}(t)+\omega^{2} y(t)=0 \\
\phi^{i v}(x)-a^{4} \phi(x)=0
\end{gathered}
$$

onde

$$
\omega^{2} \equiv \frac{a^{4} E I}{\bar{m}}
$$

A solução para a equação (4.11) é da forma:

$$
\phi(x)=G * \exp (s x)
$$

Substituindo, tem-se,

$$
\left(s^{4}-a^{4}\right) G * \exp (s x)=0
$$

onde $s= \pm$ ia e $s= \pm a$. 
Incorporando as raízes na equação e compondo a resposta, pode-se obter:

$$
\phi(x)=G_{1} * \exp (i a x)+G_{2} * \exp (-i a x)+G_{3} * \exp (a x)+G_{4} * \exp (-a x)
$$

onde $G_{1}, G_{2}, G_{3}$ e $G_{4}$ são constantes complexas. Expressando as funções exponenciais em termos das funções trigonométricas e hiperbólicas equivalentes, e anulando a parte imaginária, tem-se:

$$
\phi(x)=A_{1} \cosh (a x)+A_{2} \cos (a x)+A_{3} \operatorname{senh}(a x)+A_{4} \operatorname{sen}(a x)
$$

onde agora $A_{1}, A_{2}, A_{3}$ e $A_{4}$ são constantes reais e dependem das condições de contorno do problema.

Do equilíbrio de forças e momentos do elemento, pode se deduzir também:

$$
\begin{gathered}
M(x, t)=E I v^{\prime \prime}(x, t) \\
V(x, t)=M^{\prime}(x, t)
\end{gathered}
$$

onde $M(x, t)$ é o momento fletor ao longo da viga e $V(x, t)$, a força cortante.

Para um problema de viga engastada, 4 condições de contorno devem ser satisfeitas:

$$
\begin{gathered}
\phi(0)=0 \\
\phi^{\prime}(0)=0 \\
M(L)=E I \phi^{\prime \prime}(L)=0 \\
V(L)=E I \phi^{\prime \prime \prime}(L)=0
\end{gathered}
$$

E a solução dessa equação, ou seja, o modo de vibração do modo $n$ é descrito por:

$$
\phi_{n}(x)=\cosh \left(\frac{\lambda_{n} x}{L}\right)-\cos \left(\frac{\lambda_{n} x}{L}\right)-\sigma_{n}\left(\operatorname{senh}\left(\frac{\lambda_{n} x}{L}\right)-\operatorname{sen}\left(\frac{\lambda_{n} x}{L}\right)\right)
$$


onde $\lambda_{n}$ e $\sigma_{n}$ são constantes que dependem das condições de contorno do problema e do modo de vibração para o qual estão sendo calculados. $L$ é o comprimento total da viga.

No entanto, para se calcular o momento fletor e a força cortante no engaste da viga, deve-se normalizar a função de forma com a massa, como no modelo de massas concentradas. Ou seja:

$$
\int_{0}^{L} \phi_{n_{\text {norm }}}(x) * \bar{m} * \phi_{n_{\text {norm }}}(x) d x=1
$$

onde $\bar{m}$ é a massa por unidade de comprimento. Desenvolvendo de forma análoga ao modelo de massas concentradas:

$$
\begin{gathered}
\int_{0}^{L} A_{n} \phi_{n}(x) * \bar{m} * A_{n} \phi_{n}(x) d x=1 \\
A_{n}{ }^{2} \bar{m} \int_{0}^{L} \phi_{n}(x)^{2} d x=1
\end{gathered}
$$

Logo,

$$
A_{n}=\sqrt{\left(1 / \bar{m} \int_{0}^{L} \phi_{n}(x)^{2} d x\right)}
$$

Tem-se, então, a função de forma normalizada $\phi_{n_{n o r m}}$.

De forma análoga ao modelo de massas concentradas, é utilizada novamente a representação das forças internas pelas forças inerciais. Isso foi feito, porque no modelo de viga contínua, as forças calculadas não são tão precisas quanto os deslocamentos, uma vez que a força é derivada do deslocamento.

Logo, a força cortante e o momento fletor na base da estrutura também são calculados em função das forças de inércia em vibração livre, onde as somatórias passam a ser integrais. Assim:

$$
V_{0_{n}}=\frac{\mathcal{L}_{n}}{m_{n}^{*}} * S a_{n} * \int_{0}^{L} \bar{m} * \phi_{n_{n o r m}}(x) d x
$$




$$
M_{0_{n}}=\frac{\mathcal{L}_{n}}{m^{*}{ }_{n}} * S a_{n} * \int_{0}^{L}\left(\bar{m} * \phi_{n_{n o r m}}(x) * x\right) d x
$$

onde

$$
\begin{aligned}
m^{*}{ }_{n} & =\int_{0}^{L} \bar{m} *\left[\phi_{n_{\text {norm }}}(x)\right]^{2} d x \\
\mathcal{L}_{n} & =\int_{0}^{L} \bar{m} * \phi_{n_{\text {norm }}}(x) d x
\end{aligned}
$$

\subsection{Vaso do Reator}

A estrutura que suporta o reator é complexa. Até onde se encontra divulgado, o reator nuclear fica inserido em um vaso de pressão que, por sua vez, está fixado em um tanque de blindagem. O presente estudo se restringirá ao vaso do reator.

Devido à escassez de informações publicadas, este trabalho não procurou descrever minuciosamente a geometria e composição do vaso do reator. Foi realizado uma exposição superficial do reator nuclear. A começar pela visão geral de um vaso de reator do tipo PWR (Pressurized Water Reactor), que possui calotas em suas extremidades e um corpo cilíndrico central, como mostra a Figura 9.

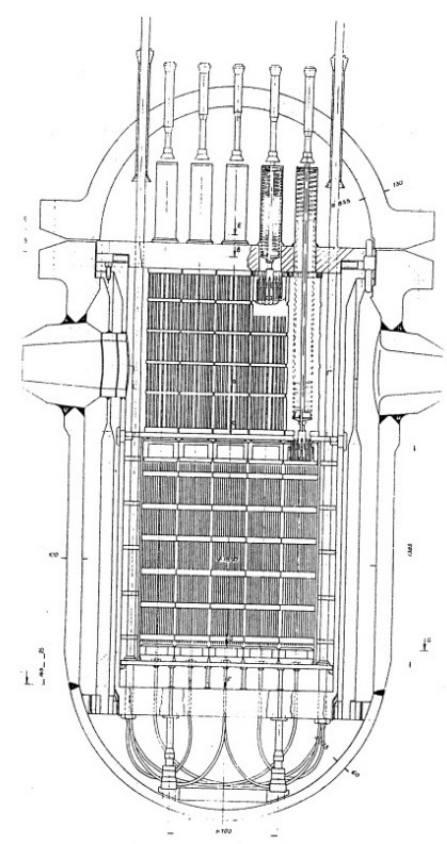

Figura 9 - Exemplo de Vaso de um Reator PWR em corte - Extraído de Augusto (1985) 
Como se pode notar, internamente ao vaso existem diversos componentes que influenciam na dinâmica da estrutura, denominados de internos do vaso. Até onde se encontra publicado, a maior parte se encontra fixada na altura do flange superior do vaso, ou seja, entre a calota superior e o restante do vaso (Figura 10). Existe também um apoio axial aos internos do vaso próximo à calota inferior que transmite apenas esforços na direção transversal ao vaso. Na Figura 13 é possível visualizar esse componente.

Dentre os internos, o elemento combustível (Figura 11) é o principal item, pois, como o próprio nome já diz, é onde ocorre a reação nuclear para geração de calor. As outras partes são estruturas que dão suporte ao elemento combustível e direcionam o fluxo da água que circula internamente.

Existem ainda componentes que transpõem às paredes do vaso na região superior e que se fixam justamente na calota superior. É o mecanismo de acionamento das barras de controle (Figura 12). Esse mecanismo tem como propósito controlar a reação nuclear que ocorre nos elementos combustíveis.

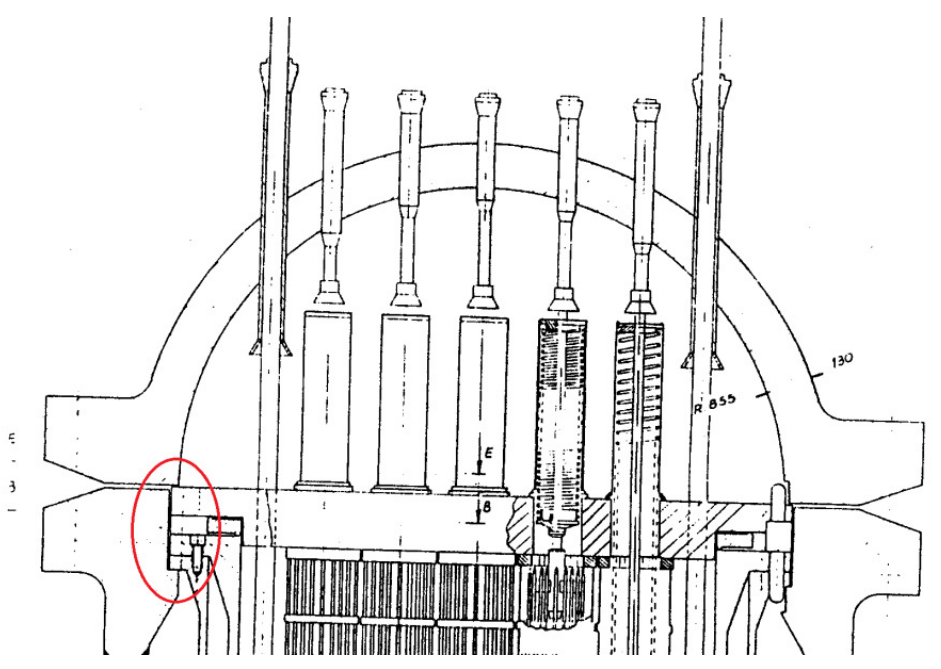

Figura 10 - Detalhe do apoio dos internos na região do flange superior do vaso 


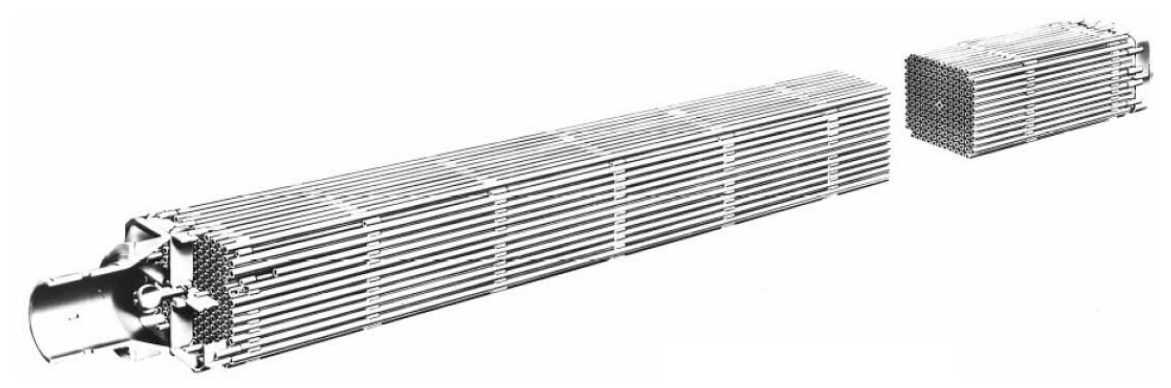

Figura 11 - Exemplo de Elemento Combustível de um Reator PWR - online: http://en.wikipedia.org/wiki/Pressurized water reactor em 06/02/2012

Sendo assim, o vaso do reator foi representado apenas pela sua casca. Os internos e os componentes superiores foram traduzidos por massas equivalentes $\mathrm{e}$ distribuídas de forma adequada pela geometria do vaso. Duas hipóteses importantes que foram adotadas são a pressão interna do vaso que foi desconsiderada para os cálculos dos esforços, bem como a massa de água que não pode ser calculada devido à falta de informações.

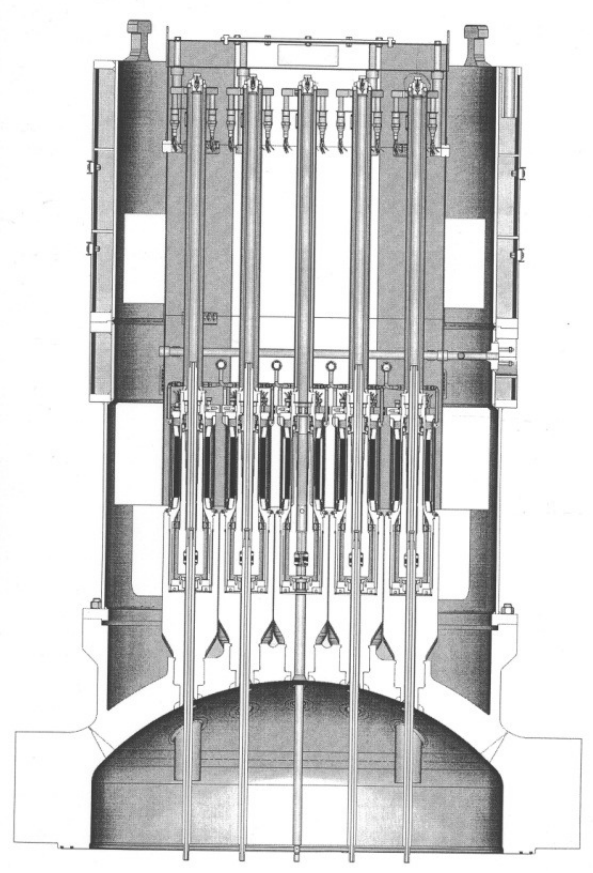

Figura 12 - Esquema do Mecanismo de Acionamento das Barras de Controle 


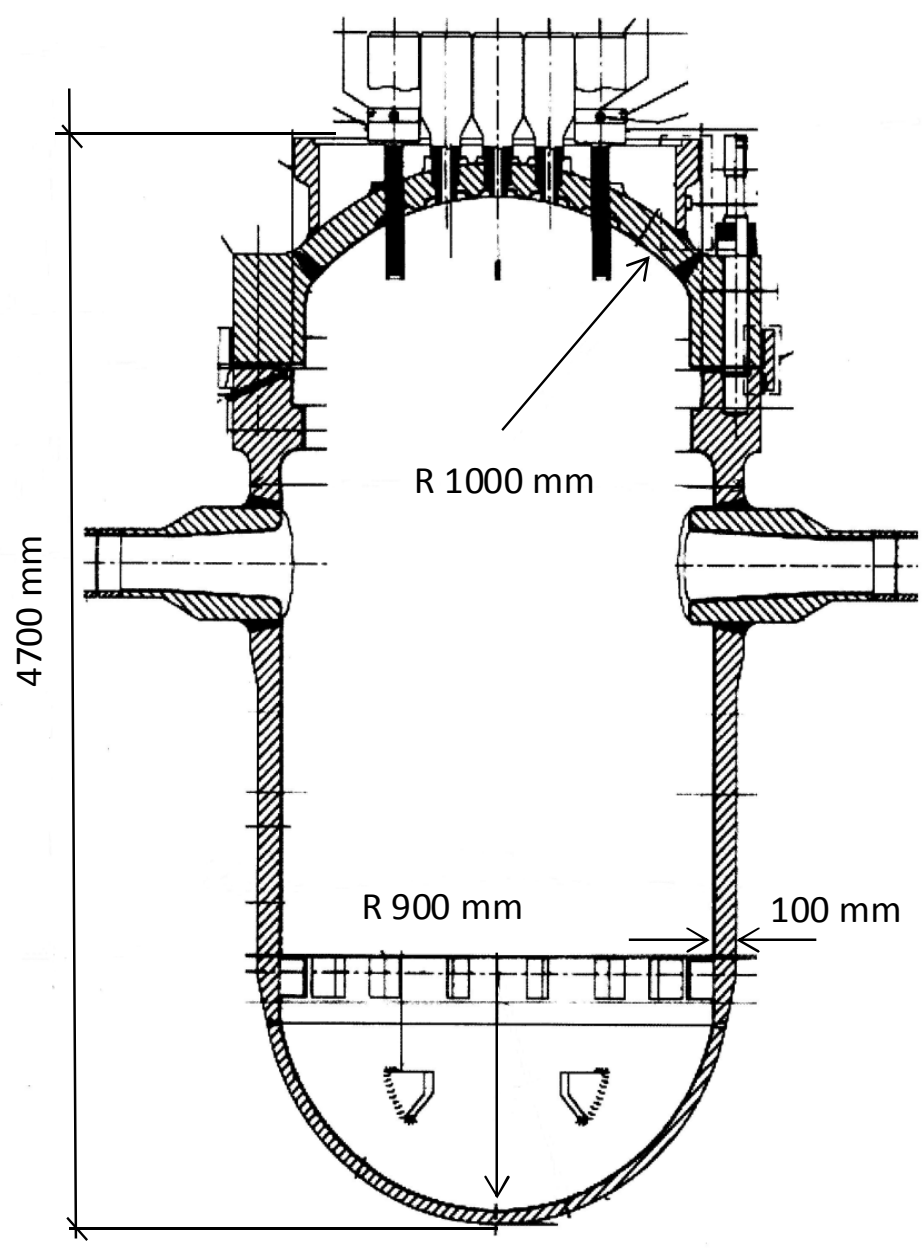

Figura 13 - Dimensões Adotadas do Vaso do Reator, segundo CTMSP

Neste trabalho, o vaso foi modelado de duas formas: por elementos de barra (BEAM) e por elementos sólidos (SOLID). E ainda, para ambos os casos, foram feitas simulações sem a massa dos internos, no intuito de se verificar a influência dela na dinâmica do vaso como um todo.

Por se tratar de um equipamento de tecnologia sigilosa, não se encontram na literatura ou em publicações, informações sobre análises estruturais realizadas. Portanto, o objetivo da análise deste equipamento neste trabalho é verificar a aplicação do DDAM, avaliar os resultados de forma qualitativa, ou seja, realizar uma comparação com os 2 diferentes modelos para a mesma estrutura. 


\section{Simulações e Resultados}

Este capítulo irá mostrar as aplicações do método DDAM na construção de um espectro de choque de projeto e na estimativa de esforços inércias provenientes de ondas de choque.

\subsection{Espectro de choque de projeto}

A partir do algoritmo mostrado no capítulo 3.11, é possível obter os espectros de choque de projeto desenvolvidos por O'Hara e Belsheim (1963). Esses gráficos mostram uma estimativa das máximas velocidades ou acelerações que um equipamento sofre quando submetido a uma excitação de choque, em função do seu peso modal. Em outras palavras, são calculados os valores do espectro de choque máximos sem se conhecer a onda de choque.

Como já mencionado, esses espectros são divididos em 2 categorias: Submarinos e Navios de superfície.

O Gráfico 1 e o Gráfico 2 mostram os espectros de choque de projeto (velocidades e acelerações) para um equipamento fixado na estrutura primária do submarino, submetido a um carregamento de choque na direção vertical ou na direção de través.

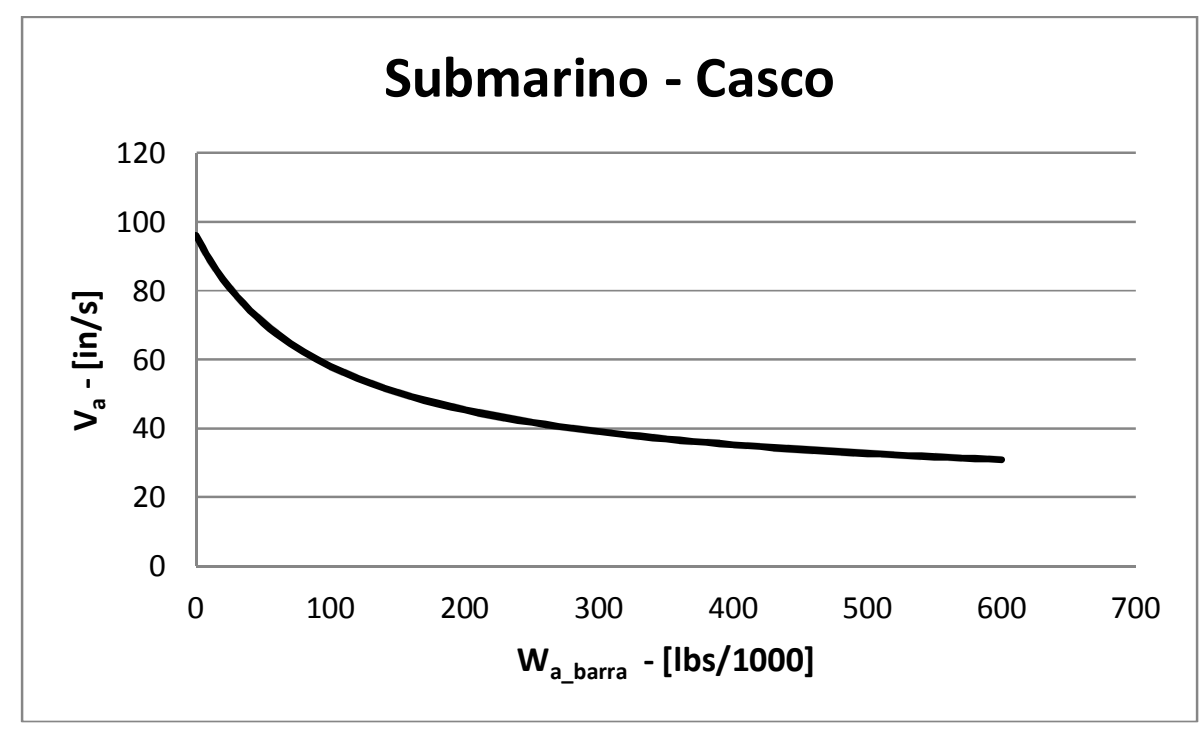

Gráfico 1 - Espectro de choque de projeto em termos de velocidade - Submarino - Casco Vertical ou Través 


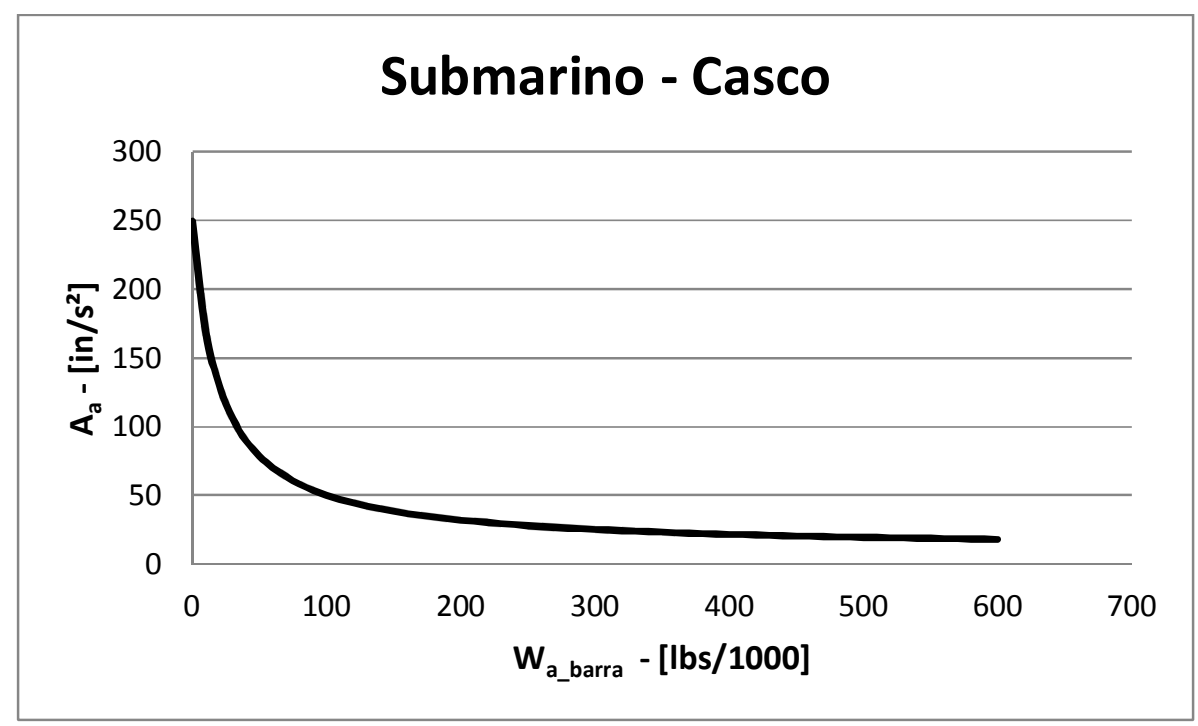

Gráfico 2 - Espectro de choque de projeto em termos de aceleração - Submarino - Casco Vertical ou Través

O Gráfico 3 e o Gráfico 4 mostram os espectros de choque de projeto (velocidades e acelerações) para um equipamento fixado em um convés do submarino, submetido a um carregamento de choque na direção vertical.

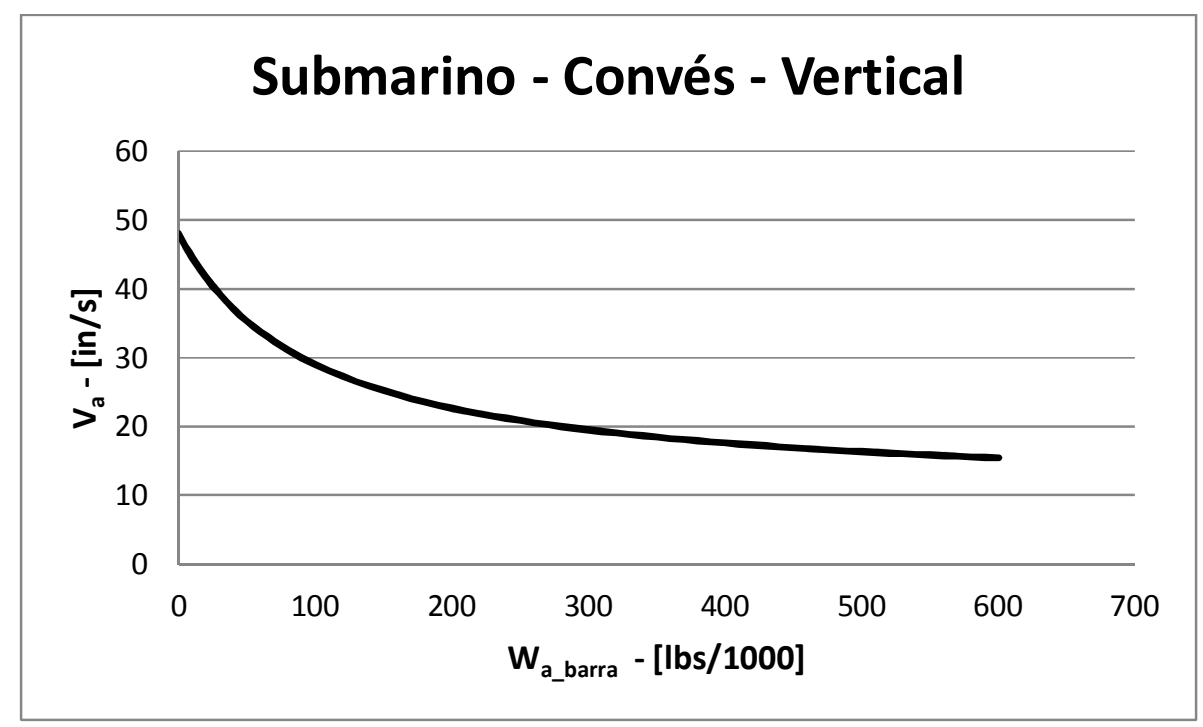

Gráfico 3 - Espectro de choque de projeto em termos de velocidade - Submarino - Convés Vertical 


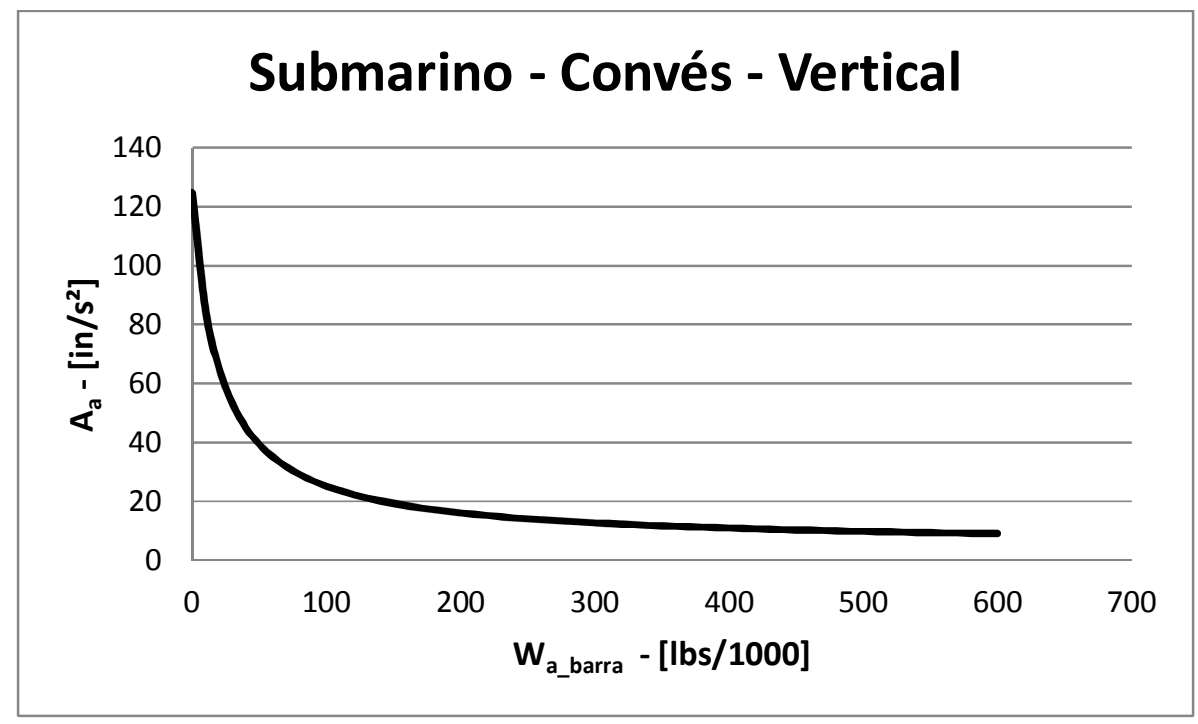

Gráfico 4 - Espectro de choque de projeto em termos de aceleração - Submarino - Convés Vertical

O Gráfico 5 e Gráfico 6 mostram os espectros de choque de projeto (velocidades e acelerações) para um equipamento fixado em um convés do submarino, mas agora, submetido a um carregamento de choque por través.

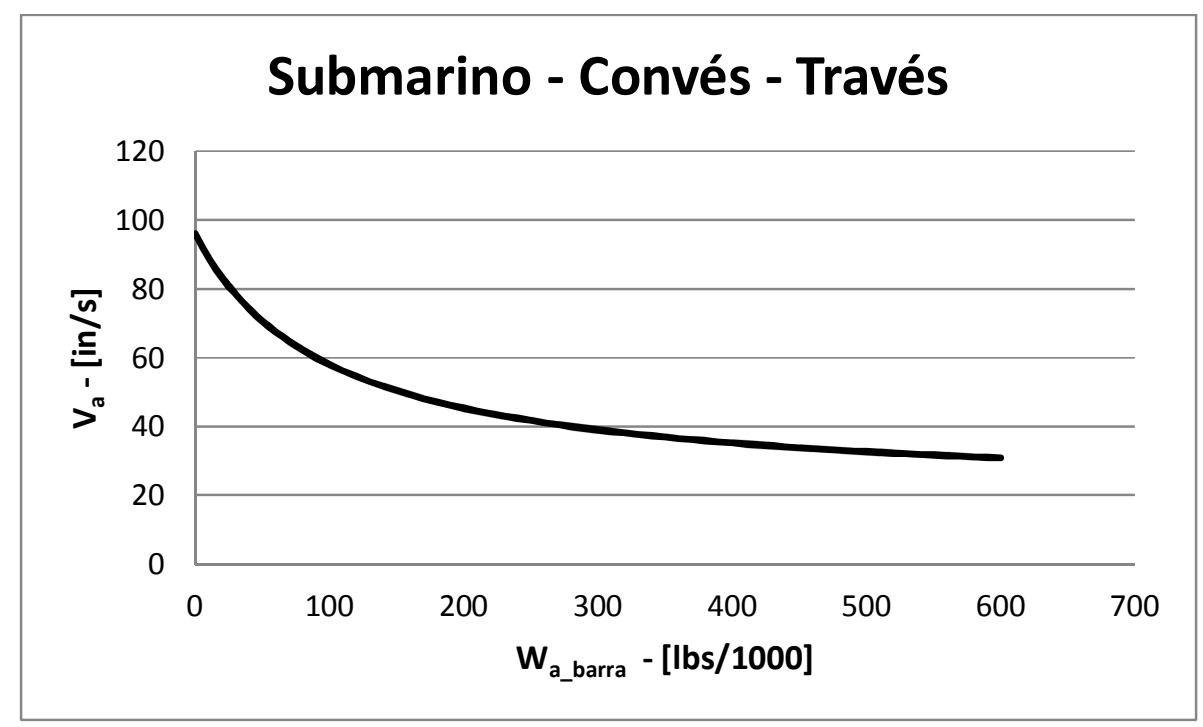

Gráfico 5 - Espectro de choque de projeto em termos de velocidade - Submarino - Convés Través 


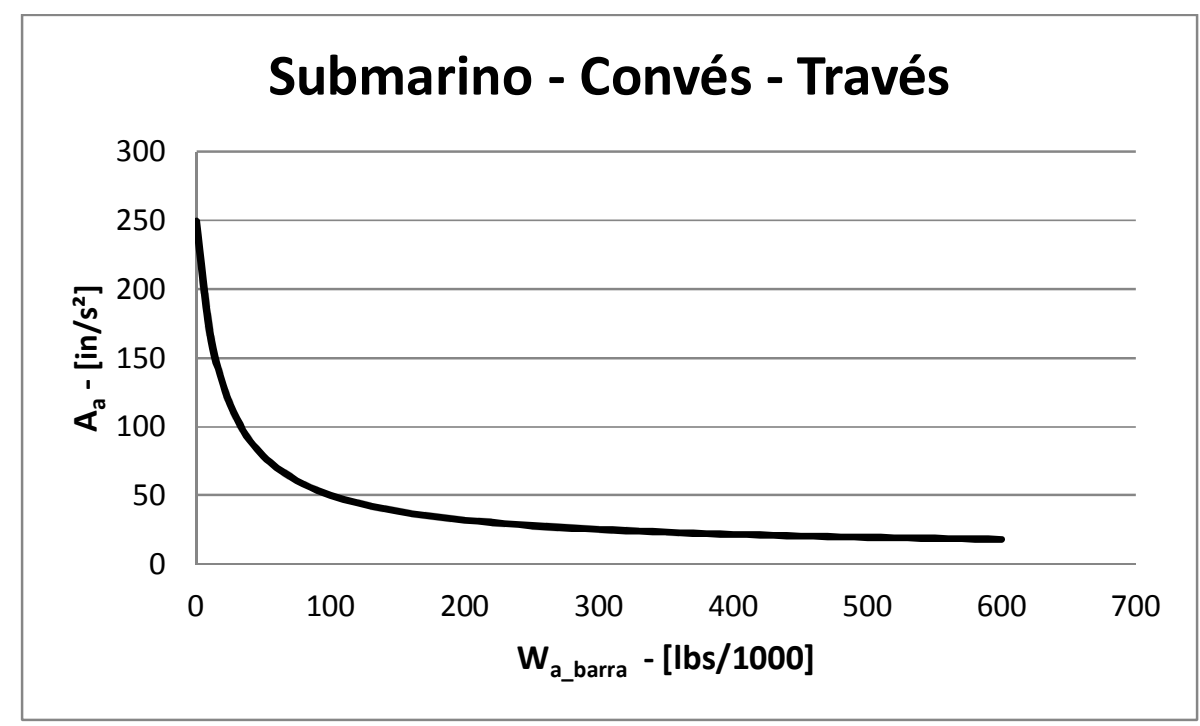

Gráfico 6 - Espectro de choque de projeto em termos de aceleração - Submarino - Convés Través

Para equipamentos de embarcações de superfície, os espectros de choque de projeto também foram calculados. Do Gráfico 7 ao Gráfico 14 são apresentados tais espectros utilizados na estimativa de esforços em um sistema submetido a carregamentos de choque.

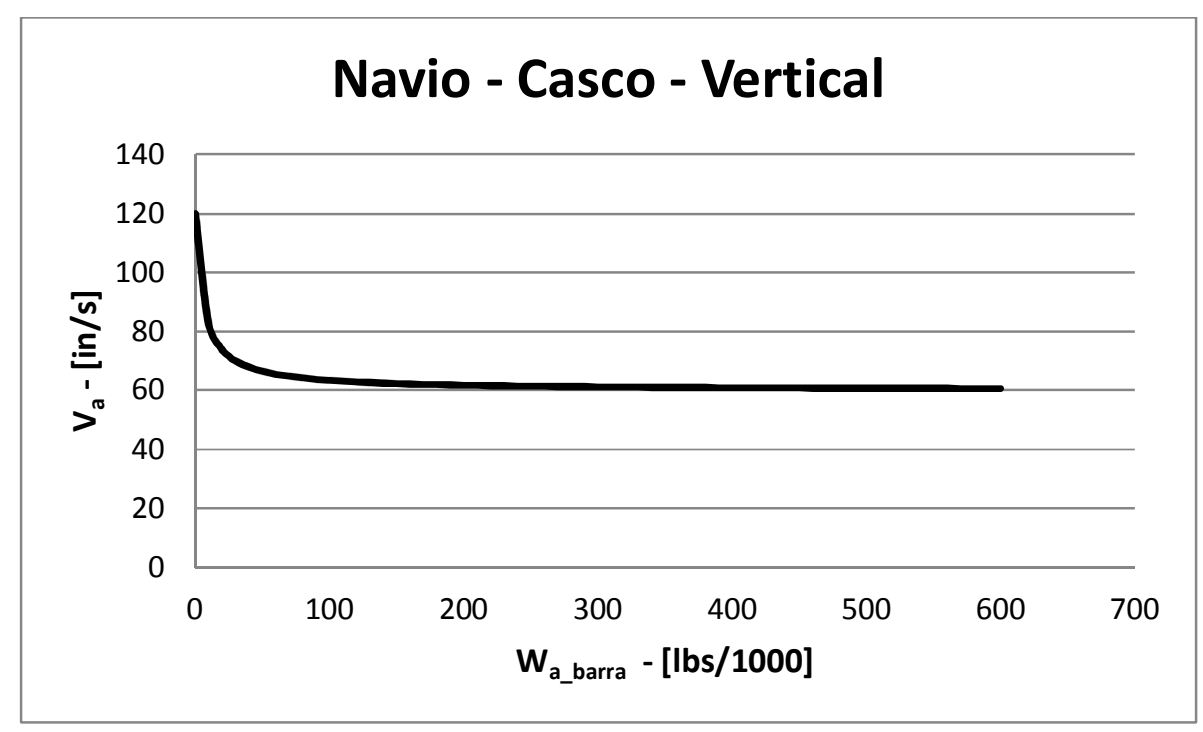

Gráfico 7 - Espectro de choque de projeto em termos de velocidade - Navio - Casco - Vertical 


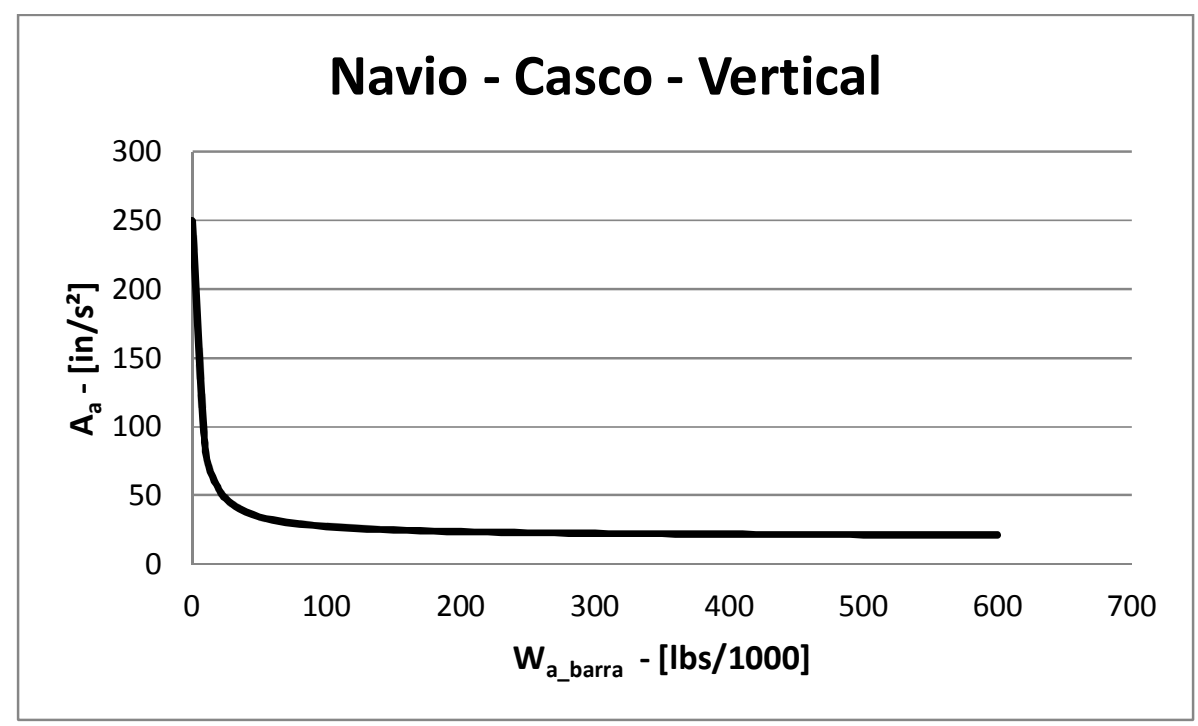

Gráfico 8 - Espectro de choque de projeto em termos de aceleração - Navio - Casco - Vertical

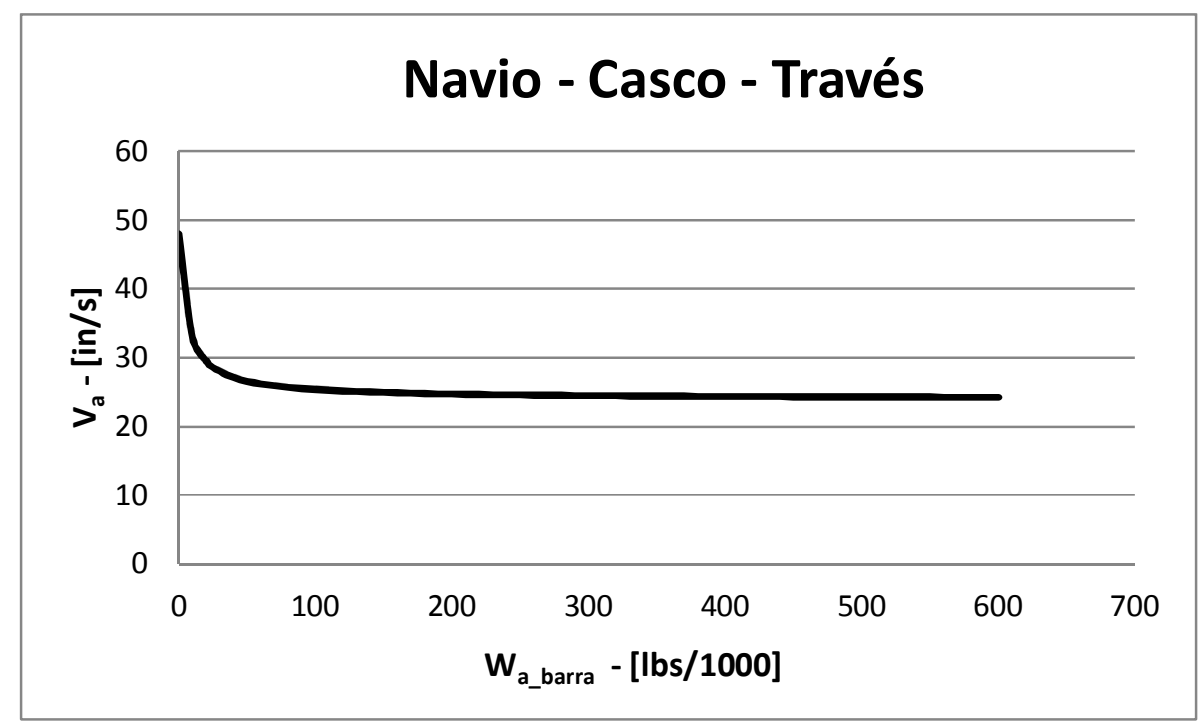

Gráfico 9 - Espectro de choque de projeto em termos de velocidade - Navio - Casco - Través 


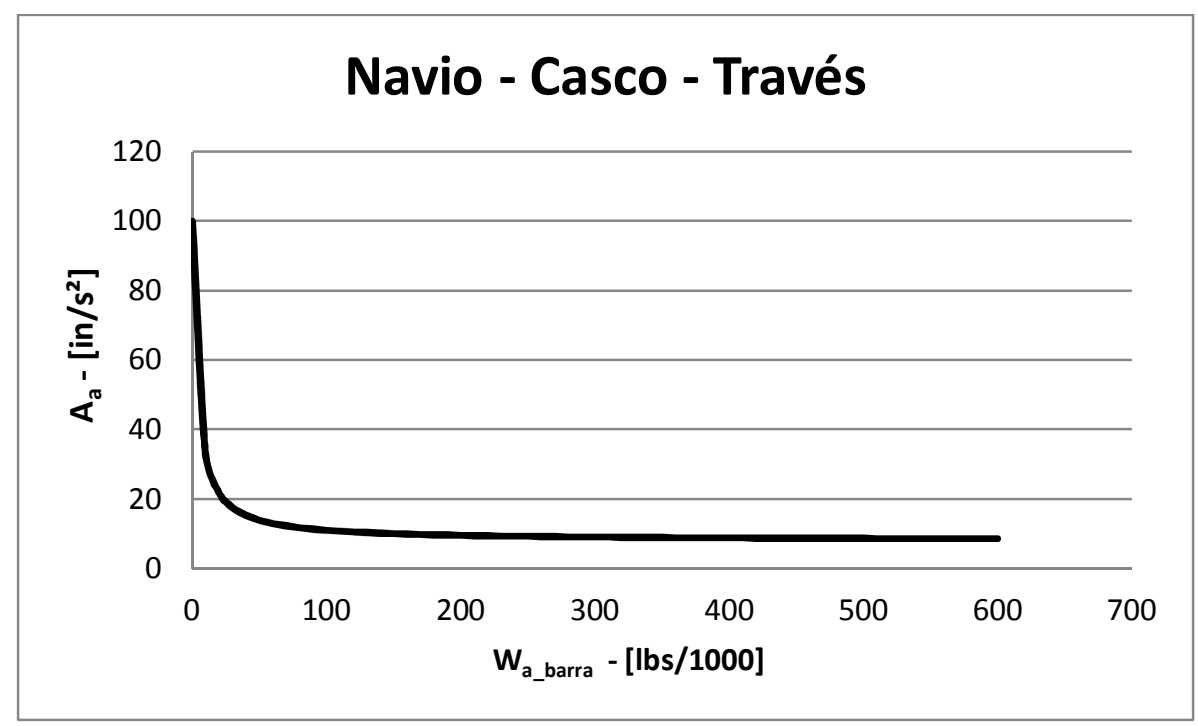

Gráfico 10 - Espectro de choque de projeto em termos de aceleração - Navio - Casco - Través

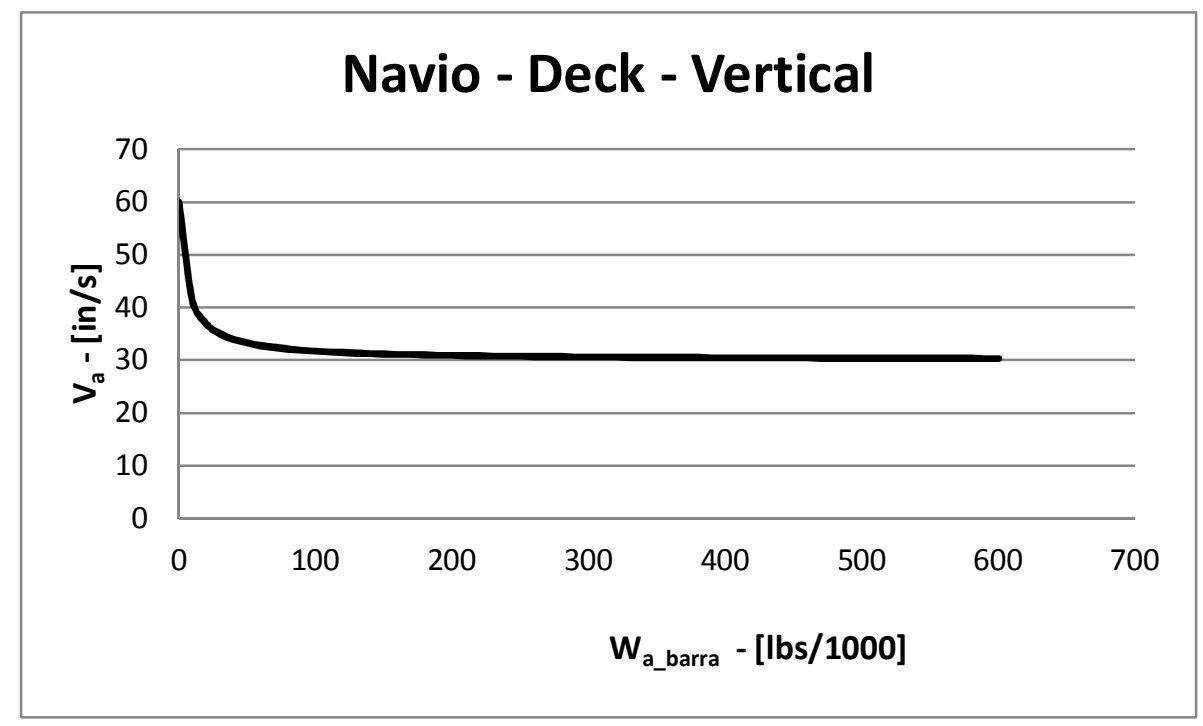

Gráfico 11 - Espectro de choque de projeto em termos de velocidade - Navio - Convés Vertical 


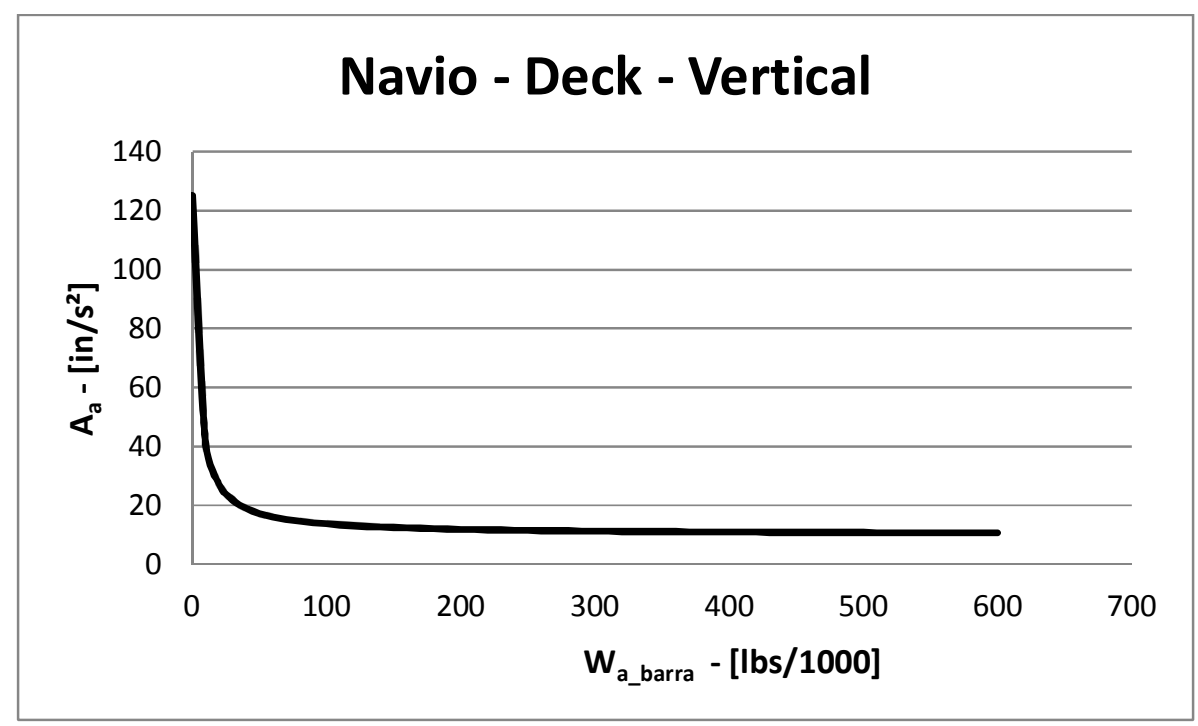

Gráfico 12 - Espectro de choque de projeto em termos de aceleração - Navio - Convés Vertical

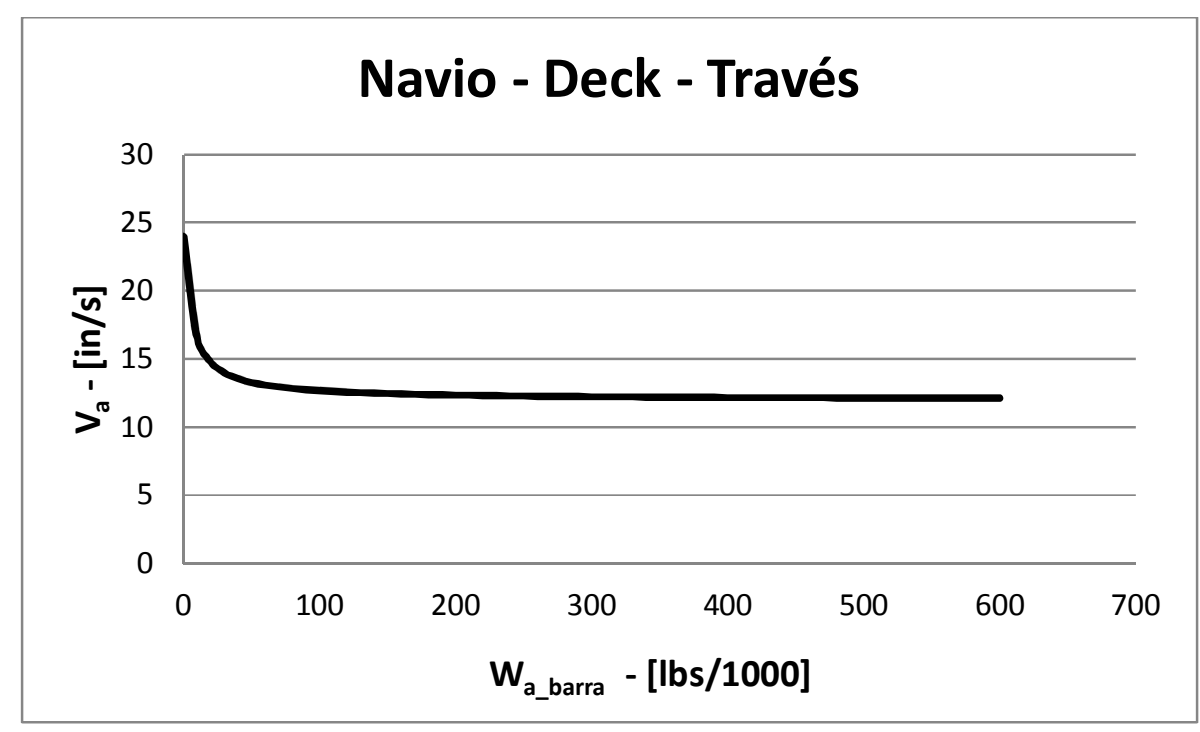

Gráfico 13 - Espectro de choque de projeto em termos de velocidade - Navio - Convés Través 


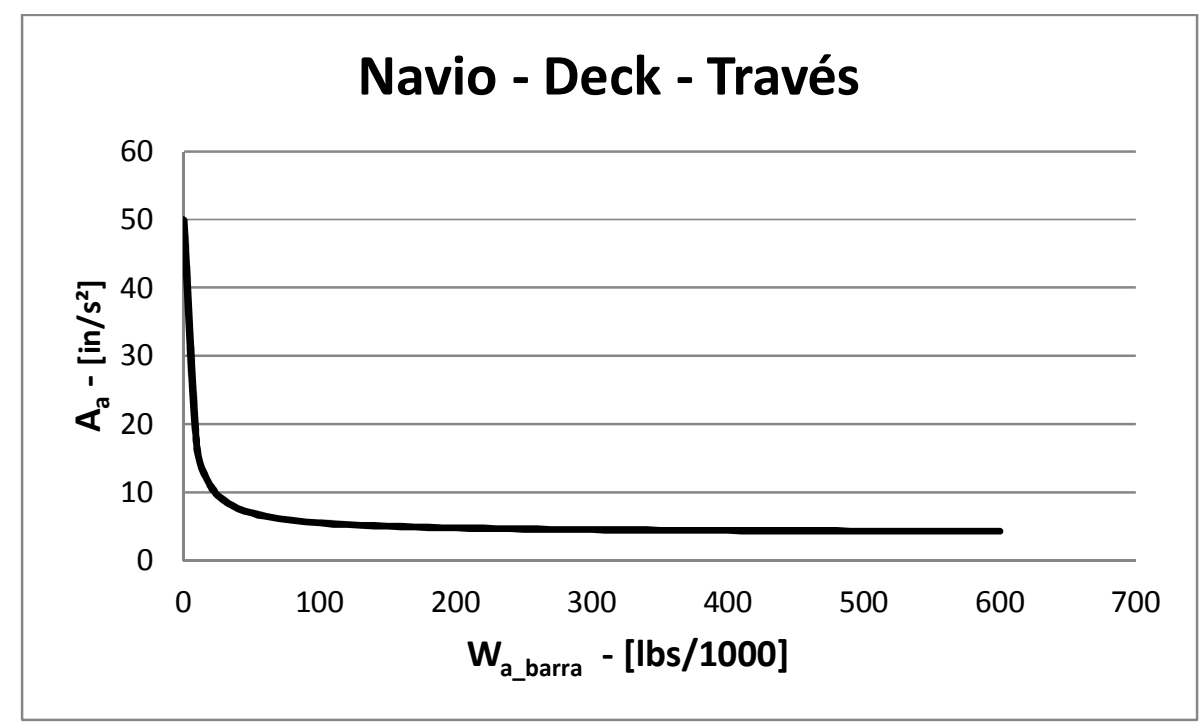

Gráfico 14 - Espectro de choque de projeto em termos de aceleração - Navio - Convés Través

Esses gráficos foram utilizado para se calcular os deslocamentos, forças e momentos nos exemplos que foram feitos para verificar a aplicação do DDAM e a avaliar os resultados que o método fornece.

\subsection{Exemplo - Sistema com 1 grau de liberdade}

O exemplo de aplicação mostrado a seguir tem o objetivo de exemplificar a aplicação do DDAM. Será feita uma estimativa de esforços de uma barra engastada de 1 grau de liberdade.

Considera-se uma barra engastada de perfil I. A Tabela 7 mostra as características da barra em unidade do sistema americano de medidas, pois o método é descrito dessa forma. Supõe-se também que essa barra esteja fixada no casco de um submarino.

Tabela 7 - Características da barra - O’Hara \& Belsheim, 196145 p.

\begin{tabular}{|l|l|r|l|}
\hline Peso específico & W & 1 & $\mathrm{Ib} / \mathrm{in}$ \\
\hline Área & $\mathrm{A}$ & 2.93 & $\mathrm{in}^{2}$ \\
\hline Comprimento & $\mathrm{L}$ & 72 & $\mathrm{in}$ \\
\hline Momento de Inércia & $\mathrm{I}$ & 8.31 & $\mathrm{in}^{\wedge} 4$ \\
\hline Módulo de elasticidade & $\mathrm{E}$ & 29000000 & $\mathrm{Ib} \mathrm{in}^{2}$ \\
\hline
\end{tabular}


Para uma análise dinâmica é razoável pensar que, para o caso de uma viga engastada, nem toda massa irá contribuir para as reações inerciais na base. Sendo assim, foi considerado $2 / 3$ da massa total sendo que:

$$
W=2 / 3 * 72 * 1=48 \mathrm{lbs}
$$

$W$ é o peso modal e está concentrada no centro dos $2 / 3$ externos da barra, ou seja, a 48 in da base. É necessário ainda que se conheça a rigidez $K$ equivalente da barra para se calcular sua freqüência natural $\omega$.

$$
K=3 E I / L^{3}
$$

Substituindo os valores, tem-se que:

$$
K=6537 \mathrm{lbs} / \mathrm{in}
$$

Assim,

$$
\omega=\sqrt{K g / W}=229,3 \mathrm{rad} / \mathrm{s}
$$

onde $g=386 \mathrm{in} / \mathrm{s}^{2}$ é a aceleração da gravidade.

Conhecendo o peso modal $W$, depreende-se dos espectros de choque (capítulo 5.1) os valores de velocidade e aceleração a que esse sistema está submetido. Para $W=48 \mathrm{lbs}$, e um equipamento fixo ao casco, em uma análise elástica:

$$
\begin{gathered}
V_{0}=249 \mathrm{in} / \mathrm{s} \\
A_{0}=96 \mathrm{~g}
\end{gathered}
$$

Deve se ajustar os valores de $V_{0}$ e $A_{0}$, segundo a Tabela 1. Assim, esses valores se mantêm iguais para esse caso.

Adota-se, então, o menor valor entre $V_{0} \omega / \mathrm{g}$ e $A_{0}$, que é $A_{0}=96 \mathrm{~g}$. 
Logo, a força efetiva que atua no sistema é:

$$
F=W A_{0}=4606 \frac{\mathrm{lbm}}{\mathrm{in}^{2}} \cong 12 \mathrm{lbf}
$$

Ou seja, o esforço devido a um choque nessa barra é de aproximadamente $12 \mathrm{lbf}$.

Todavia não existem publicados parâmetros de como esses espectros de choque de projeto foram obtidos, ou seja, não é conhecido o sinal de choque do qual esses dados foram gerados.

\subsection{Exemplo - Viga engastada}

Nesse exemplo, foi adotado como diretriz o estudo feito por Abbey \& Weinberg. Nele, os autores aplicam o DDAM em um modelo simples de viga dividido em 10 elementos, através do software MSC.NASTRAN. A Figura 8 mostra as características da estrutura.

Sendo assim, um modelo dessa viga foi feito no ANSYS para, em seguida, ser submetido ao DDAM. Além disso, por se tratar de uma estrutura simples, foram criados mais 2 modelos analíticos, um de massas concentradas e o outro de viga contínua, a fim de se comparar também com os resultados divulgados no trabalho de Abbey \& Weinberg. 


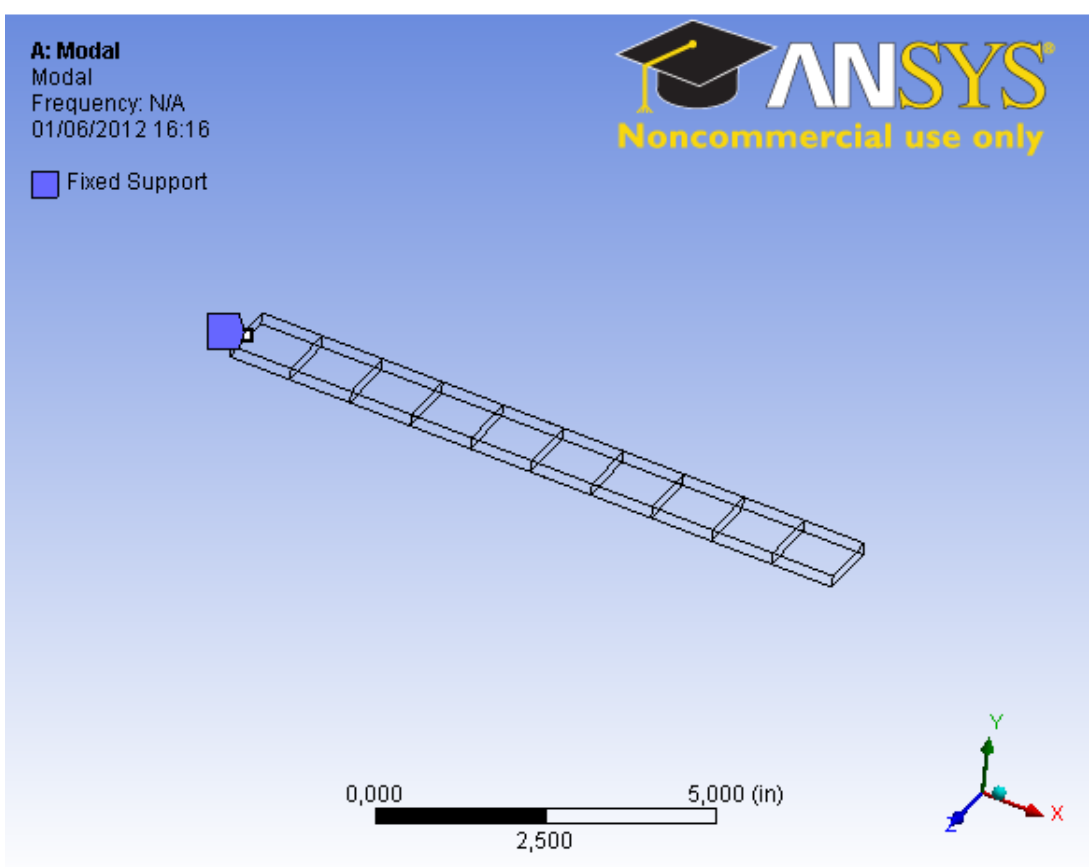

Figura 14 - Modelo de viga com 10 elementos no ANSYS 14.0

Para se aplicar a sub-rotina do DDAM, presente no ANSYS, é necessário que se realize uma análise modal previa. Em seguida, insere-se a sub-rotina do DDAM por linha de comando quando o Workbench é utilizado como interface. Os resultados comparados foram, além do momento fletor e a força cortante que atuam na base da viga, os deslocamentos ao longo da viga.

Para os valores do espectro de choque de projeto, foram adotadas as mesmas condições daquelas utilizadas no trabalho de Abbey \& Weinberg, que define a viga como uma estrutura fixada em um convés de um navio submetido a um carregamento de través (tangencial). No modelo, essa direção corresponde à direção do eixo Y, como mostra a Figura 14.

Ainda, a análise no ANSYS foi realizada de duas maneiras diferentes. Uma que levou em conta os 20 primeiros modos de vibração, como aquela realizada por Abbey \& Weinberg. E outra que levou em que todos os modos de rotação e, os de translação nos eixos $X$ e $Z$, ou seja, somente a flexão na vertical (em $Y$ ) foi permitida. Além disso, foram considerados apenas os 3 primeiros modos de flexão vertical da viga, que a própria publicação mostra que são os únicos modos 
relevantes para a flexão propriamente dita. A Figura 14 mostra os eixos de coordenadas que foram adotados.

Além disso, foi realizada uma análise de convergência através do modelo de massas concentradas, variando-se o número de massas que discretizam a viga (100, 50 e 25 massas concentradas), para se comparar com o valor do modelo de viga contínua.

Desse modo, os deslocamentos ao longo da viga, bem como a força cortante e o momento fletor no engaste, foram calculados seguindo as equações do capítulo 4.2 .

\subsubsection{Resultados - Modelo Analítico}

As tabelas seguintes mostram os resultados para os modelos analíticos.

Tabela 8 - Resultados Modelos Viga Engastada - Deslocamento Máximo

\begin{tabular}{|c|c|c|c|c|c|}
\hline Resultado & & \multicolumn{4}{|c|}{ Deslocamento Máximo [in] } \\
\hline Modo & Frequências & Contínuo & $\mathrm{N}=100$ & $\mathrm{~N}=50$ & $\mathrm{~N}=\mathbf{2 5}$ \\
\hline 1ㅇ Modo & 63,5 & 0,091 & 0,090 & 0,090 & 0,088 \\
\hline 20 Modo & 398 & 0,001 & $-0,001$ & $-0,001$ & $-0,001$ \\
\hline 3ㅇ Modo & 1114 & 0,000 & 0,000 & 0,000 & 0,000 \\
\hline NRL Sum & & 0,092 & 0,091 & 0,091 & 0,089 \\
\hline
\end{tabular}

Tabela 9 - Resultados Modelos Viga Engastada - Força Cortante na base

\begin{tabular}{|c|c|c|c|c|c|}
\hline Resultado & & \multicolumn{4}{|c|}{ Força Cortante [lbf] } \\
\hline Modo & Frequências & Contínuo & $\mathbf{N = 1 0 0}$ & $\mathbf{N = 5 0}$ & $\mathbf{N = 2 5}$ \\
\hline 10 Modo & 63,5 & 2,93 & 2,95 & 2,96 & 3,00 \\
\hline 2ㅇMㅇodo & 398 & 0,90 & 0,85 & 0,79 & 0,68 \\
\hline 3ㅇModo & 1114 & 0,31 & 0,33 & 0,35 & 0,39 \\
\hline & & & & & \\
\hline NRL Sum & & $\mathbf{3 , 8 9}$ & $\mathbf{3 , 8 5}$ & $\mathbf{3 , 8 3}$ & $\mathbf{3 , 7 8}$ \\
\hline
\end{tabular}


Tabela 10 - Resultados Modelos Viga Engastada - Momento Fletor na base

\begin{tabular}{|c|c|c|c|c|c|}
\hline Resultado & & \multicolumn{4}{|c|}{ Momento Fletor [lbf*in] } \\
\hline Modo & Frequências & Contínuo & $\mathbf{N}=\mathbf{1 0 0}$ & $\mathbf{N}=\mathbf{5 0}$ & $\mathbf{N = 2 5}$ \\
\hline 1ㅇ Modo & 63,5 & 21,29 & 21,51 & 21,74 & 22,18 \\
\hline 2o Modo & 398 & 1,89 & 1,61 & 1,34 & 0,85 \\
\hline 3ㅇModo & 1114 & 0,40 & 0,53 & 0,67 & 0,98 \\
\hline & & & & & \\
\hline NRL Sum & & $\mathbf{2 3 , 2 3}$ & $\mathbf{2 3 , 2 1}$ & $\mathbf{2 3 , 2 4}$ & $\mathbf{2 3 , 4 8}$ \\
\hline
\end{tabular}

Observa-se que os resultados dos modelos de massas concentradas convergem para o de viga contínua na medida em que a discretização da viga aumenta, o que mostra consistência nos cálculos realizados.

\subsubsection{Resultados - Modelo ANSYS}

Já no ANSYS, os resultados foram muito próximos entre os dois modelos feitos. As frequências naturais e os deslocamentos alcançaram os mesmos valores tanto para o modelo com 20 modos computados quanto para aquele com 3 modos.

Seguem então os resultados dos modelos em ANSYS para uma viga engastada submetida ao DDAM na condição de equipamento fixado em um convés de um navio sob um carregamento de través. 


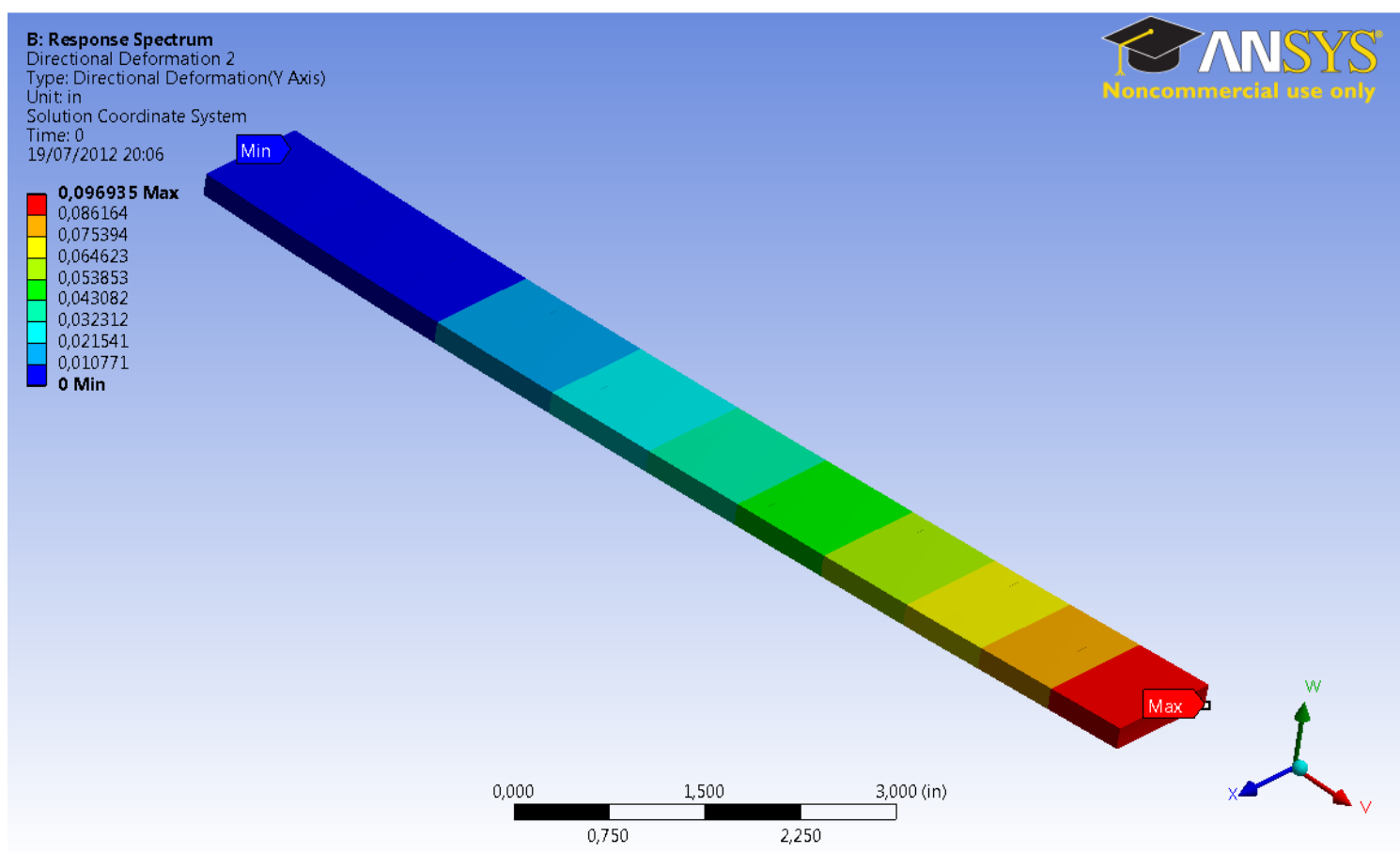

Figura 15 - DDAM ANSYS - Deslocamento total da viga 3 modos

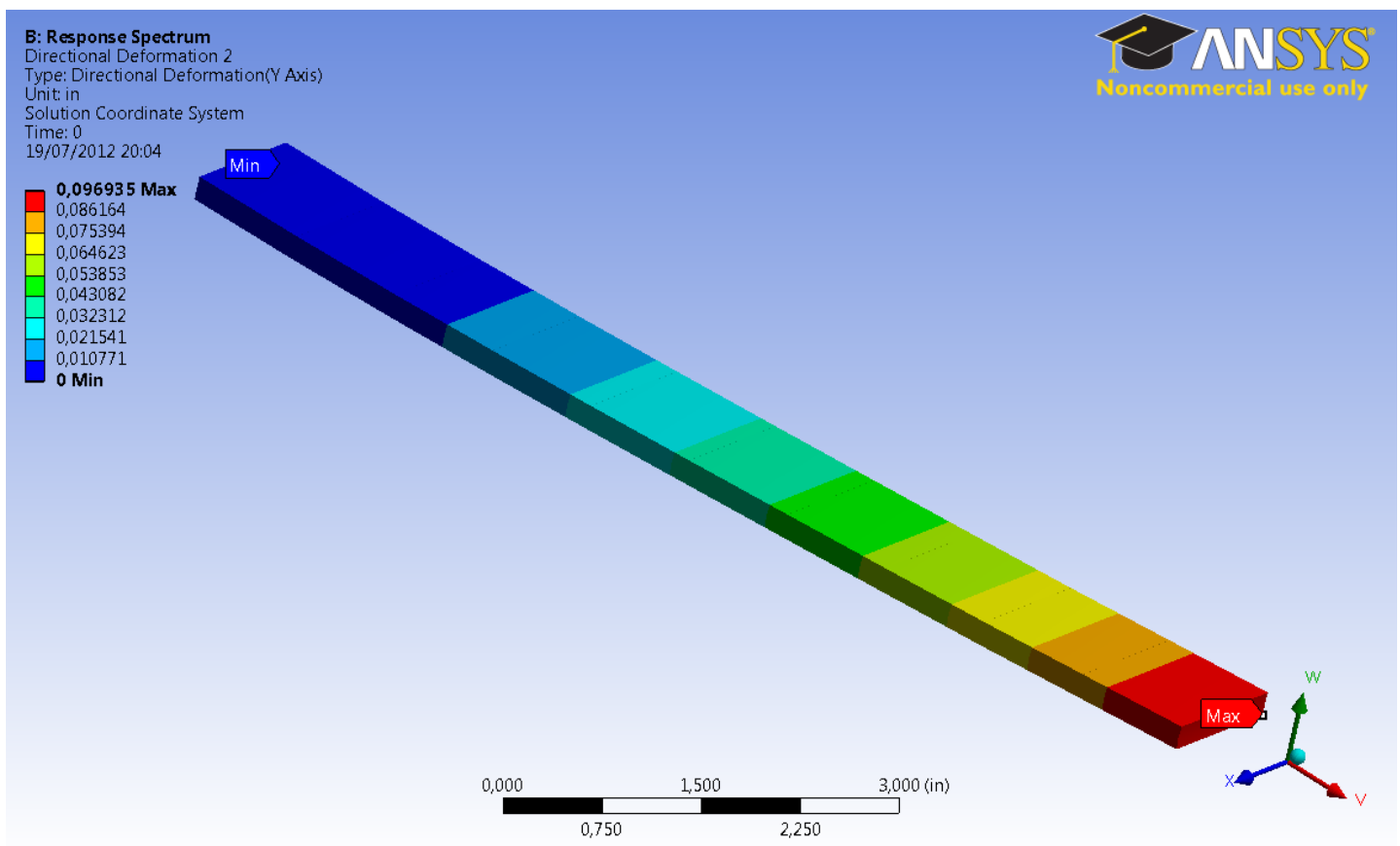

Figura 16 - DDAM ANSYS - Deslocamento total da viga 20 modos 
A Figura 15 e a Figura 16 mostram a equivalência na composição dos deslocamentos entre os dois modelos da viga. Já as reações no engaste são apresentadas a seguir.

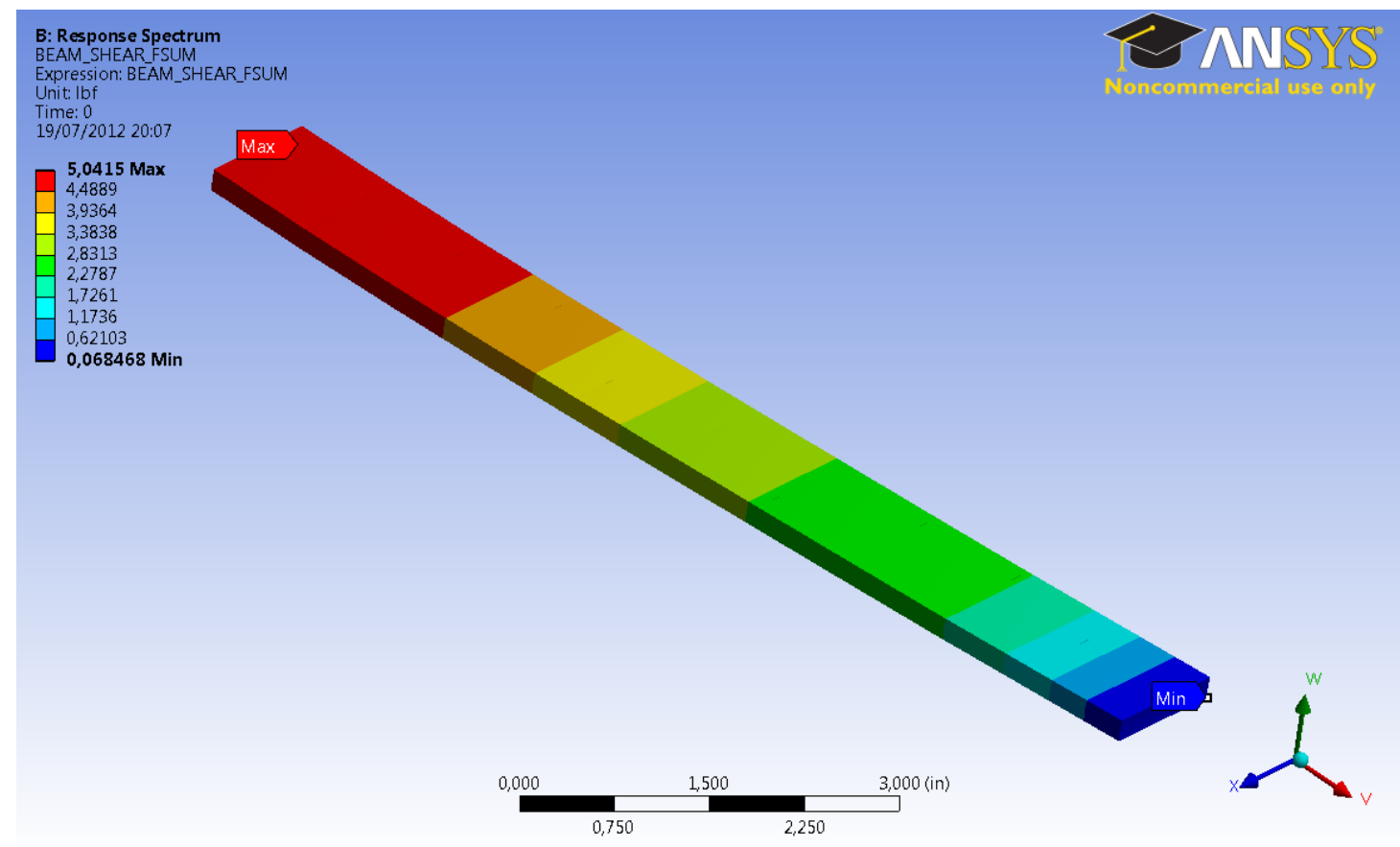

Figura 17 - DDAM ANSYS - Força cortante viga 3 modos

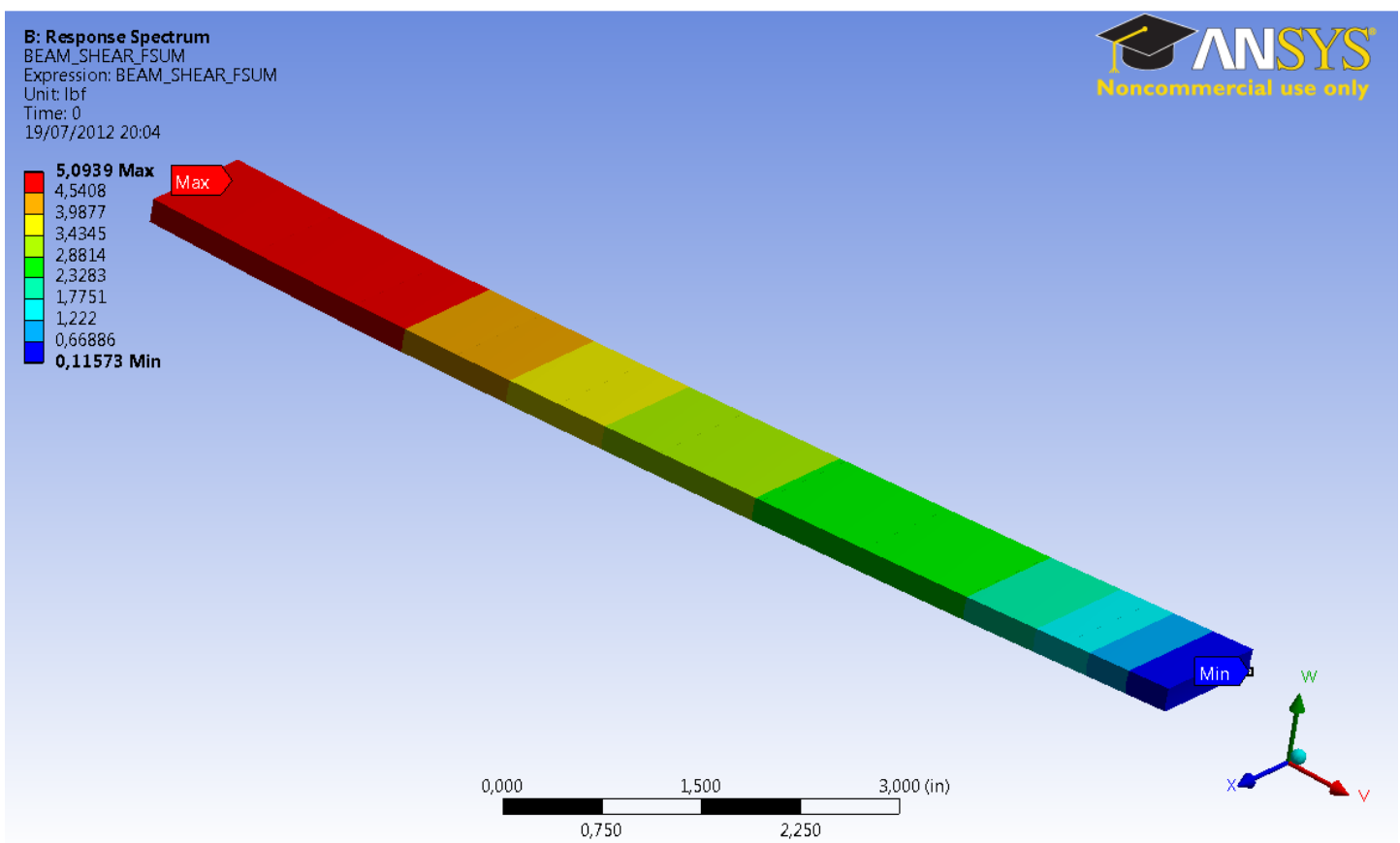

Figura 18 - DDAM ANSYS - Força cortante viga 20 modos 


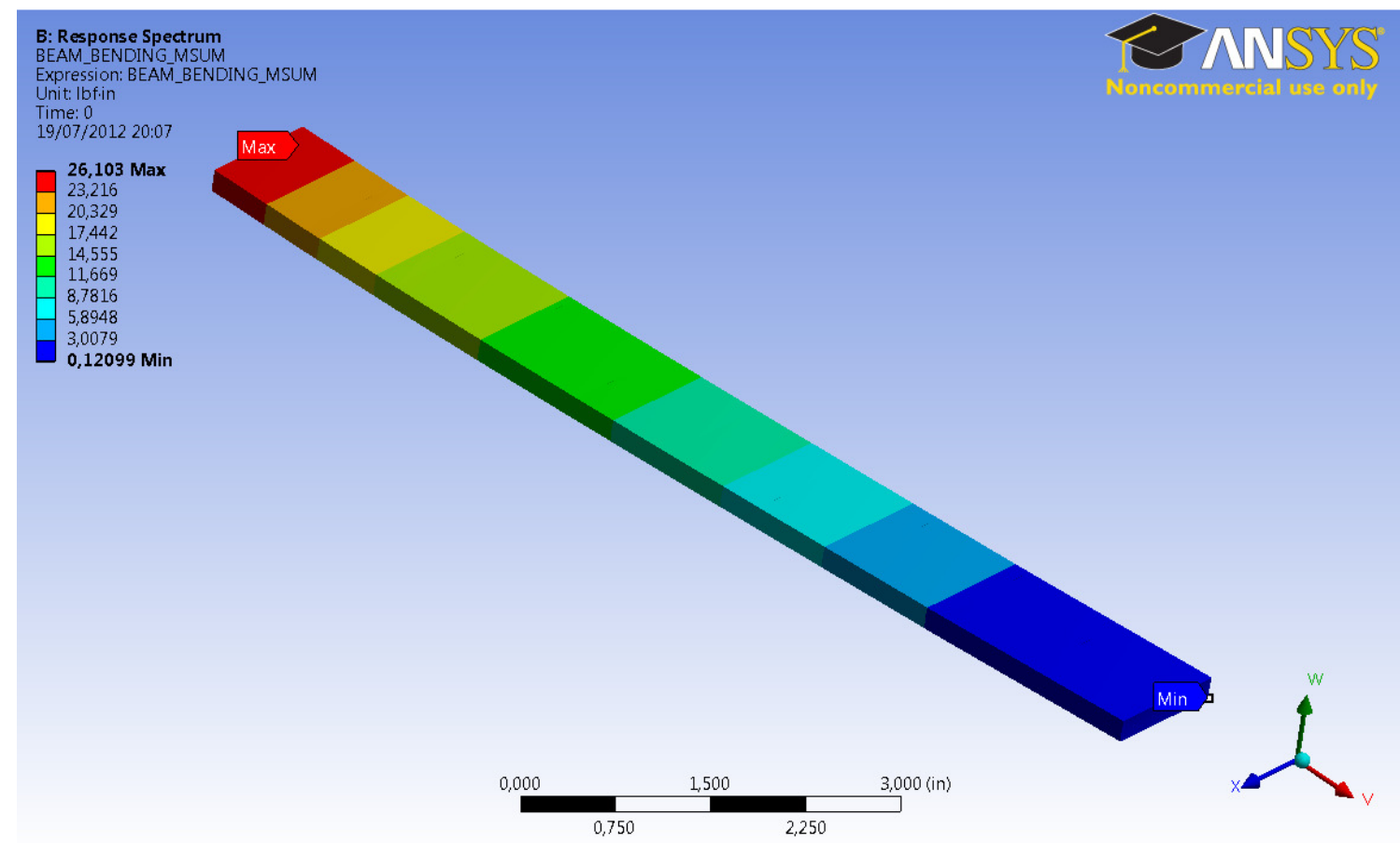

Figura 19 - DDAM ANSYS - Momento Fletor viga 3 modos

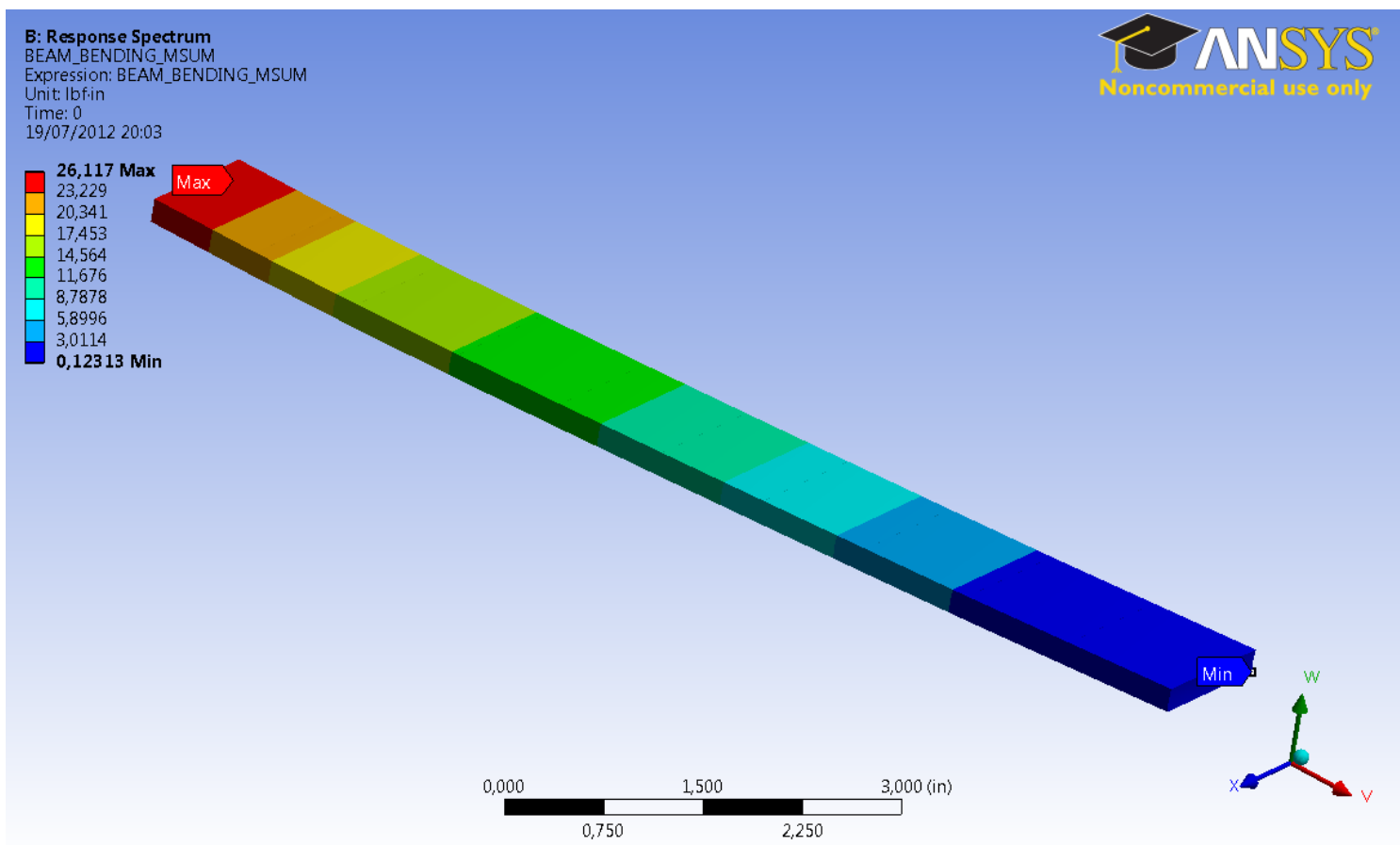

Figura 20 - DDAM - Momento Fletor viga 20 modos 
A força cortante e o momento fletor calculados tiveram valores muito próximos se comparados entre o modelo de 20 e o de 3 modos. Vale observar que essas grandezas tiveram valores ligeiramente maiores no modelo de 20 modos.

Segue então a Tabela 11, que resume os resultados calculados pelo ANSYS:

Tabela 11 - Resultados Modelos Vaso do Reator ANSYS

\begin{tabular}{|l|c|c|c|}
\hline & $\begin{array}{c}\text { NASTRAN - } \\
\mathbf{2 0} \text { modos }\end{array}$ & $\begin{array}{c}\text { ANSYS - 20 } \\
\text { modos }\end{array}$ & $\begin{array}{c}\text { ANSYS - } \\
\mathbf{3} \text { modos }\end{array}$ \\
\hline Deslocamento máx. [in] & - & 0,097 & 0,097 \\
\hline Força Cortante [lbf] & 5 & 5,1 & 5,0 \\
\hline Momento Fletor [lbf*in] & 23,4 & 26,1 & 26,1 \\
\hline
\end{tabular}

É importante ressaltar que os resultados de ambos os modelos se mostraram consistentes entre si e com aqueles apresentados por Abbey \& Weinberg, exceto pelos deslocamentos que não são apresentados naquele trabalho. Além disso, notase que o modelo no ANSYS que levou em conta apenas 3 modos de vibração e restrição nos graus de liberdade que não os de flexão, apresentou resultados muito próximos daquele com 20 modos, o que indica que a superposição modal levando em conta apenas esses 3 modos representam de maneira precisa a dinâmica da estrutura e a aplicação do DDAM. Mesmo o trabalho de Abbey \& Weinberg cita que esses 3 primeiros modos de flexão são os mais relevantes para a resposta final da estrutura.

Logo, pode-se fazer uma comparação entre o modelo analítico de viga engastada e o modelo reproduzido no ANSYS. Os resultados apresentados por Abbey \& Weinberg, que usaram o NASTRAN como ferramenta, foram utilizados para delinear essa comparação. Como o modelo analítico considerou os 3 primeiros modos de flexão, o modelo do ANSYS a ser comparado será o análogo, por questão de coerência. 
Tabela 12 - Comparação Frequências Naturais - Viga Engastada

\begin{tabular}{|c|c|c|c|}
\hline Frequências [Hz] & Contínuo & $\begin{array}{c}\text { ANSYS - } \\
\text { 3 modos }\end{array}$ & $\begin{array}{c}\text { NASTRAN - } \\
\text { 20 modos }\end{array}$ \\
\hline 1ㅇ Modo & 63,5 & 64,5 & 63,2 \\
\hline 2o Modo & 398 & 397 & 391 \\
\hline 3ㅇ Modo & 1114 & 1109 & 1081 \\
\hline
\end{tabular}

Tabela 13 - Comparação Resultados - Viga Engastada

\begin{tabular}{|l|c|c|c|}
\hline & Contínuo & $\begin{array}{c}\text { ANSYS - } \\
\text { 3 modos }\end{array}$ & $\begin{array}{c}\text { NASTRAN - } \\
\text { 20 modos }\end{array}$ \\
\hline Deslocamento máx. [in] & 0,092 & 0,097 & - \\
\hline Força Cortante [lbf] & 4 & 5 & 5 \\
\hline Momento Fletor [lbf*in] & 23,2 & 26,1 & 23,4 \\
\hline
\end{tabular}

Observa-se que os resultados da simulação no ANSYS estão muito próximos daqueles extraídos dos modelos analíticos quanto às frequências naturais e os deslocamentos, como mostram a Tabela 12 e a Tabela 13. As diferenças ocorreram para a força cortante e o momento fletor na base. Uma possível causa é o fato de que essas grandezas calculadas são derivadas do deslocamento, e ao se derivar funções, geram-se aproximações, que podem levar a erros, mesmo que mínimos. 


\subsection{Exemplo - Vaso do Reator}

Como já dito anteriormente, o vaso do reator foi representado de duas maneiras no ANSYS. Uma delas por elementos de barra (BEAM) com seção tubular e a outra por elementos sólidos (SOLID). Além disso, para cada um desses modelos, foi realizada a aplicação do DDAM sem a massa dos internos incluída, para se verificar sua influência na dinâmica da estrutura.

Dessa forma, foram extraídos os primeiros 15 modos naturais de cada modelo e, em seguida, o DDAM foi empregado. O espectro de choque de projeto utilizado foi para equipamentos de submarinos fixados na estrutura primária (Hull) submetidos a um carregamento de través.

O vaso do reator foi modelado de acordo com as dimensões fornecidas pelo CTMSP (Figura 13) bem como as massas dos componentes internos e do mecanismo de acionamento das barras de controle. Já a massa do vaso do reator foi calculada pelo ANSYS. Segue a Tabela 14 que mostram esses valores em kg e lb.

Tabela 14 - Massa do Vaso e Seus Componentes

\begin{tabular}{|l|c|c|c|c|}
\hline \multicolumn{1}{|c|}{ MASSAS } & BEAM [lb] & SOLID [lb] & BEAM [kg] & SOLID [kg] \\
\hline Vaso do Reator & 49582 & 49223 & 22490 & 22327 \\
\hline $\begin{array}{l}\text { Mecanismo } \\
\text { Acionamento }\end{array}$ & 6614 & 6614 & 3000 & 3000 \\
\hline $\begin{array}{l}\text { Componentes } \\
\text { Internos }\end{array}$ & 37479 & 37479 & 17000 & 17000 \\
\hline
\end{tabular}

\subsubsection{Modelo Elementos de Barra (BEAM)}

O modelo do vaso em elementos de barra (BEAM) foi gerado a partir de um corpo unifilar, como mostra a Figura 21. Já a seção transversal dos elementos dessa estrutura foram definidos como seções tubulares de diâmetro igual ao diâmetro máximo do corpo do vaso (Figura 22). Contudo, alterações foram feitas nas seções dos elementos das extremidades superior e inferior (redução gradual do diâmetro) de modo que as calotas fossem melhores representadas geometricamente. Um último detalhe é o fato de que os elementos mais extremos têm como seção, um círculo sólido e não um tubo como o restante, como mostra a Figura 23. 
Line Body

01/08/2012 16:09

口

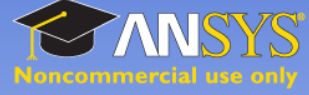

व

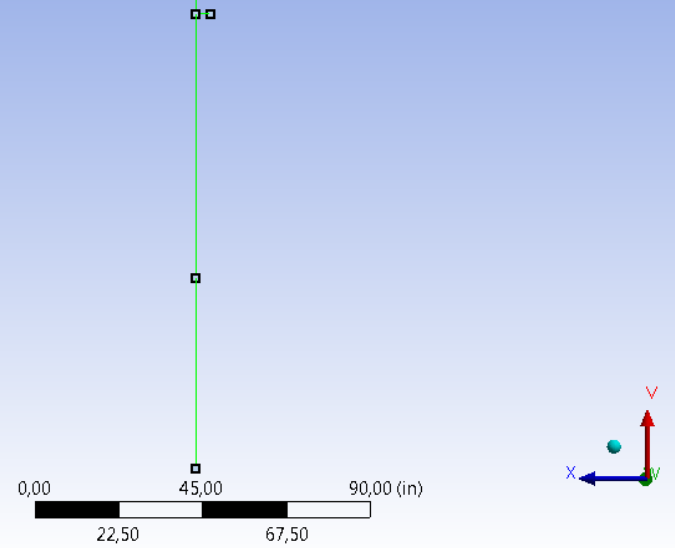

Figura 21 - Modelo BEAM Vaso do Reator ANSYS - Line Body

\section{A: Modal
Solution}

Frequency: N/A

01/08/2012 15:46

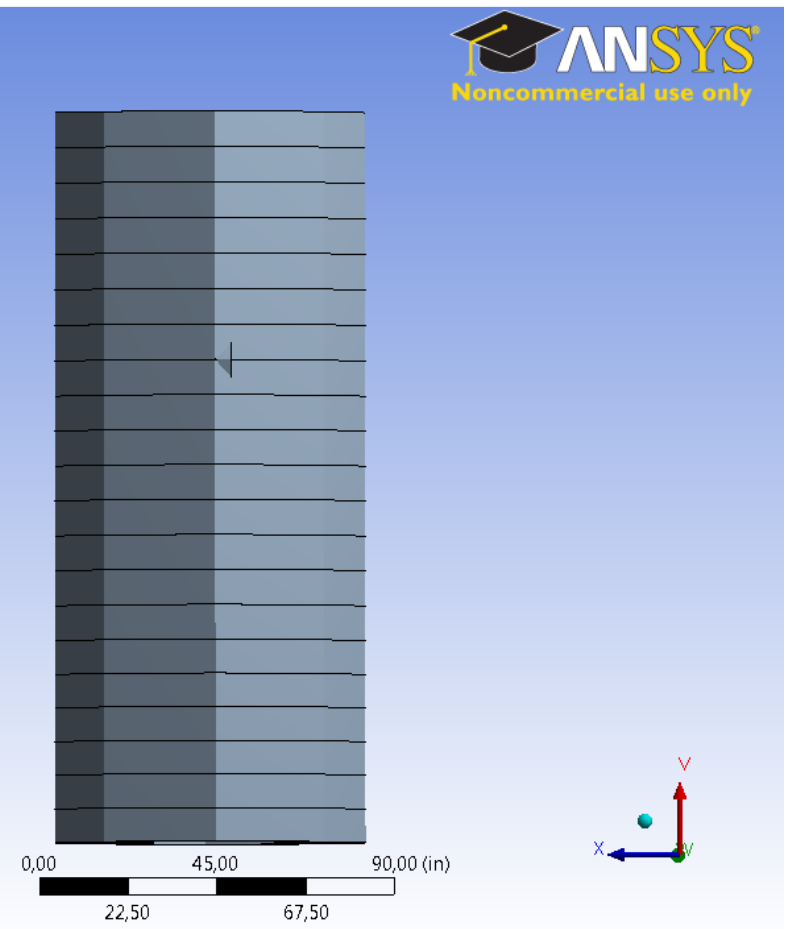

Figura 22 - Modelo BEAM Vaso do Reator ANSYS - Elementos BEAM 


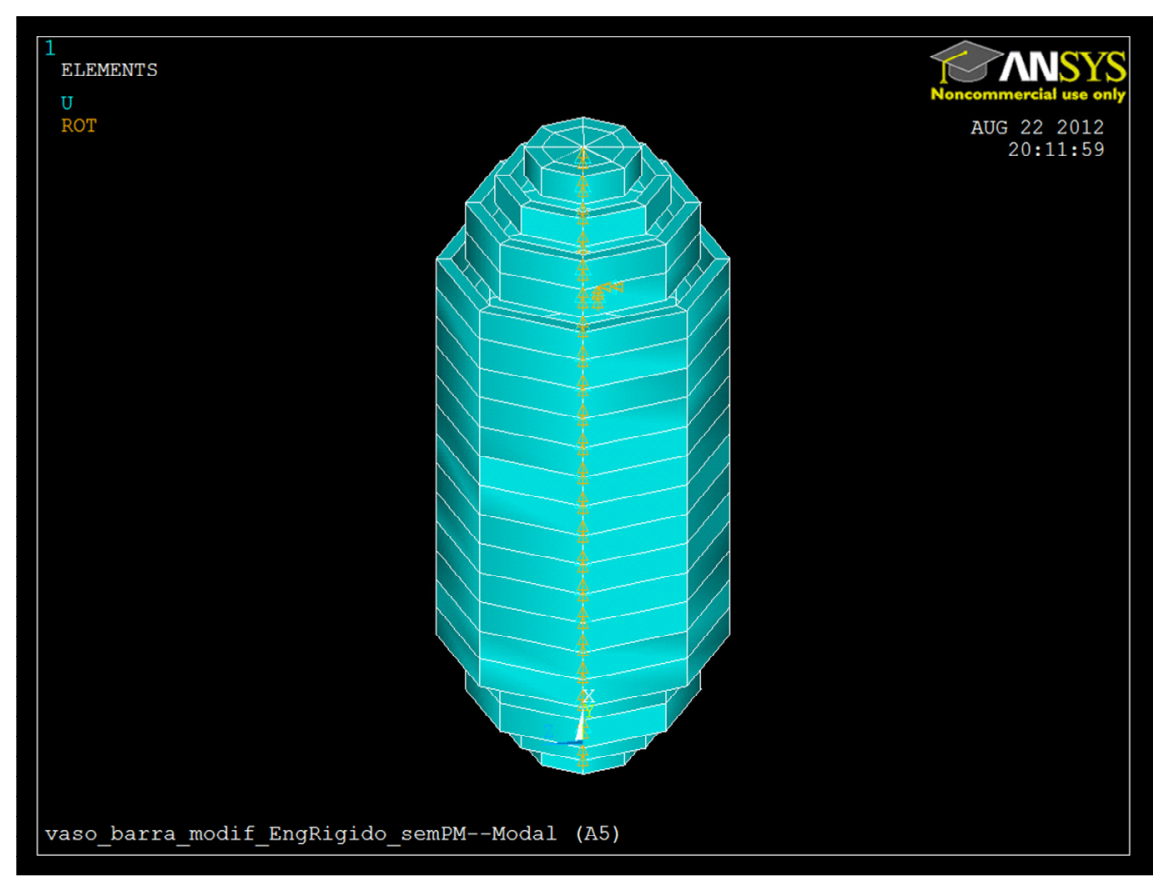

Figura 23 - Modelo BEAM Vaso do Reator ANSYS - Detalhe Calotas

Outro detalhe da modelagem importante de ser exposto é a construção do suporte do vaso. O apoio foi modelado como uma estrutura rígida fora do eixo do vaso de modo que, se houvesse um suporte fixo na região intermediária do vaso, o apoio não afetasse a dinâmica de toda a estrutura devido à geometria ser bidimensional. A Figura 24 mostra o detalhe da modelagem do suporte. Outro motivo do apoio ser construído dessa maneira é a localização das massas concentradas inseridas para representar os internos e os componentes superiores.

Como já mencionado, foi considerado que toda a massa dos internos está apoiada na região do flange superior, que é justamente o local onde o vaso é suportado. A Figura 25 e a Figura 26 mostram a localização das massas concentradas e o detalhe da fixação da massa dos internos, respectivamente.

Ainda, fez-se outra hipótese em que parte da massa dos internos estaria sendo transmitida ao vaso por meio do apoio axial na região entre a calota inferior do vaso e o corpo. Desse modo, construiu-se mais um modelo onde metade da massa dos internos é associada à região do flange superior e a outra metade, à região de união entre a calota inferior e o corpo do vaso. A Figura 27 mostra o modelo BEAM com a massa dos internos dividida em 2 pontos. 


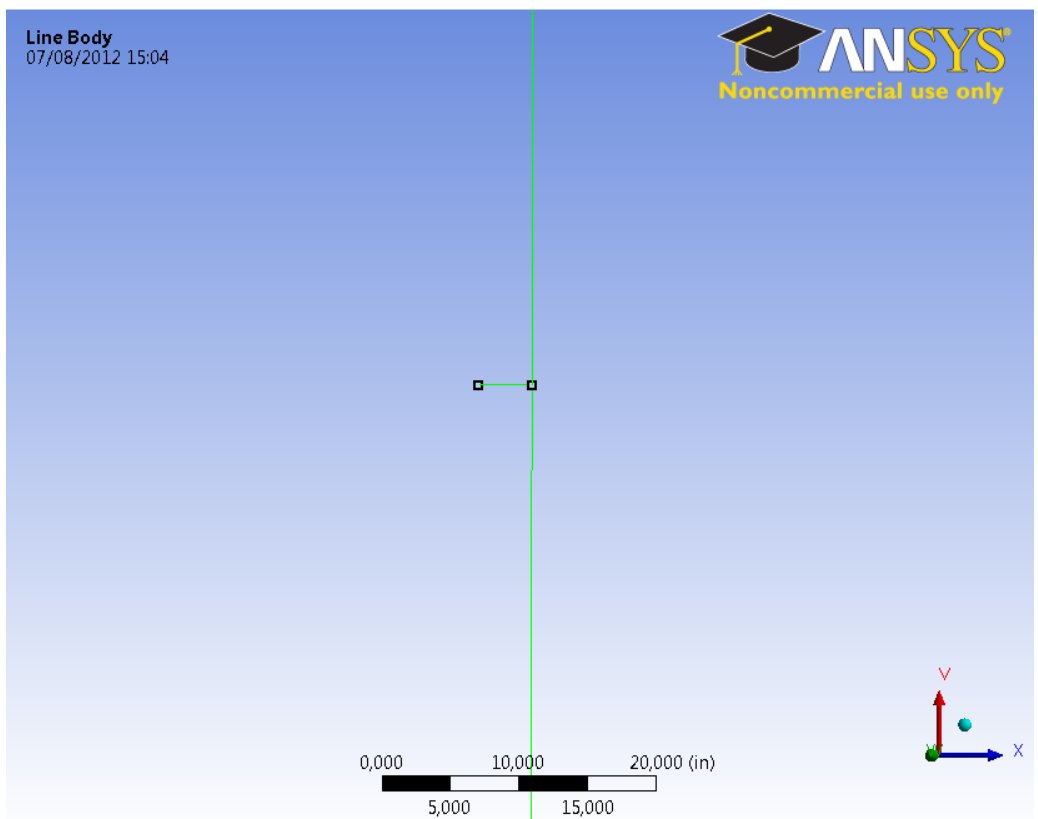

Figura 24 - Modelo BEAM Vaso do Reator ANSYS - Detalhe Geometria Suporte

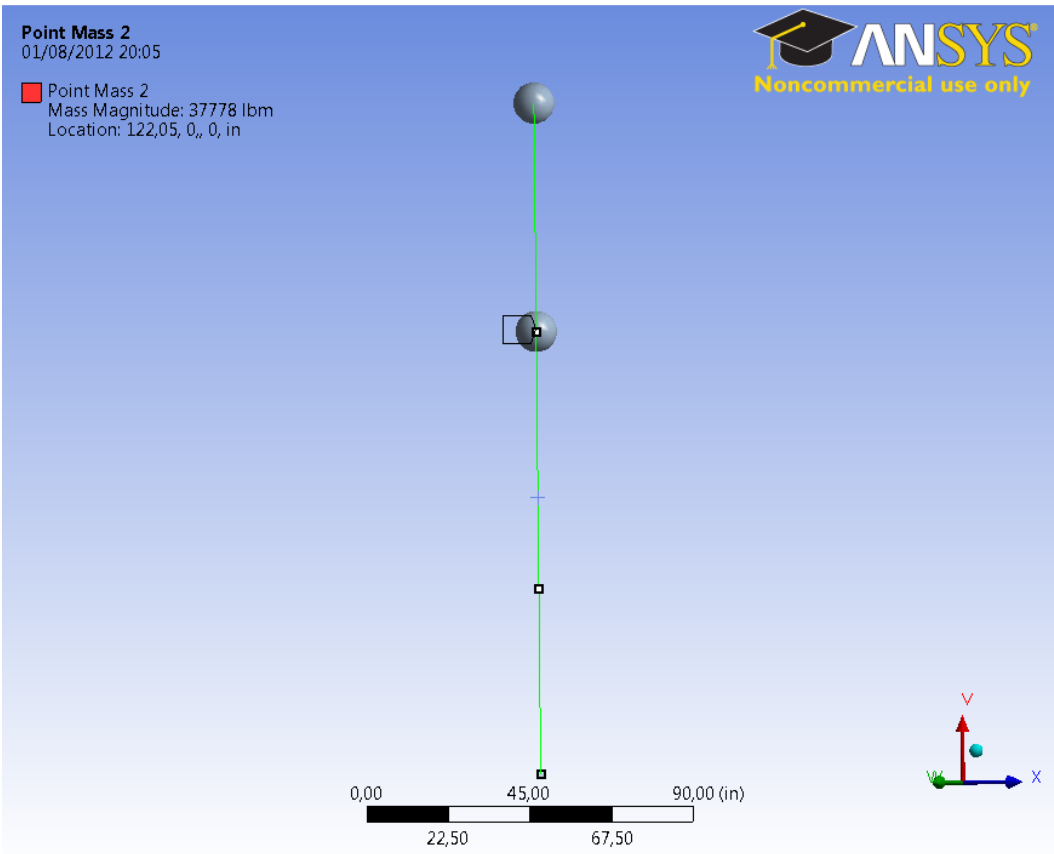

Figura 25 - Modelo BEAM Vaso do Reator ANSYS - Massa Internos - 1 ponto 


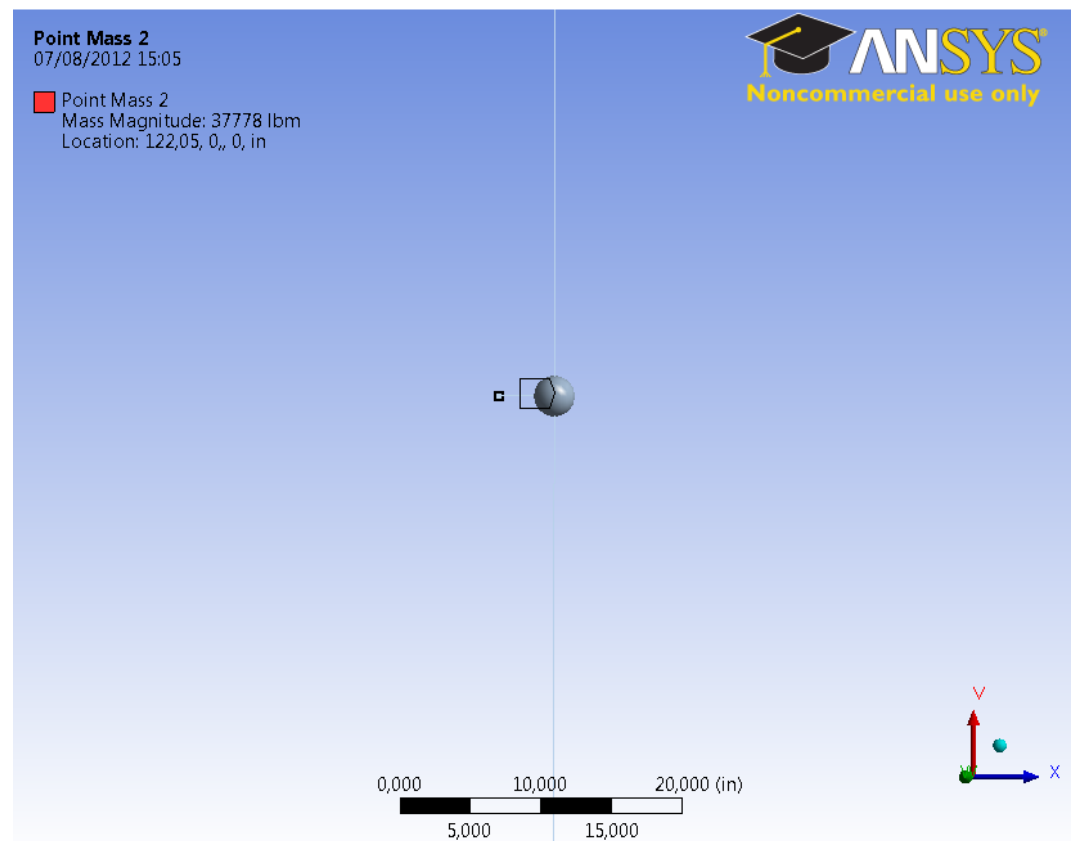

Figura 26 - Modelo BEAM Vaso do Reator ANSYS - Detalhe Internos Inferiores

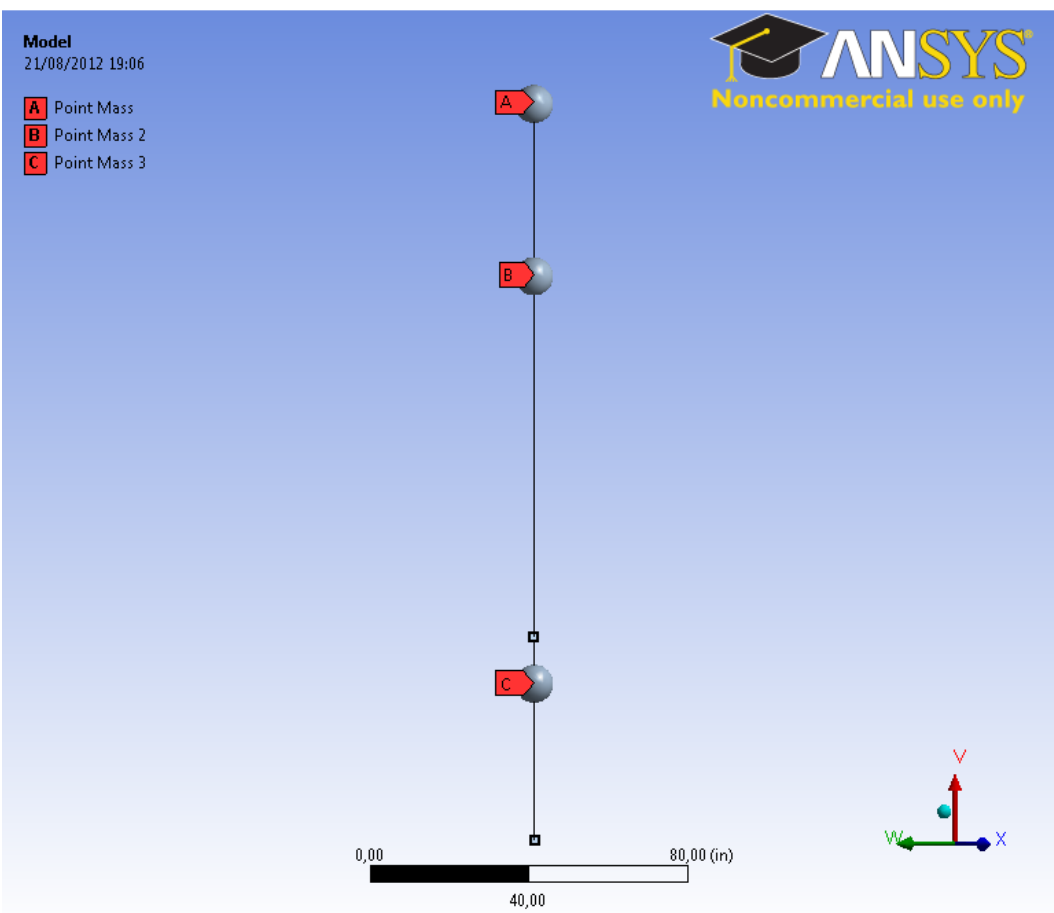

Figura 27 - Modelo BEAM Vaso do Reator ANSYS - Massa Internos - 2 pontos 


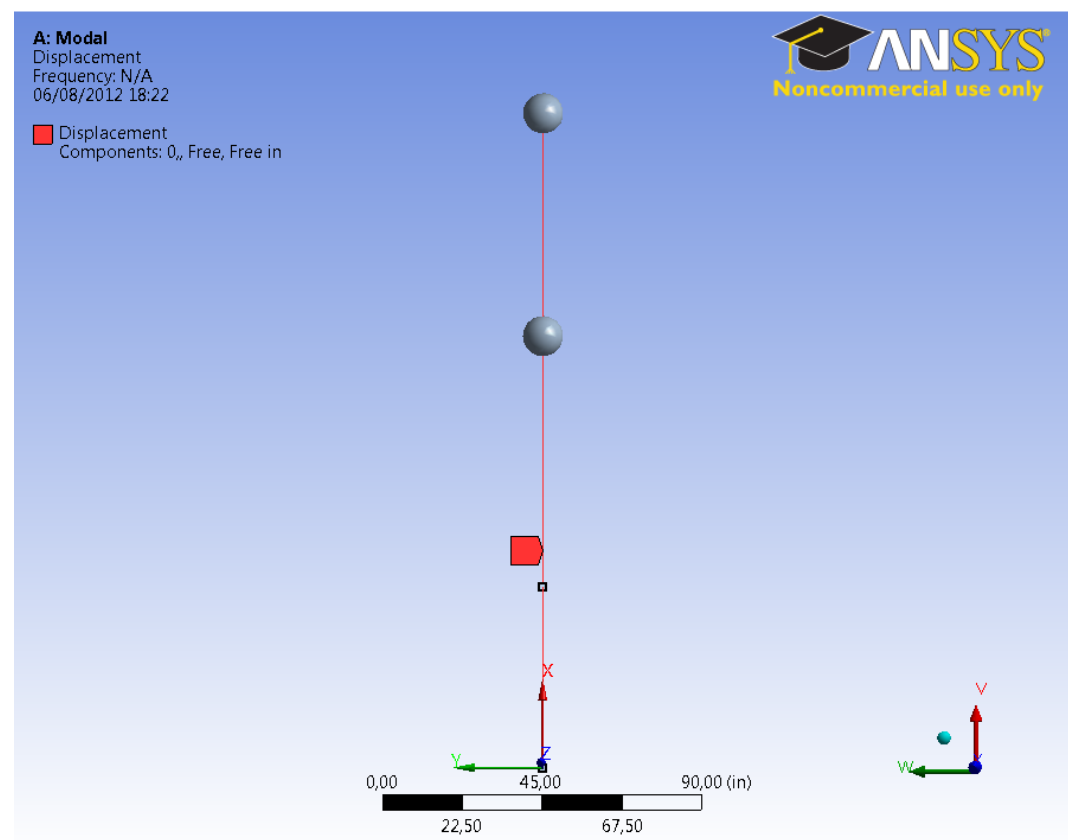

Figura 28 - Modelo BEAM Vaso do Reator ANSYS - Restrição Deslocamento Axial

Para aproximar a análise dos dois modelos, foram impostas algumas condições de contorno. No modelo BEAM, os deslocamentos axiais, como ilustra a Figura 28. Assim, a análise modal foi calculada e o DDAM foi aplicado.

\subsubsection{Modelo Vaso do Reator - Elementos Sólidos (SOLID)}

A geometria do vaso do reator foi construída segundo dados fornecidos pelo Centro Tecnológico da Marinha em São Paulo - CTMSP. Foram feitas aproximações geométricas e hipóteses do modelo em elementos finitos para a geometria real, pois mesmo essa possuía imprecisões intencionais em suas dimensões, dado que é um conteúdo sigiloso. Contudo, ambos os modelos reproduzidos no ANSYS (o de elementos BEAM e o de elementos SOLID) são consistentes entre si, ou seja, foram feitos a partir das mesmas aproximações feitas, para que suas análises tivessem a maior coerência possível. 


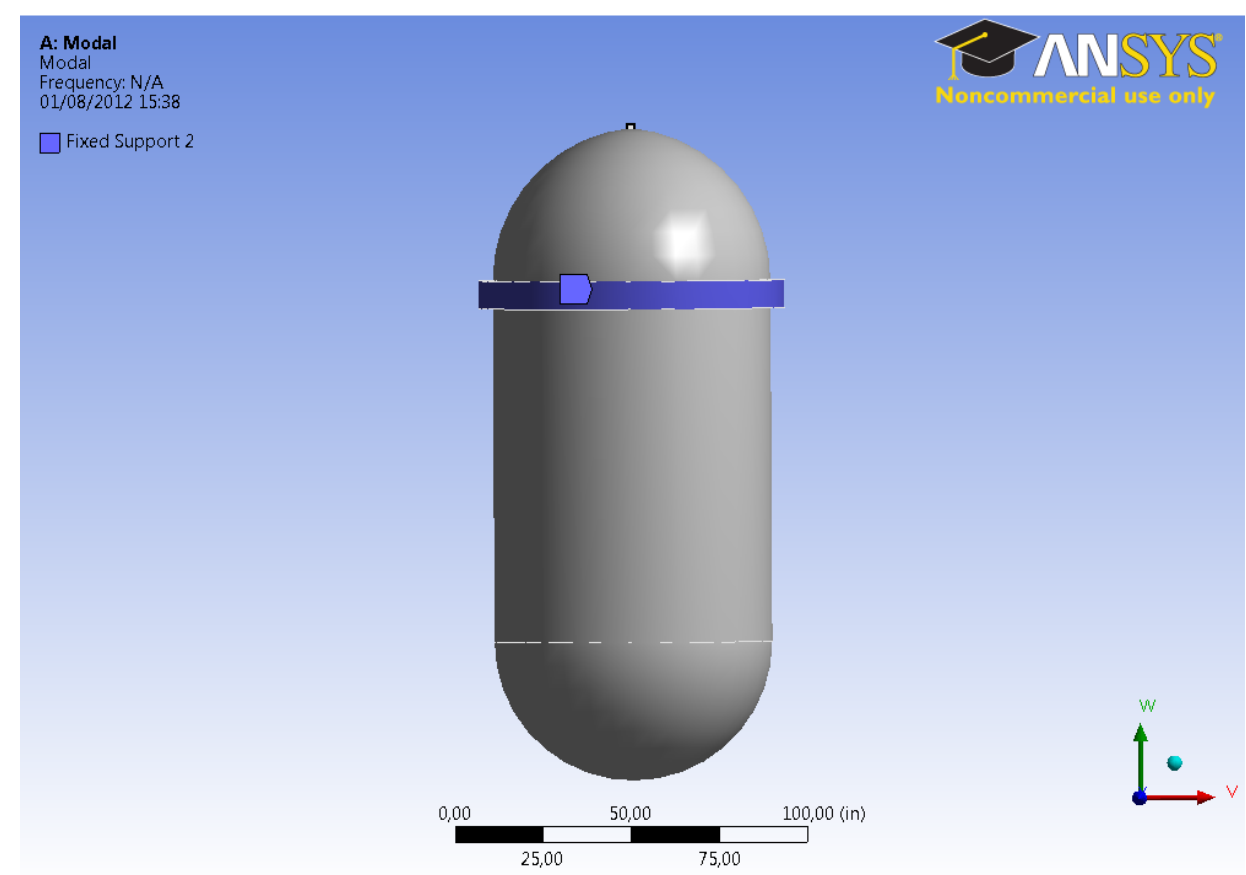

Figura 29 - Modelo SOLID Vaso do Reator no ANSYS - Suporte Anel Flange

Uma das condições de contorno adotadas foi que o suporte circular na superfície externa do anel do flange seria rígido, como mostra a Figura 29. Até onde se encontra publicado, o vaso do reator é suportado por uma estrutura circular muito rígida, que para o modelo, se traduziu em um apoio fixo.

Analogamente ao modelo BEAM, a massa dos internos foi associada à geometria do vaso. A porção que representa a massa dos mecanismos de acionamento de controle foi atribuída a toda superfície interna da calota superior. Já os componentes que estão apoiados internamente ao flange superior foram representados de duas formas também: uma delas é inteiramente agregada a um anel do lado interno do corpo do vaso que está na altura desse flange (Figura 30), e, em outra representação, a massa foi dividida em duas partes iguais e associadas a anéis internos do corpo do vaso na ligação com as calotas superior e inferior, como mostra a Figura 31. 


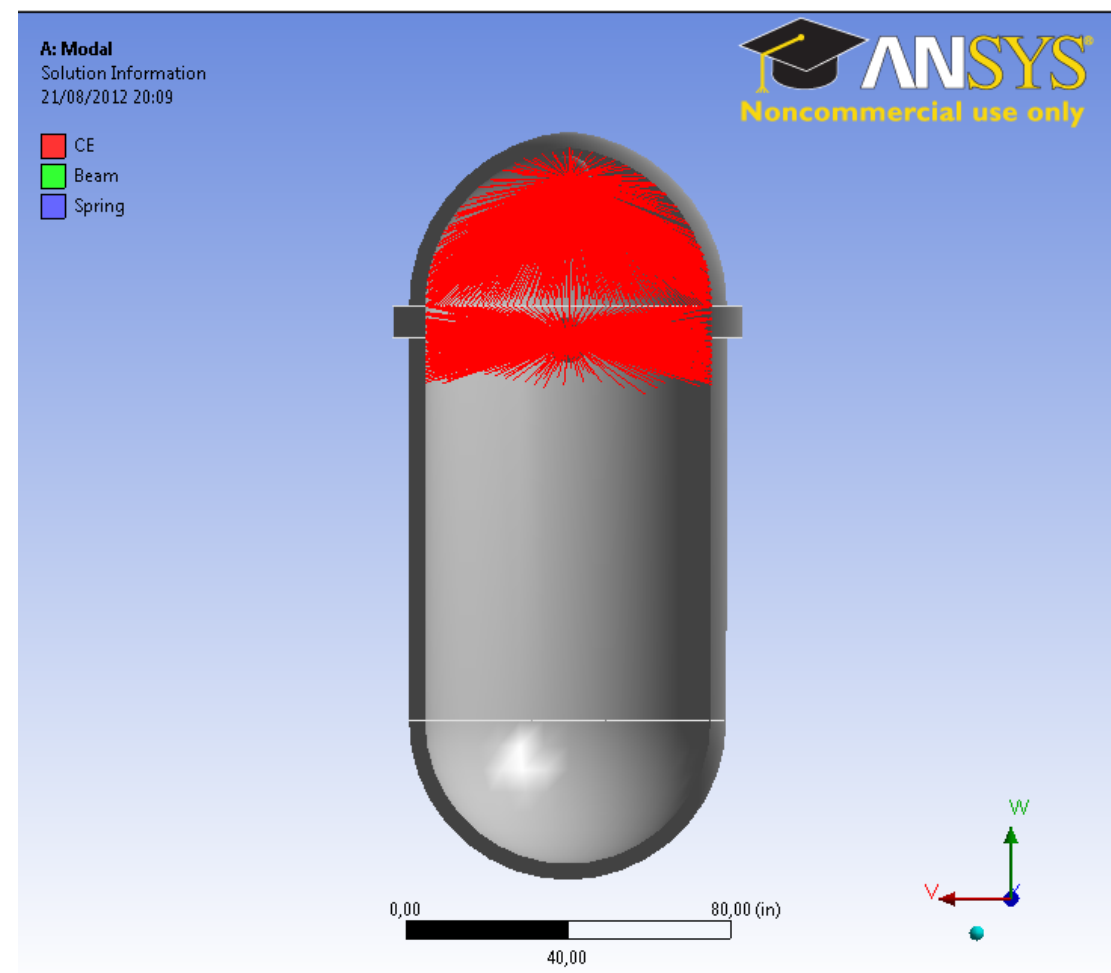

Figura 30 - Modelo SOLID Vaso do Reator no ANSYS - Detalhe Massa Internos em 1 região

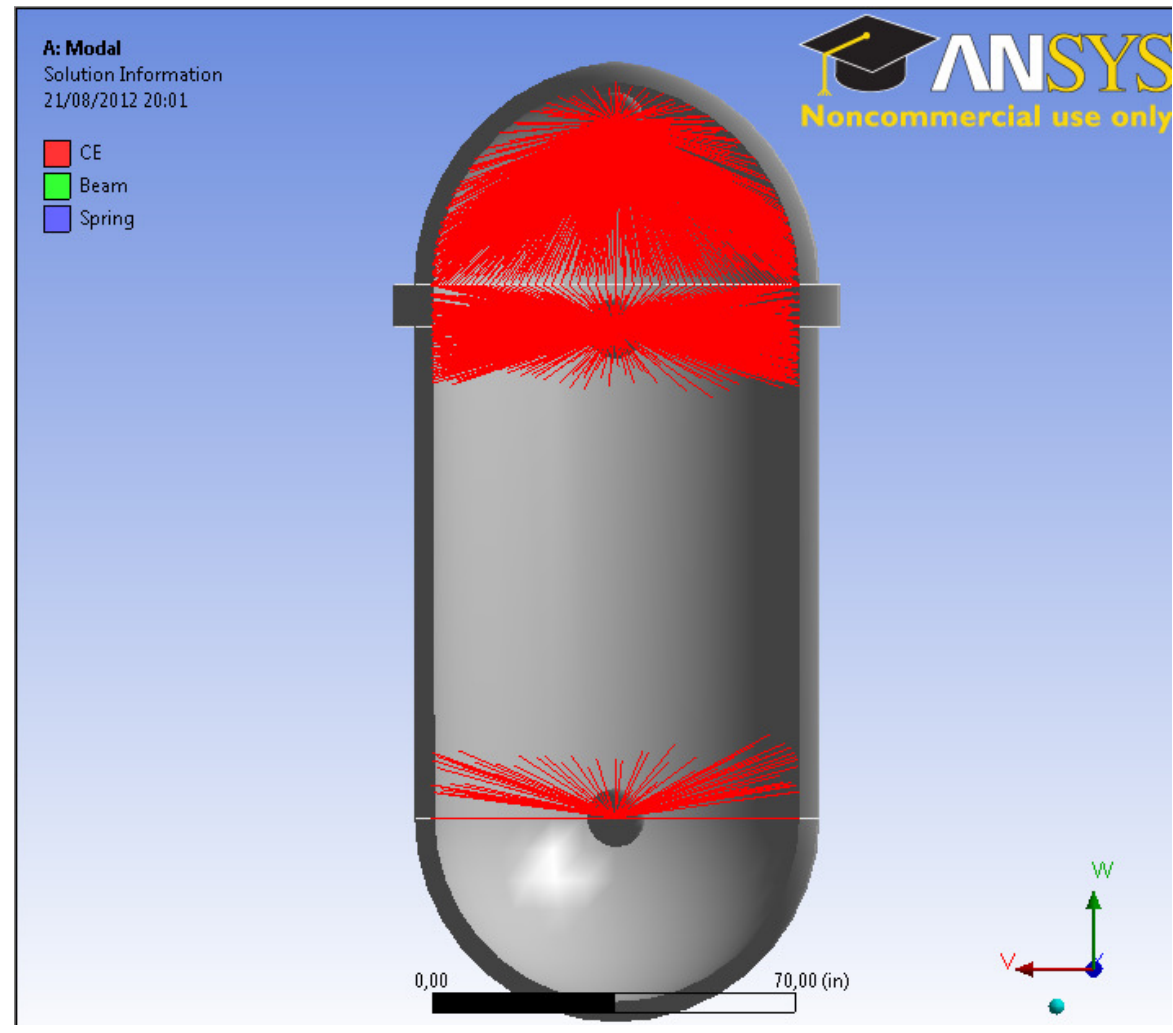

Figura 31 - Modelo SOLID Vaso do Reator no ANSYS - Detalhe Massa Internos em 2 regiões 


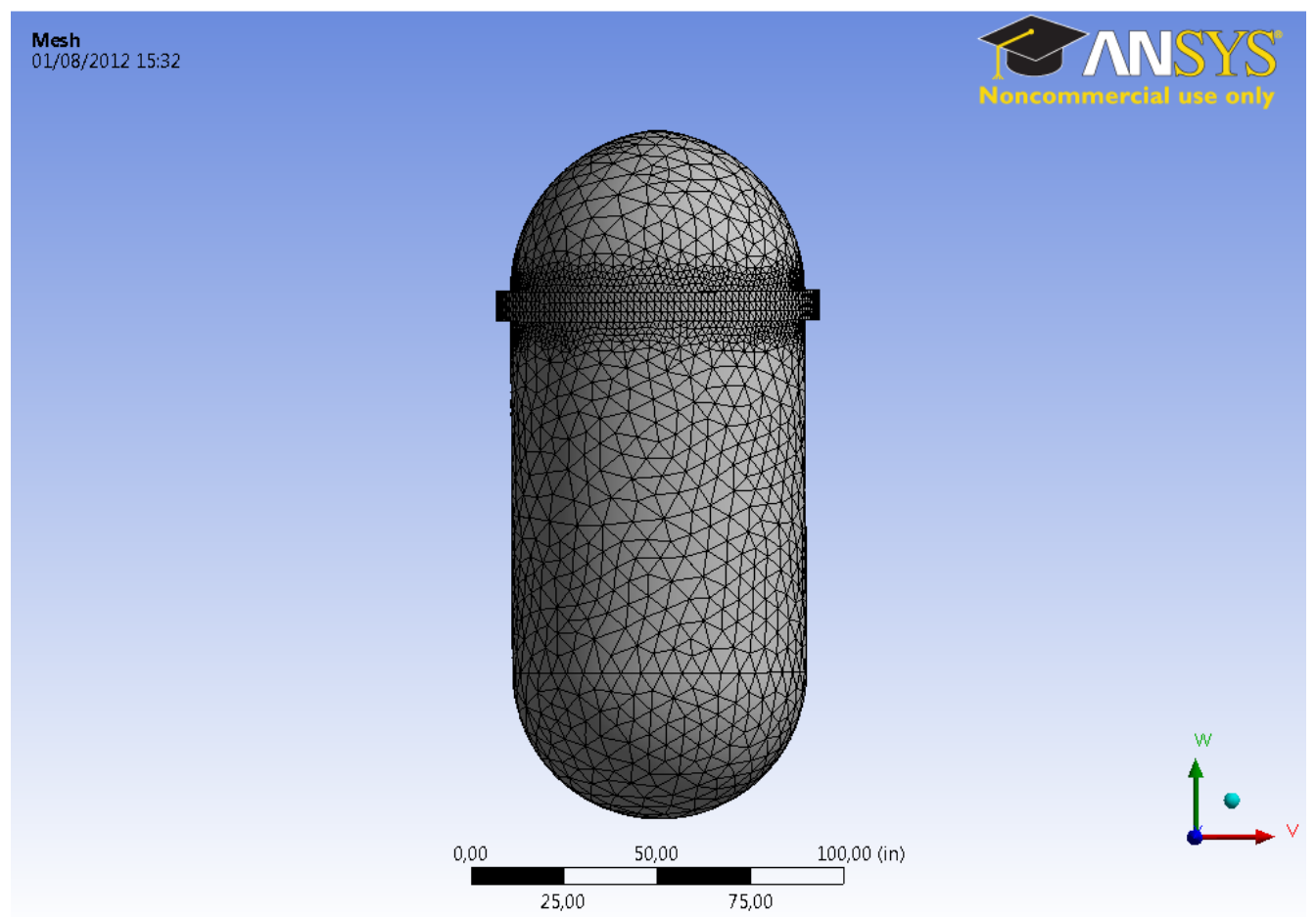

Figura 32 - Modelo SOLID Vaso do Reator no ANSYS - Elementos SOLID

Foram feitas também aproximações geométricas no corpo do vaso quanto a sua espessura. Foi adotada uma espessura única para se obter um desenho mais próximo daquele do modelo de elementos BEAM. Além disso, a malha da região próxima ao apoio do vaso foi refinada por maior precisão nos resultados naquele local, como mostra a Figura 32.

Com isso, o DDAM foi também aplicado para esse modelo e, de forma análoga ao modelo BEAM, uma simulação desconsiderando a massa dos internos também foi feita.

\subsection{Resultados - Comparação Modelo BEAM e Modelo SOLID}

Com os resultados dos 2 modelos, cada qual com três simulações produzidas, foi possível realizar uma análise comparativa da aplicação do DDAM. Foi verificada a influência da massa dos internos de um vaso de reator na dinâmica da estrutura como um todo, e, ainda, foi feita uma confrontação da dinâmica do vaso do reator do modelo BEAM e o modelo SOLID. 
Porém, como já citado anteriormente, estudos específicos sobre a dinâmica de um vaso PWR não foram encontrados, de modo que, uma análise estrutural do vaso não poderia ser feita sem parâmetros para sua fundamentação. Assim, os resultados finais do DDAM, como momentos e tensões não foram passíveis de quaisquer comparações e conclusões. Dessa forma, este trabalho se restringiu a comparar a análise modal que precede a análise espectral pelo DDAM, e os deslocamentos e forças que são os resultados passíveis de uma comparação qualitativa.

Então, os 3 primeiros modos de flexão do vaso do reator foram extraídos das 2 análises (com e sem a massa dos internos) de ambos os modelos a fim de se poder estudar a influência dos internos nos modos de vibração, e ainda, verificar a dinâmica estrutural do modelo do vaso em elementos SOLID e compará-lo com o modelo BEAM.

A Tabela 15 e a Tabela 16 mostram as frequências naturais dos 6 modelos de vaso do reator construídos no ANSYS e submetidos ao DDAM.

Tabela 15 - Frequências Naturais - Modelo BEAM

\begin{tabular}{|c|c|c|c|}
\hline Frequências [Hz] & $\begin{array}{c}\text { BEAM - } \\
\text { Sem Internos }\end{array}$ & $\begin{array}{c}\text { BEAM - } \\
\text { 1 Point Mass }\end{array}$ & $\begin{array}{c}\text { BEAM - } \\
\text { 2 Point Mass }\end{array}$ \\
\hline 10 Modo & 113 & 113 & 81 \\
\hline 2o Modo & 504 & 282 & 288 \\
\hline 3o Modo & 349 & 349 & 348 \\
\hline
\end{tabular}

Tabela 16 - Frequências Naturais - Modelo SOLID

\begin{tabular}{|c|c|c|c|}
\hline Frequências [Hz] & $\begin{array}{c}\text { SOLID - } \\
\text { Sem internos }\end{array}$ & $\begin{array}{c}\text { SOLID - } \\
\text { 1 Point Mass }\end{array}$ & $\begin{array}{c}\text { SOLID - } \\
\text { 2 Point Mass }\end{array}$ \\
\hline 1ㅇModo & 168 & 168 & 124 \\
\hline 2o Modo & 524 & 414 & 414 \\
\hline 3o Modo & 469 & 458 & 464 \\
\hline
\end{tabular}

Algumas observações podem ser feitas a partir desses resultados. Uma delas é a influência da massa dos internos que altera as frequências naturais da estrutura, como as tabelas destacam em vermelho. Isso se deve ao fato de que uma das 
massas concentradas se localiza na extremidade superior e o modo de flexão da calota superior é influenciado significativamente ao se adicionar massa à região.

Outra importante ressalva é a diferença das frequências do modelo BEAM para o modelo SOLID. Nota-se que o $2^{\circ}$ modo de vibração (a flexão da região/calota superior) do modelo SOLID possui uma frequência natural mais alta, ou seja, o modelo SOLID apresenta maior rigidez naquele local. Isso pode ser atribuído ao fato de que a calota foi modelada como uma semiesfera contínua.

Vale ressaltar também a diferença na frequência natural do $1^{\circ}$ modo dos modelos que consideram a massa dos internos. No modelo em que essa massa está dividida em 2 locais, a frequência do $1^{\circ}$ modo se mostrou mais baixa do que no modelo onde a mesma massa está concentrada em apenas 1 região. Isso pode ser explicado pelo fato do modo de vibração nessa frequência ser caracterizado pela flexão da extremidade inferior e a adição de parte da massa dos internos no local faz com que a rigidez da estrutura nessa condição diminua.

Os modos de vibração foram ilustrados nas figuras que seguem (Figura 33 à Figura 38). Observa-se que, apesar das frequências terem sido diferentes, os modos de flexão são semelhantes para ambos os modelos que consideraram a presença dos internos. Contudo, é necessário destacar que, no modelo SOLID, surgiram modos de casca com frequências intermediárias às dos modos de flexão, como mostram a Figura 39 e a Figura 40. Com isso, pode-se afirmar que o modelo BEAM está representando a dinâmica do vaso do reator de forma parcial ou incompleta.

Sendo assim, os deslocamentos e forças que resultaram das análises foram publicados no intuito de se verificar as ordens de grandeza e assim averiguar a consistência entre os modelos. Foram extraídos apenas os resultados na direção do carregamento, e para os modelos que consideraram os internos.

Tabela 17 - Resultados Modelos do Vaso do Reator - Deslocamentos e Forças

\begin{tabular}{|l|c|c||c|c|}
\hline & $\begin{array}{c}\text { BEAM - } \\
\text { 2 Point Mass }\end{array}$ & $\begin{array}{c}\text { BEAM - } \\
\text { 1 Point Mass }\end{array}$ & $\begin{array}{c}\text { SOLID - } \\
\text { 2 Point Mass }\end{array}$ & $\begin{array}{c}\text { SOLID - } \\
\text { 1 Point Mass }\end{array}$ \\
\hline $\begin{array}{l}\text { Deslocamento - Dir. } \\
\text { Carregamento [in] }\end{array}$ & 0,125 & 0,076 & 0,045 & 0,031 \\
\hline $\begin{array}{l}\text { Forças - Dir. } \\
\text { Carregamento [lbf] }\end{array}$ & $3,33 \mathrm{E}+06$ & $2,37 \mathrm{E}+06$ & $8,17 \mathrm{E}+03$ & $5,93 \mathrm{E}+03$ \\
\hline
\end{tabular}




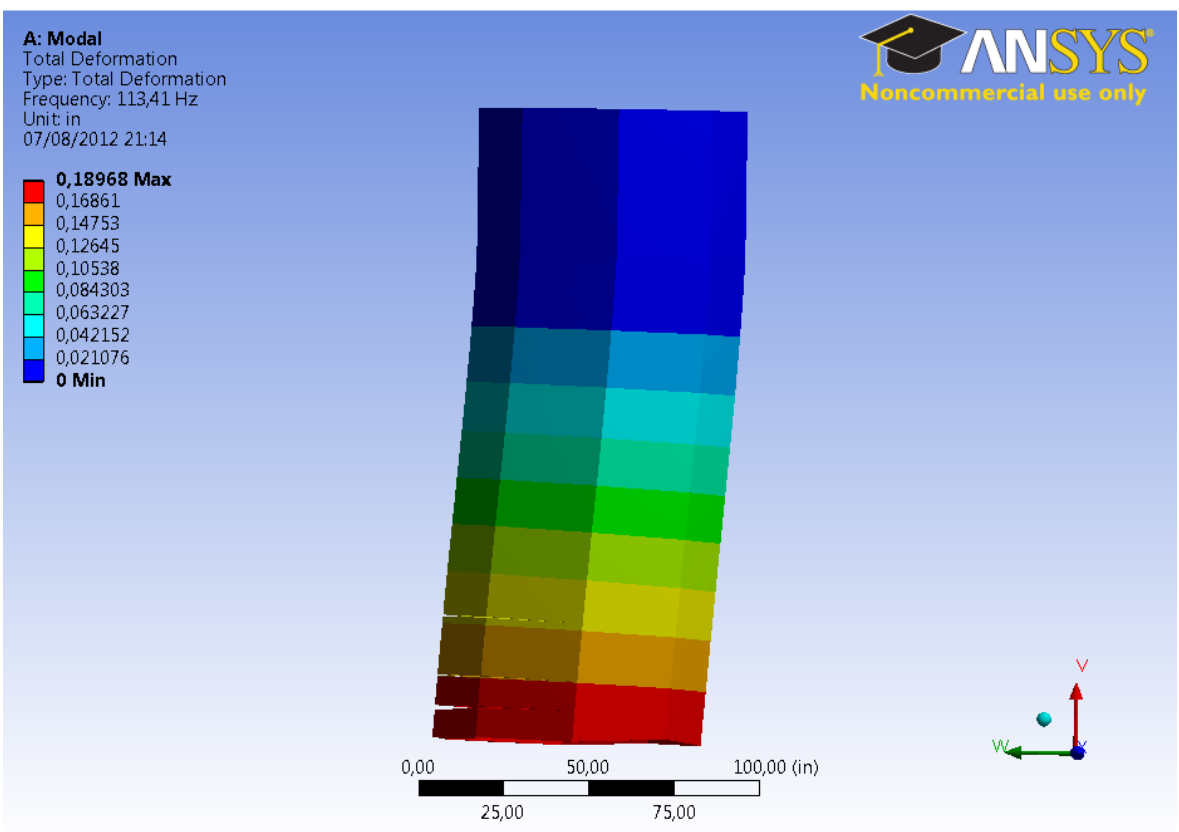

Figura 33 - Modelo Vaso do Reator BEAM - $1^{\circ}$ Modo

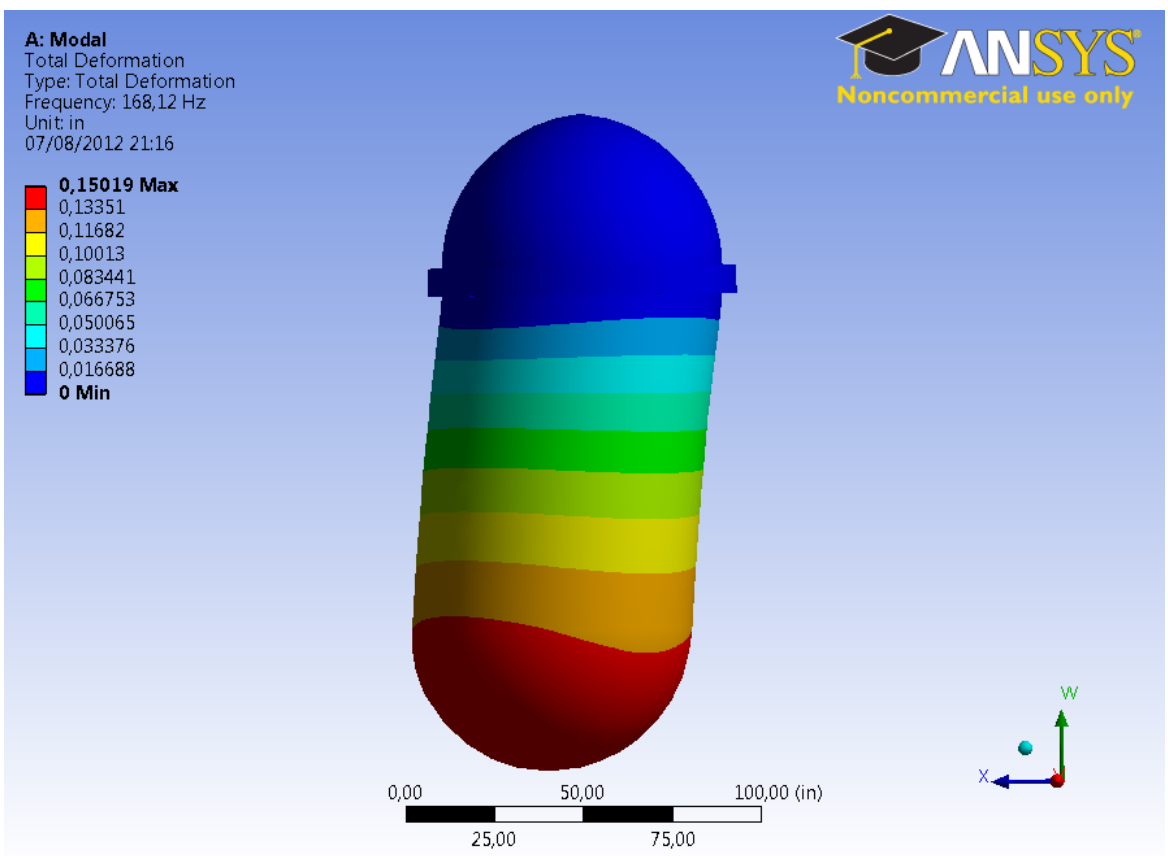

Figura 34 - Modelo Vaso do Reator SOLID - 1ํ Modo 


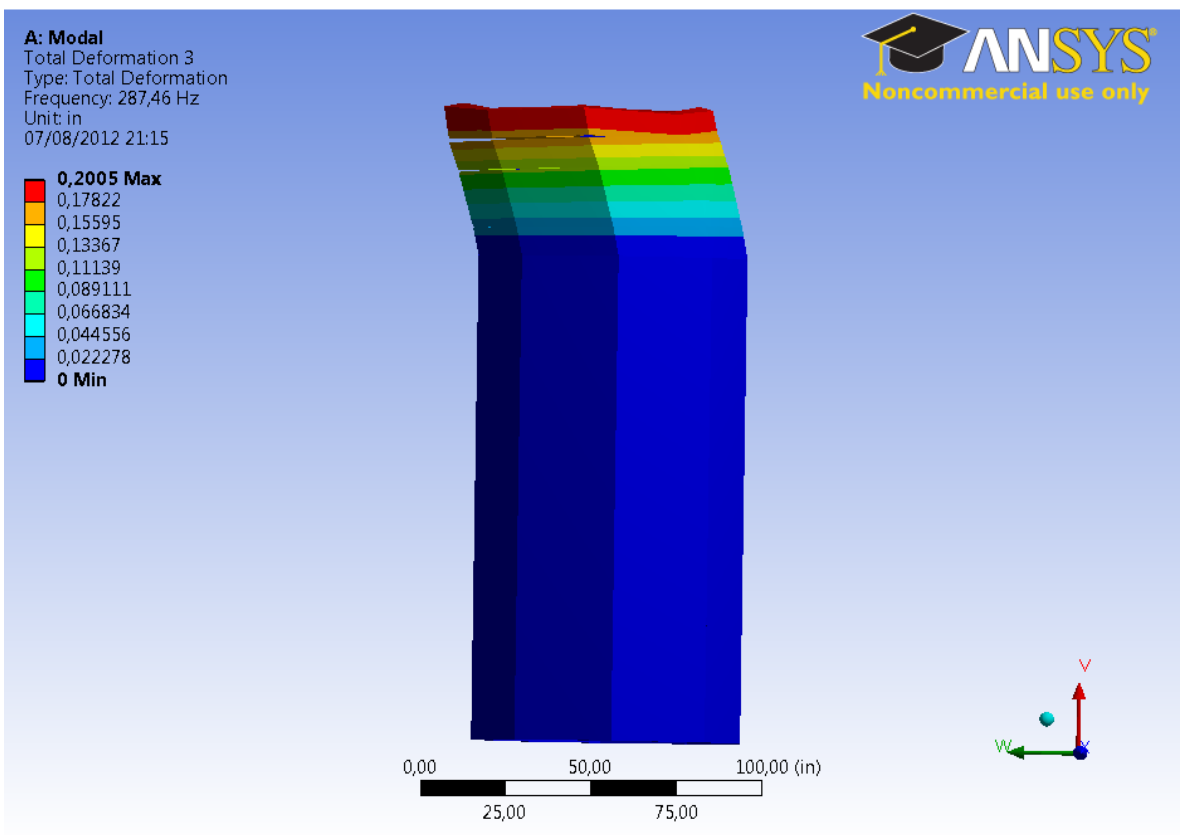

Figura 35 - Modelo Vaso do Reator BEAM - 2ํㅡㅇㅣ Modo

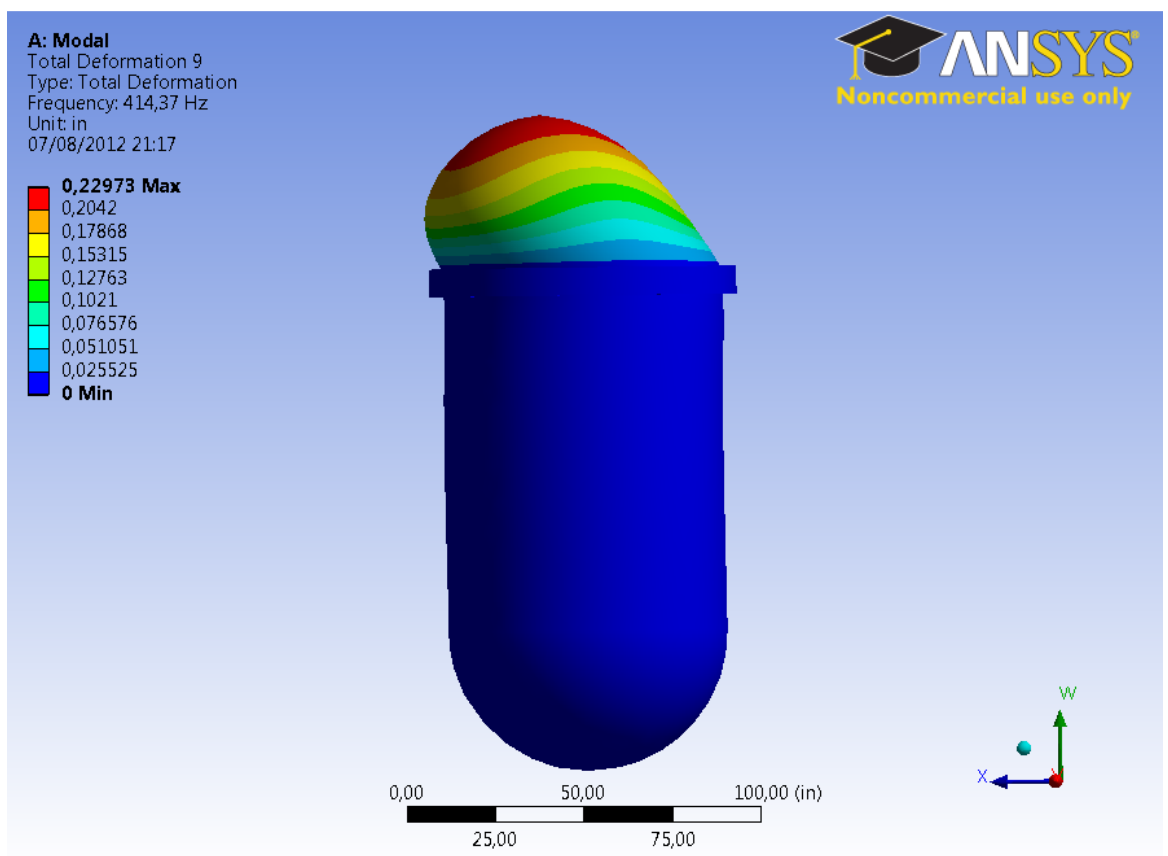

Figura 36 - Modelo Vaso do Reator SOLID - 2ำ Modo 


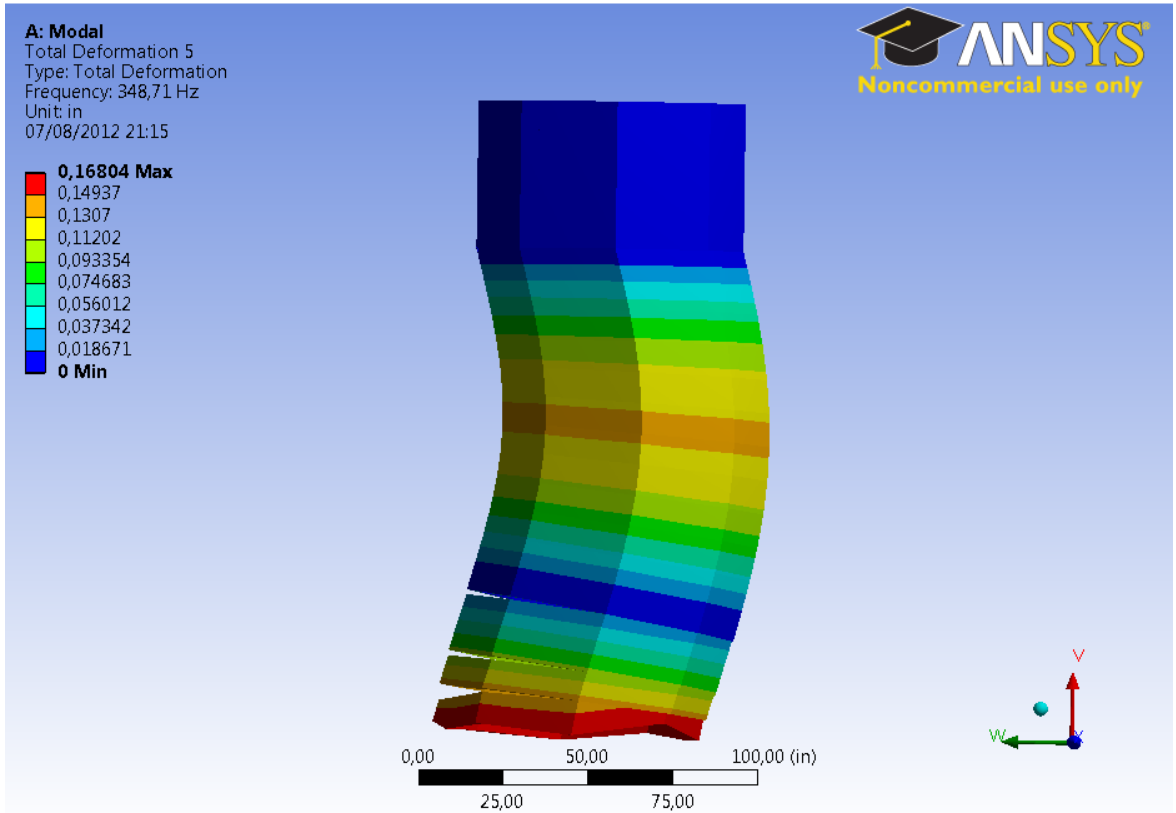

Figura 37 - Modelo Vaso do Reator BEAM - 3ํModo

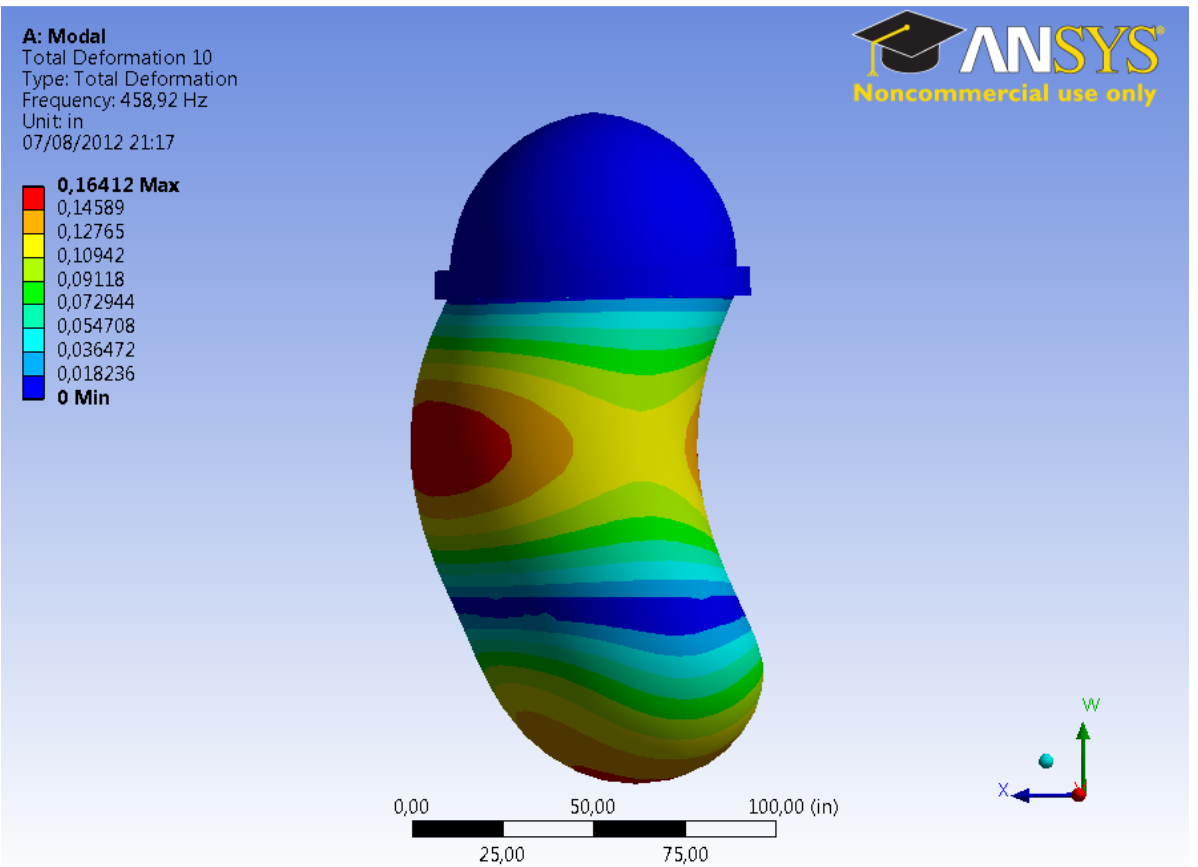

Figura 38 - Modelo Vaso do Reator SOLID - 3ํModo 


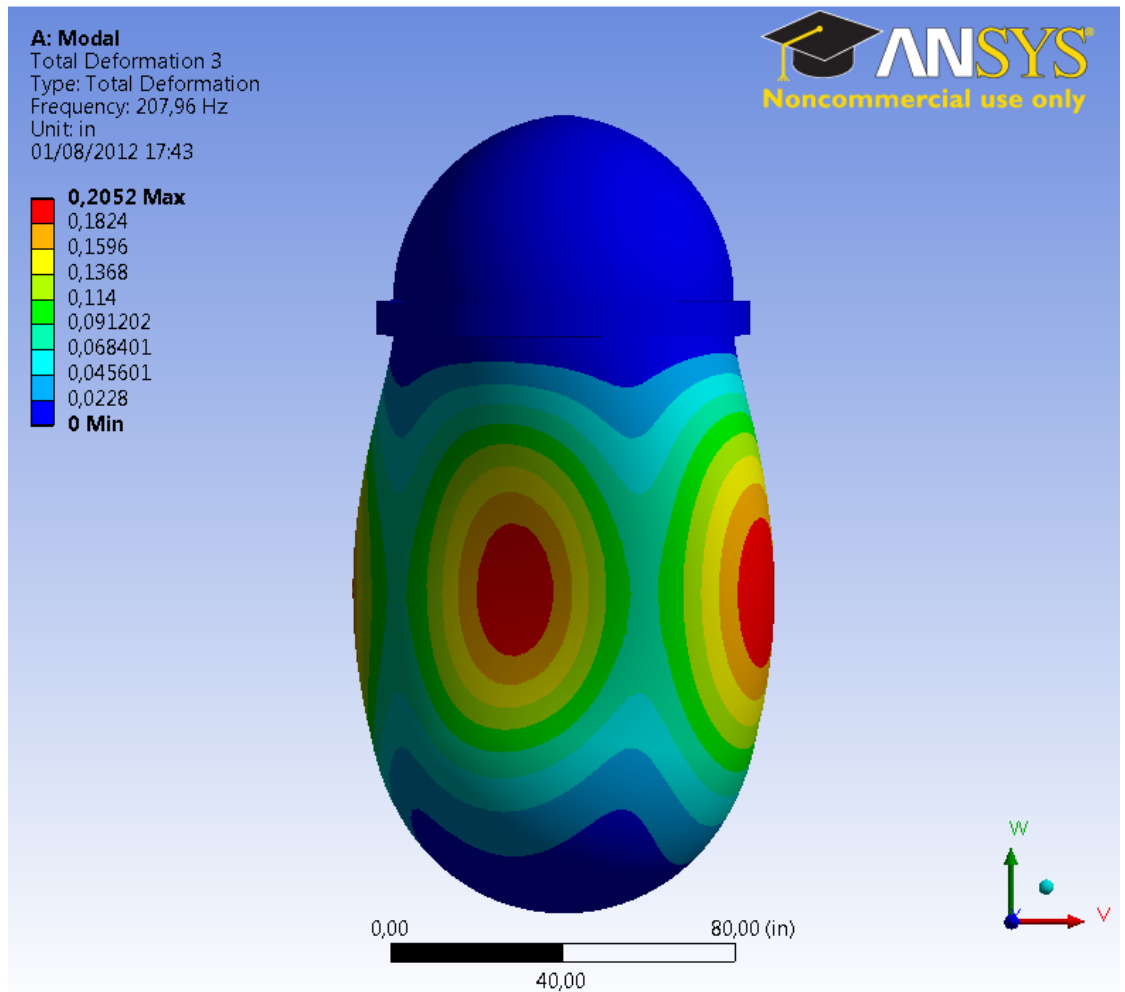

Figura 39 - Modelo Vaso do Reator SOLID - 1ํModo de Casca

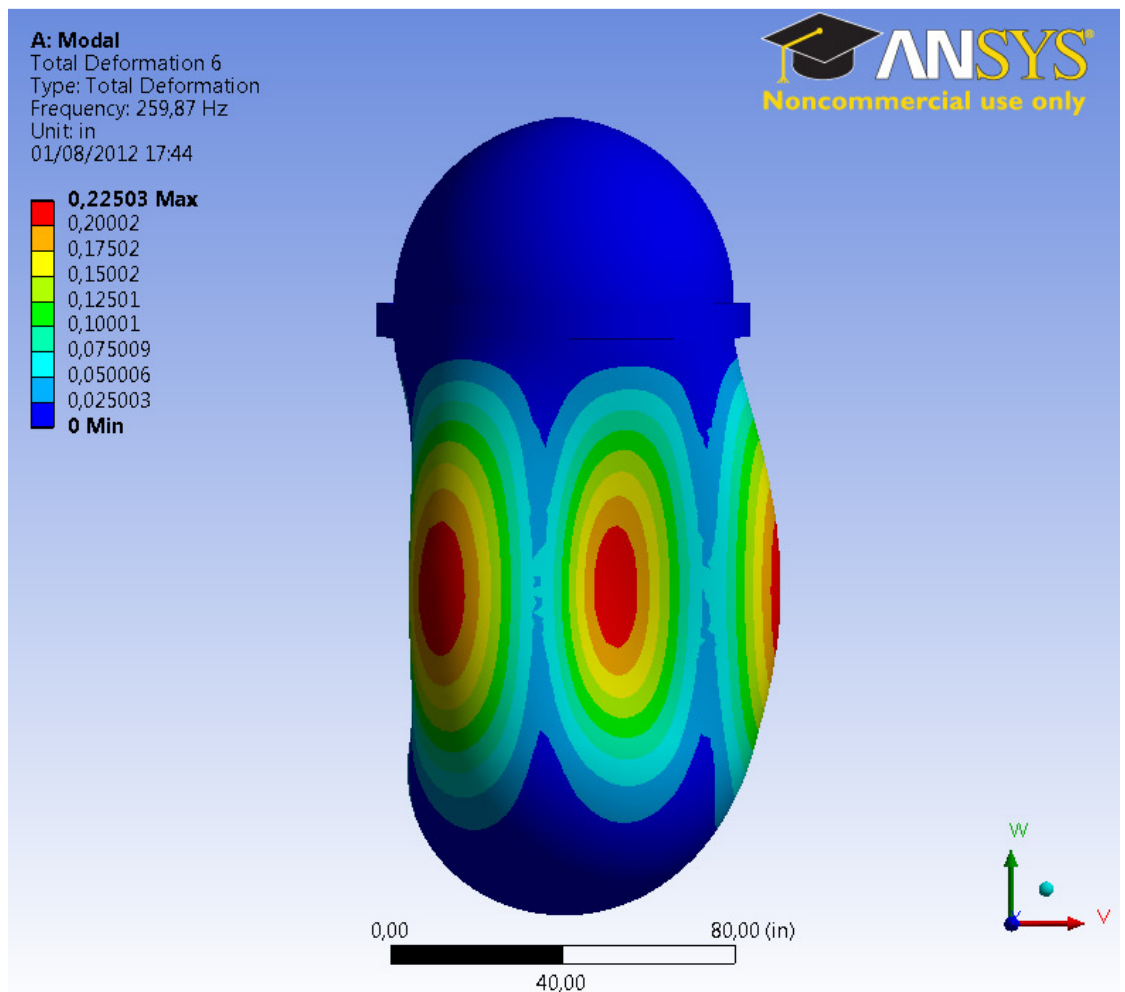

Figura 40 - Modelo Vaso do Reator SOLID - 2ํModo de Casca 
Como se vê na Tabela 17, a influência dos internos na dinâmica da estrutura pode ser notada com clareza. Novamente, o modelo em que os internos estão divididos em 2 localidades do vaso (2 Point Mass) se mostrou menos rígido em decorrência do aumento da inércia da extremidade inferior. Assim, os deslocamentos foram maiores tanto no modelo BEAM quanto no modelo SOLID, se comparados aos respectivos modelos em que os internos estão concentrados em 1 só local.

A tabela mostra também que o modelo SOLID é mais rígido, como era esperado, pois os deslocamentos e forças são menores que os encontrados no modelo BEAM. Uma razão para isso é a diferença quanto ao tipo de elemento utilizado e a geometria discretizada de forma mais acurada no modelo SOLID. Esse fato também pode ser atribuído como uma das causas da grande diferença nas forças reativas entre o modelo BEAM e o SOLID.

Outro fator que deve ser levado em conta é a existência dos modos de casca entre os modos de flexão que absorvem energia de vibração da estrutura. $\mathrm{E}$ ainda, a diferença na modelagem dos apoios que, para o modelo BEAM, se representou por uma barra rígida e, para o modelo SOLID, se fez pela superfície do anel externo do flange que é mais rígida do que a primeira, o que influenciou nas respostas à aplicação do DDAM.

As seguintes figuras (Figura 41 a Figura 48) mostram os resultados para os modelos BEAM e SOLID para os deslocamentos e forças na direção do carregamento. Cabe ressaltar que no modelo BEAM a geometria apresentada não aparenta estar com os elementos das extremidades alterados. Isso se deve ao fato de que o ANSYS Workbench (Interface do ANSYS utilizada neste trabalho) não plota essas alterações de seção dos elementos em seu pós-processador. Contudo, os cálculos dos deslocamentos e esforços e a superposição dos modos foram feitas baseadas na geometria modificada.

Outro detalhe importante de ser mencionado é em relação à Figura 45 e à Figura 46. Elas mostram a força no elemento que representa o apoio que também é plotada com a seção inalterada, apesar de ter sido modificada para uma seção mais robusta de grande rigidez. 


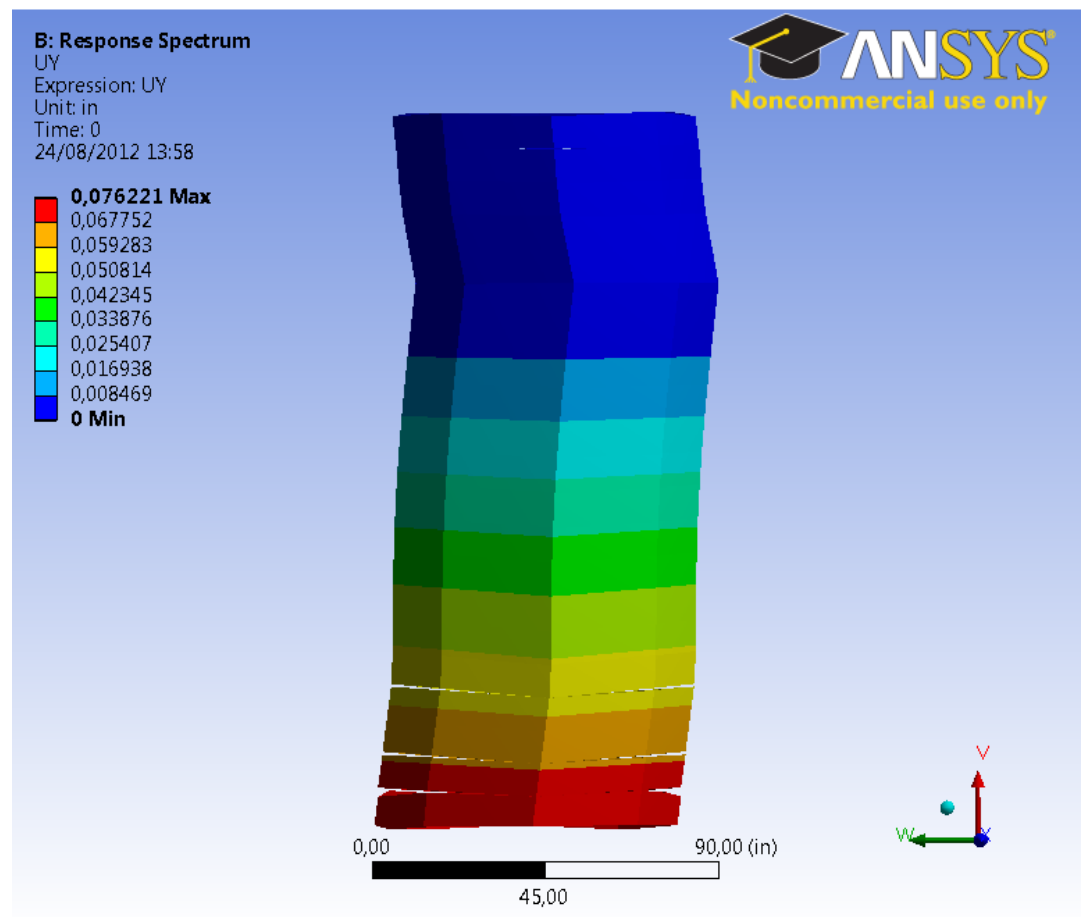

Figura 41 - Modelo Vaso do Reator BEAM - Internos em 1 Ponto - Deslocamento Final na Direção do Carregamento

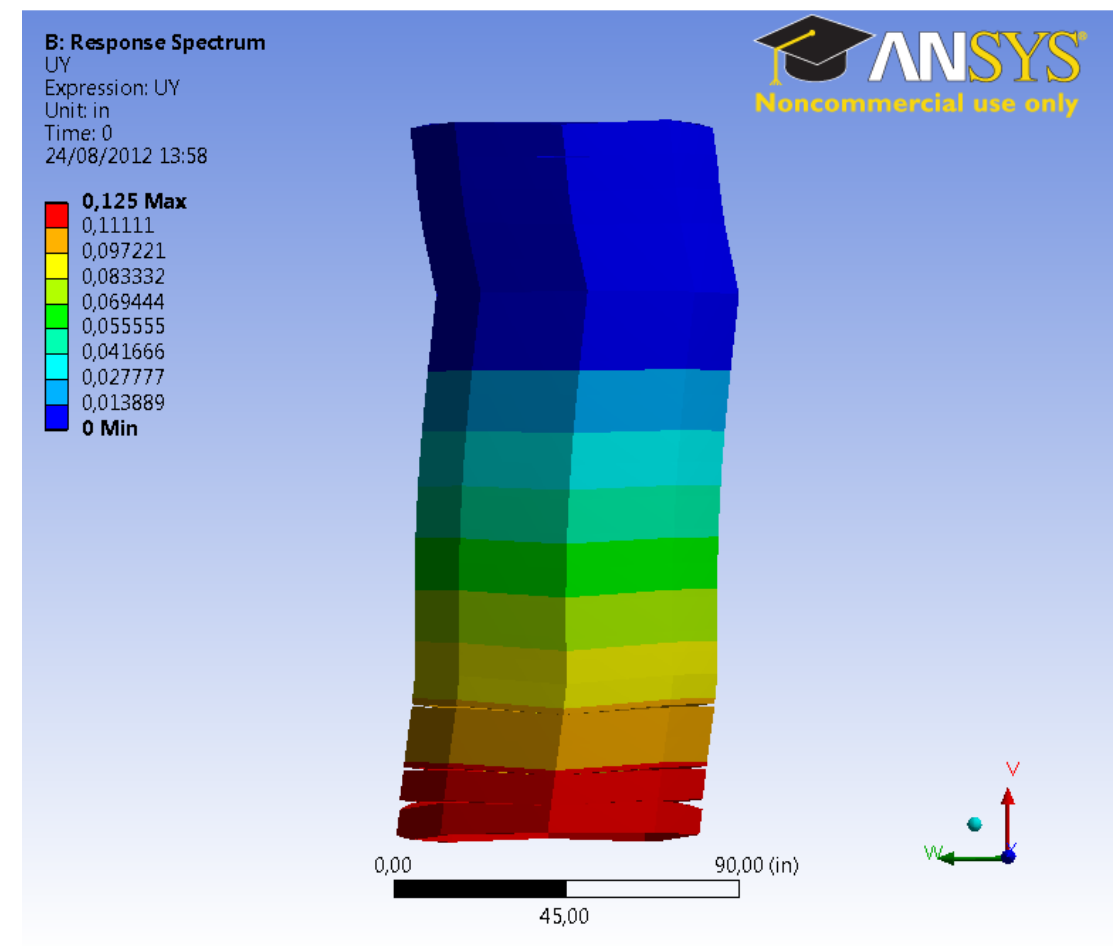

Figura 42 - Modelo Vaso do Reator BEAM - Internos em 2 Pontos - Deslocamento Final na Direção do Carregamento 


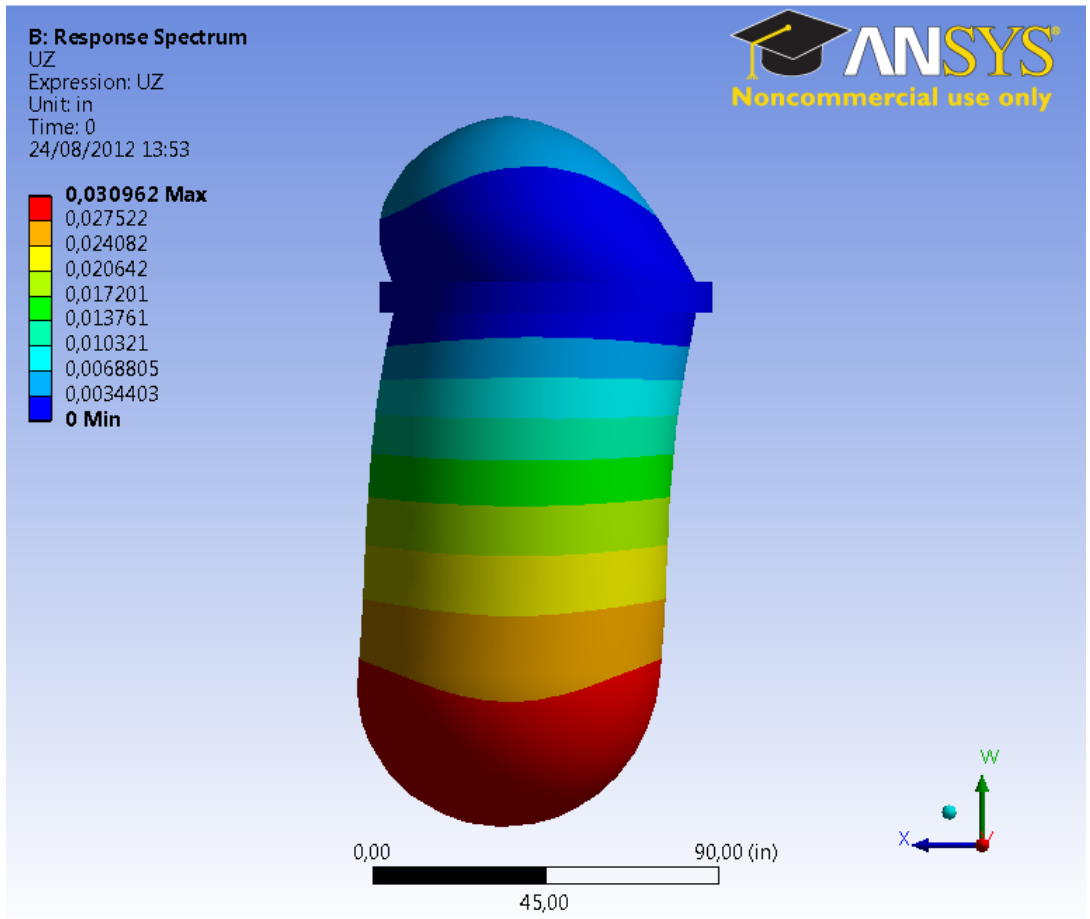

Figura 43 - Modelo Vaso do Reator SOLID - Internos em 1 Ponto - Deslocamento Final na Direção do Carregamento

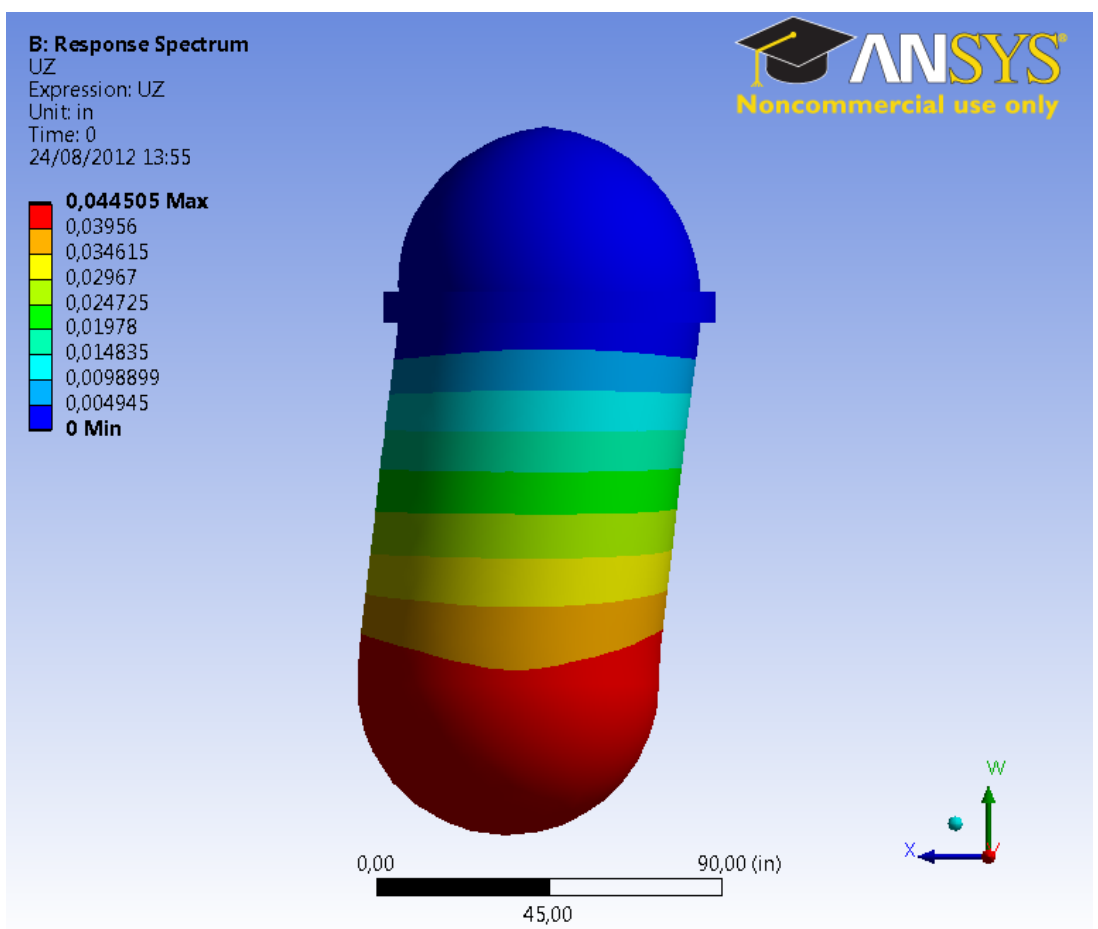

Figura 44 - Modelo Vaso do Reator SOLID - Internos em 2 Pontos - Deslocamento Final na Direção do Carregamento 


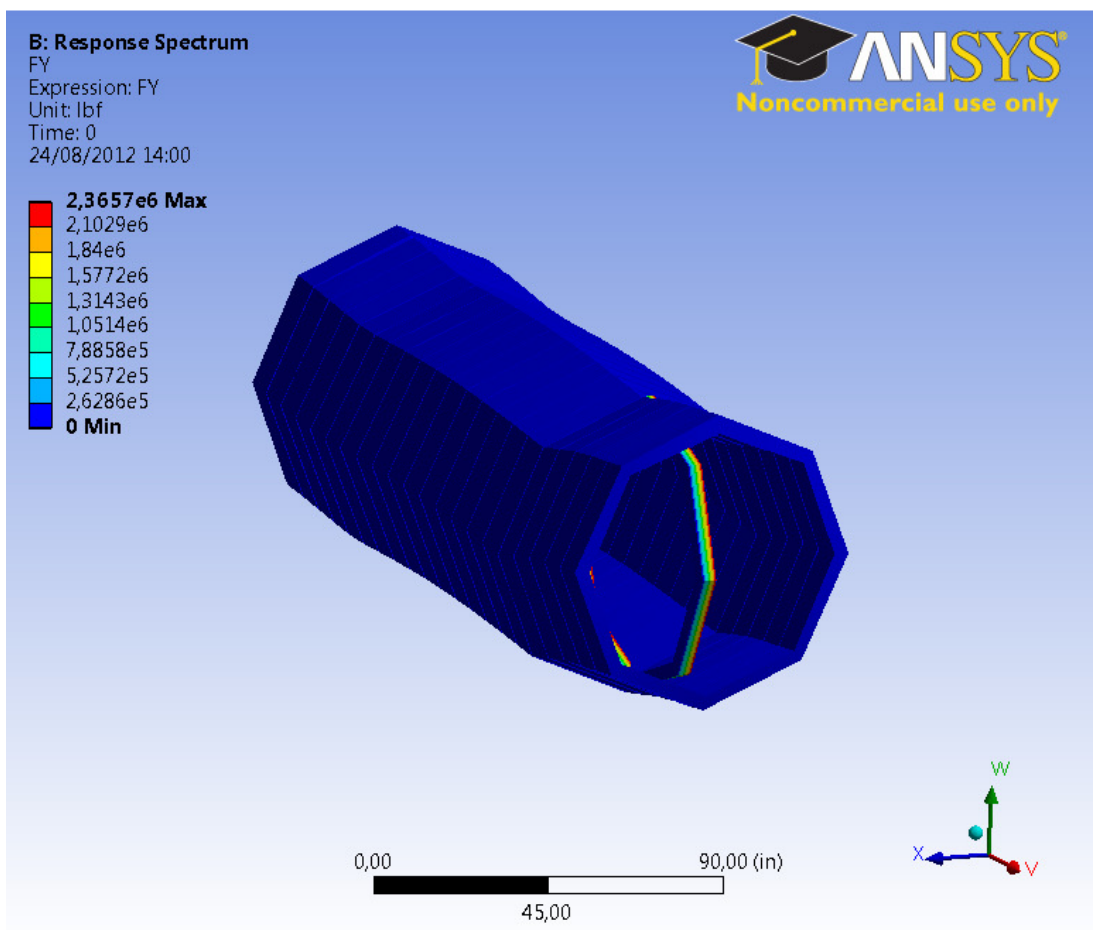

Figura 45 - Modelo Vaso do Reator BEAM - Internos em 1 Ponto - Força Máxima na Direção do Carregamento

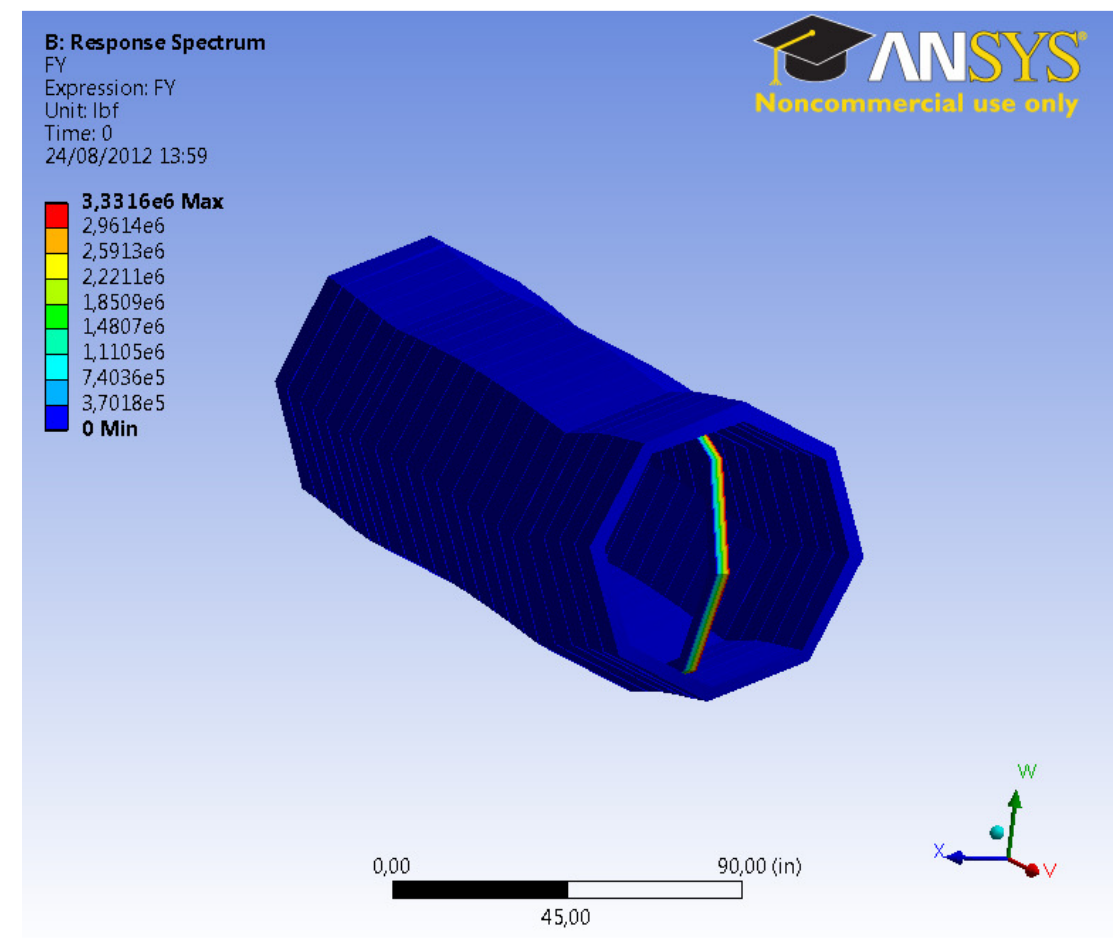

Figura 46 - Modelo Vaso do Reator BEAM - Internos em 2 Pontos - Força Máxima na Direção do Carregamento 


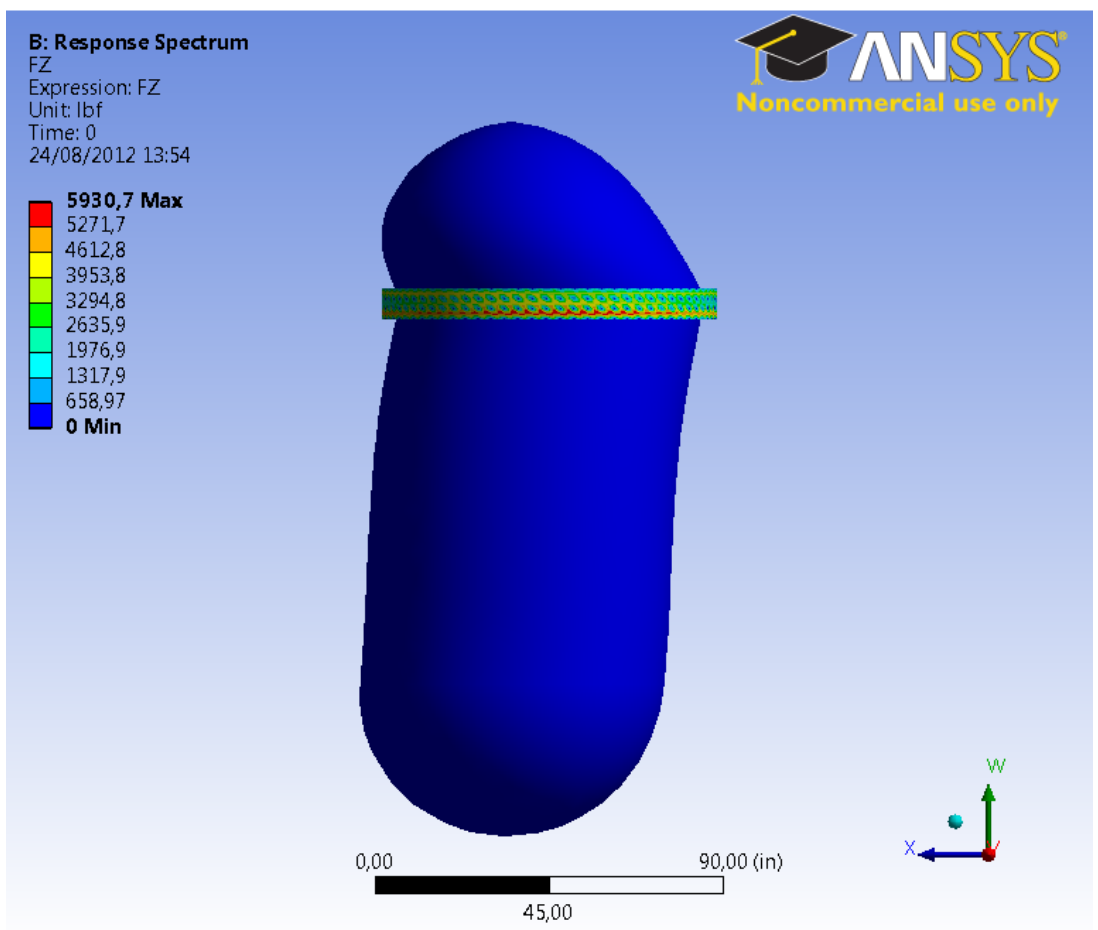

Figura 47 - Modelo Vaso do Reator SOLID - Internos em 1 Ponto - Força Máxima na Direção do Carregamento

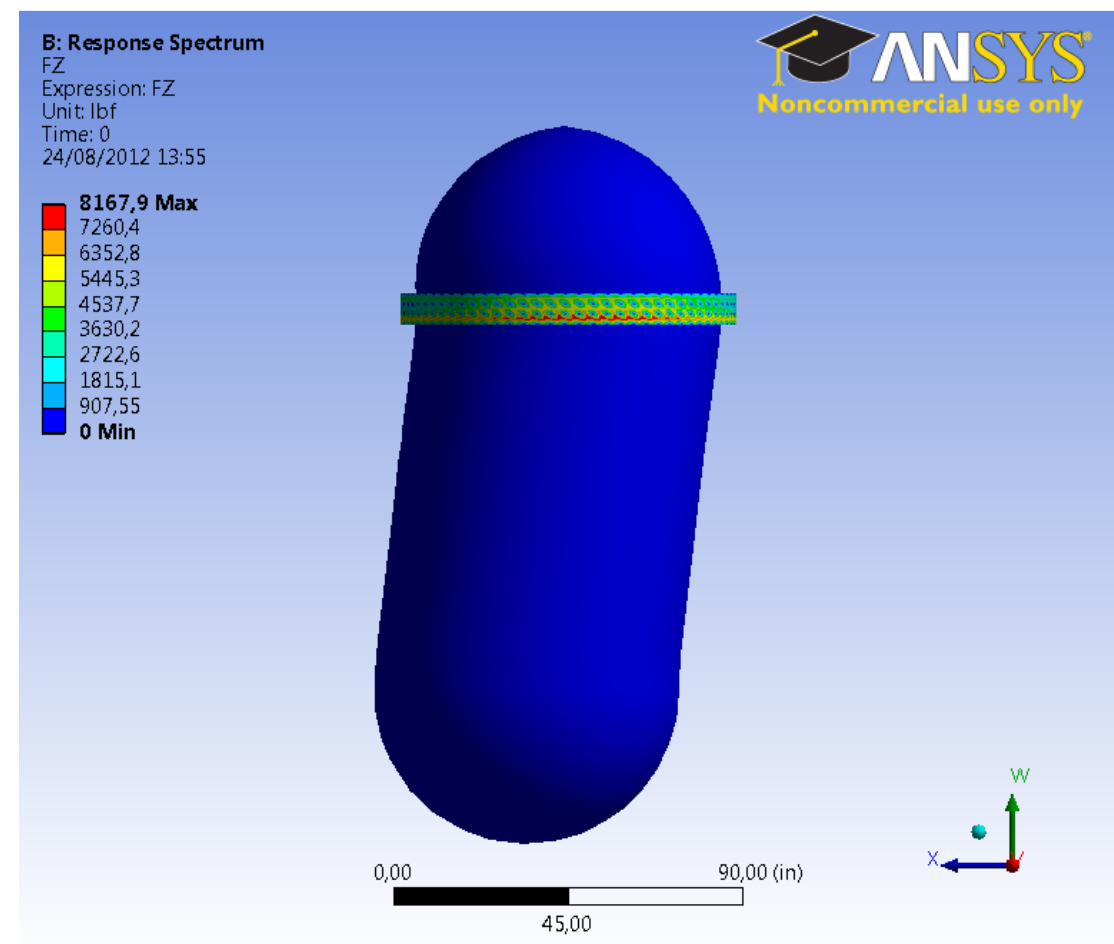

Figura 48 - Modelo Vaso do Reator SOLID - Internos em 2 Pontos - Força Máxima na Direção do Carregamento 


\section{Comentários, Conclusões e Recomendações para Trabalhos Futuros}

Com esse estudo, foi evidenciado que o problema da dinâmica de estruturas sujeitas a carregamentos de choque pode ser estudado por meio do espectro de choque ou espectro de choque de projeto. Conhecendo o espectro de choque de uma estrutura, os esforços inerciais provenientes desse choque podem ser estimados. Se o espectro de choque não for conhecido, o espectro de choque de projeto pode ser estimado, e é essa abordagem que o DDAM utiliza.

Contudo, não se encontram divulgados os parâmetros com que o algoritmo foi desenvolvido, dificultando a plena compreensão do problema que o método se propõe a resolver. Mais precisamente, não são conhecidos os pulsos de choque utilizados como excitação da estrutura. Essa metodologia de análise dinâmica de equipamentos se mostrou muito prática do ponto de vista da aplicação. E os exemplos aqui expostos exemplificaram tal fato. Porém, tal aplicação é válida apenas para uma avaliação inicial dos esforços inerciais oriundos das respostas da estrutura.

No exemplo feito de uma viga engastada, pôde-se verificar a aplicação do DDAM com todos os procedimentos que o método propõe e ainda os fundamentos teóricos que envolvem a metodologia como dinâmica de estruturas, análise modal, análise espectral, e os espectros de choque de projeto que o DDAM fornece, como expostos e exemplificados no modelo analítico. Pôde-se ver também a forma como ocorre a superposição das respostas de cada modo via soma NRL.

E ainda, foi possível averiguar o modo como o software ANSYS aplica o DDAM em um modelo de elementos finitos, que é através de uma análise modal seguida por uma análise por espectro de resposta utilizando os resultados empíricos que o DDAM fornece como espectro de choque e compondo os resultados com a superposição modal.

A vantagem de se utilizar o ANSYS para a aplicação do DDAM em estudos de dinâmica de estruturas é óbvia no sentido de que o programa traduz uma metodologia desenvolvida para sistemas dinâmicos de massas concentradas (lumped mass), para modelos em elementos finitos. 
Com a metodologia consolidada, modelos simplificados do vaso do reator PWR foram construídos em elementos finitos para serem submetidos ao DDAM. A partir da comparação desses modelos e seus resultados, pode-se chegar a algumas conclusões, ainda que qualitativas, sobre a dinâmica estrutural do vaso.

A principal conclusão que os resultados do ANSYS da aplicação do DDAM no vaso do reator trouxeram à tona foi o fato de que o modelo do vaso representado por elementos de barra (BEAM) se mostrou ser um modelo incompleto para representar a dinâmica dessa estrutura de forma precisa. Isso ocorreu na medida em que o modelo em elementos sólidos (SOLID) apresentou modos de casca em frequências intermediárias aos modos de flexão, o que impactou significativamente nos resultados finais, apesar de se mostrarem a favor da segurança nesse caso.

Além disso, os componentes internos do vaso foram representados apenas como um adicional de massa à estrutura do vaso, e os resultados do ANSYS mostraram que tais componentes influenciam na resposta do vaso a carregamentos de choque, fazendo-se necessária uma modelagem mais precisa e detalhada desses componentes, para se ter uma resposta mais próxima da realidade. Ainda, os resultados dos modelos em elementos finitos do vaso apresentaram também a importância de se definir e se modelar adequadamente os apoios da estrutura.

Portanto, esse trabalho pôde mostrar a aplicação de uma metodologia que visa estimar esforços provenientes de carregamentos impulsivos, i.e., ondas de choque, de uma maneira empírica, porém prática do ponto de vista de utilização e manipulação. Nesse sentido, se mostrou uma ferramenta útil no projeto de equipamentos de bordo que possam ser expostos a esse tipo de cargas.

Contudo, para se ter uma compreensão total de todo o problema na parte em que os parâmetros foram calculados empiricamente, ou seja, os espectros de choque de projeto, são necessários experimentos em equipamentos reais para que os espectros de choque reais sejam conhecidos e, assim, para que os valores empíricos de espectro (espectro de choque de projeto) sejam estimados. 


\section{Referências Bibliográficas}

1. Abbey, T., Weinberg, D. J. "Dynamic Design Analysis DDAM and Modal Effective Mass" Noran Engeneering Inc. - Westminster, CA, [200-?].

2. Abbey, T. "The Effective Dynamic Analysis of a whole Boat Model for Naval Vibration and Shock Analysis." Westminster CA, [200-?].

3. Alexander, J. E., "The Shock Response Spectrum - A Primer." Proceedings of the IMAC - XXVII, 2009

4. Barber, P, e K Arden. "Dynamic Design Analysis Method (DDAM) Using MSC/Nastran." Newport News Shipbuuilding., [196-?].

5. Bathe, K. J., C. Nitikitpaiboon, and X. Wang. "A Mixed Displacement-Based Finite Element Formulation for Acoustic Fluid-Structure Interaction." Computers \& Structures Vol. 56 No. 2/3, 1995: 225-237.

6. Belsheim, R. O., e G. J. O'Hara. "Shock Design of Shipboard Equipment Part I - Dynamic Design Analysis Method." Washington D.C., 1961.

7. Biot, M., "A Mechanical Analyzer for the Prediction of Earthquake Stresses" Bulletin of the Seismological Society of America, 1940: 151-171

8. Biot, M., "Theory of Elastic Systems Vibrating Under Transient Impulse with an Application to Earthquake-Proof Buildings." Proceedings of National Academy of Science, 1933: 262-268.

9. Blevins, R. "Formulas for Natural Frequency and Mode Shape" Krieger Publishing Company, Malabar - FL, 2001.

10. Clements, E. W. "Shipboard Shock and Navy Devices for its Simulation." Washington D.C., 1972.

11. Clough, R., Penzien, J., "Dynamics of Structures" Computers and Structures Inc., Berkeley - CA, 3rd Ed., 2003. 
12. Cole, Robert H. "Underwater Explosions”. Princeton: Princeton University Press, 1948.

13. Cunniff, P. F., Collins, R. P., "Structural Interaction Effects on Shock Spectra" The Journal of the Acoustical Society of America vol. 43, 1968: 239-244

14. Cunniff, P. F., O’Hara, G. J. "A Procedure for Generating Shock Design Values" Journal of Sound and Vibration 134 vol. 1, 1989: 155-164.

15. Ergin, A. "The Response Behaviour of a Submerged Cylindrical Shell Using the Doubly Asymptotic Approximation Method (DAA)." Computers \& Structures Vol. 62 No. 6, 1997: 1025-1034.

16.Kwon, Y. W., e P. K. Fox. "Underwater Shock Response of a Cylinder Subjected to a Side-on Explosion." Computers \& Structures Vol. 48 No. 4, 1993: 637646.

17. Kwon, Y. W., e R. E. Cunningham. "Comparison of USA-DYNA Finite Element Models for a Stiffened Shell Subject to Underwater Shock." Computers \& Structures Vol. 66 No. 1, 1998: 127-144.

18. Liang, Cho-Chung, Ching-Yu Hsu, e Wen-Hao Lai. "A Study of Transient Responses of a Submerged Spherical Shell Under Shock Waves." Ocean Engineering 28, 2000: 71-94.

19. Liang, Cho-Chung, e Yuh-Shiou Tai. "Shock Responses of a Surface Ship Subjected to Noncontact Underwater Explosions." Ocean Engineering 33, 2006: 748772.

20. Naval Sea Systems Command. "Shock Design Criteria for Surface Ships NAVSEA 0908-LP-000-3010." New York, 1976.

21. Neto, M. Mattar, Augusto, O. B., "Análise Sísmica de Estruturas e Componentes Nucleares" Confidencial, 1986.

22. O'Hara, G. J. “Effect Upon Shock Spectra of The Dynamic Reaction of Structures" Washington D. C., 1958. 
23. O'Hara, G. J. "Shock Spectra and Design Shock Spectra." Washington D. C., 1959.

24. O’Hara, G. J. “The Shock Spectrum Dip Effect.” Washington D. C., 1984.

25. O'Hara, G. J., e R. O. Belsheim. "Interim Design Values for Shock Design of Shipboard Equipment." Washington D.C., 1963.

26. Remmers, G., "Maurice Biot 50th Anniversary Lecture - The Evolution of Spectral Techniques in Navy Shock Design" The Shock and Vibration Information Center, 1983

27.Scavuzzo, R. J., "The Spectrum Dip of Deck Mounted Systems." Shock and Vibration 17, 2010: 55-69.

28. Shin, Young S. "Ship Shock Modeling and Simulation for Far-Field Underwater Explosion." Computers and Structures Vol. 82, 2004: 2211-2219.

29. Shin, Young S., e Leonard D. Santiago. "Surface Ship Shock Modeling and Simulation: Two-Dimensional Analysis." Shock and Vibration 5, 1998: 129-137.

30. Tao, J, et. al, "The Analysis on Shock Spectrum of Shipboard Equipments." Yantai - China, 2009. 